\title{
1. Kapitel: Formale, materiale und prozedurale Rationalisierung des Rechts: ein Entwicklungsmodell
}

Im ersten Kapitel dieser Arbeit wird der rechtsphilosophische und rechtssoziologische Hintergrund erarbeitet, vor dem im zweiten Kapitel eine Theorie prozeduralen Rechts überhaupt erst entwickelt und sodann im dritten Kapitel anhand eines Beispiels zu einer Theorie des prozeduralen Rechtsstaats entfaltet werden kann. Wer es unternimmt, Aussagen über die Entwicklung der Rationalität des Rechtssystems zu treffen, muß die Bedeutung der Adjektive formal, material und prozedural in Verbindung mit Grundbegriffen der Rechtsphilosophie und Rechtssoziologie klären. Dabei überwiegt naturgemäß zunächst der darstellende, reproduzierende Charakter, während sich der eigene Beitrag auf die Auwahl der Themen und das Setzen von Akzenten beschränkt. Der intensive Einstieg in vielfach bekannte Diskussionen hat allerdings einen doppelten Sinn:

Zum einen leidet die Diskussion um eine Prozeduralisierung des Rechts, in die im zweiten Kapitel eingeführt wird, an einem Mangel an begrifflicher Präzision, weshalb häufig aneinander vorbeigeredet wird und verschiedene Theorien zur Prozeduralisierung des Rechts als unvergleichbar oder gar unvereinbar bezeichnet werden. Dem Verfasser dient das erste Kapitel deshalb als Selbstversicherung über die Grundlagen der zu entwickelnden Theorie prozeduralen Rechts, dem Leser soll es als Einführung und zugleich als Offenlegung der Grundannahmen des Verfassers dienen, damit diese intersubjektiv nachvollziehbar und gegebenenfalls auch kritisierbar werden. Das ist besonders wichtig, weil der gesamte weitere Gedankengang von den hier gefundenen Begriffen lebt und auf die hier entfalteten Definitionen zurückgreift.

Zum anderen wird dem mit der Materie vertrauten Leser auffallen, daß in der Darstellung der einzelnen in den Unterabschnitten angesprochenen Probleme ganz bewußt Akzente gesetzt werden und daß die Selektion der dargestellten Diskussionszusammenhänge am Ende zu einem Gesamtbild führt, aus dem sich relativ unproblematisch ergibt, worauf die Diskussion um eine Prozeduralisierung des Rechts aus Sicht des Verfassers hinausläuft. Ziel des ersten Kapitels ist es mit anderen Worten, eine präzise Frage zu formulieren, auf die ein prozedurales Rechtsparadigma eine Antwort geben soll.

Zunächst wird anhand einiger rechtsinterner Kriterien ein Überblick darüber gegeben, was es in juristischen Begriffen überhaupt bedeuten kann, über die Rationalität eines Rechtssystems als Ganzem zu sprechen und in diesem Zusammenhang das Begriffspaar formal/material zu verwenden (I.). Weil aus philosophischer Sicht die Rationalität des Rechts unter dem Begriff der Gerechtigkeit diskutiert wird, werden sodann verschiedene Gerechtigkeitstheorien dargestellt. Dabei wird der Begriff prozeduraler Gerechtigkeit eingeführt und als gegenüber formalen und materialen Gerechtigkeitstheorien völlig eigenständiges Konzept herausgearbeitet (II.). Für die Rationalität des modemen Rechts steht fast paradigmatisch der Begriff des Rechtsstaats. Die Entwicklung des Rechtsstaatsbegriffs wird deshalb nachgezeichnet, wobei herausgearbeitet wird, daß der sog. formale Rechtsstaat einer einseitigen Verkürzung des Gesetzgebungsmodells prozeduraler Gerechtigkeit, wie es aus den vernunftrechtlichen Lehren vom Gesellschaftsvertrag bekannt ist, entspringt. Da dies von den Verfechtern eines materiellen Rechtsstaats übersehen wurde, können hier die Grundlagen einer Theorie des prozeduralen Rechtsstaats gelegt werden (IIII.). 
Aus rechtssoziologischer Sicht wird die Entwicklung von Rechtsbegriffen sodann mit der Entwicklung der Gesellschaft und ihrer Probleme sowie mit der daraus resultierenden Ausweitung der Staatsaufgaben in Zusammenhang gebracht. Während die Materialisierung des Rechts mit dem Wandel der bürgerlichen Gesellschaft und ihrem liberalen Minimalstaat zur Industriegesellschaft mit ihrem Sozialstaat verbunden ist, zeigt sich, daß eine Antwort des Rechts auf den gegenwärtigen Wandel zur - vorläufig so bezeichneten - Risikogesellschaft mit ihrem Präventionsstaat noch weitgehend aussteht (IV.). Daß eine solche Antwort dringend nötig ist, ergibt sich aus der Analyse einer dreifachen Krisenlage des modernen Rechts. Krise des Rechtsstaats, Krise des Sozialstaats und Steuerungskrise des Rechts führen in ein Trilemma des Rechts (V.), aus dem eine prozedurale Rationalisierung des Rechts einen Ausweg weisen soll (VI.).

\section{Rechtsinterne Kriterien zur Abgrenzung eines formal-rationalen von einem material-rationalen Rechtssystem}

Die Unterscheidung zwischen formaler und materialer Rationalität des Rechts entstammt der Rechtssoziologie von Max Weber. ${ }^{1}$ Auf den wissenschaftstheoretischen Hintergrund dieser Unterscheidung von Rationalitätstypen wird später eingegangen. Hier kommt es zunächst auf jene rechtsinternen Merkmale an, auf die Weber seine Unterscheidung angewandt hat. Diese entsprechen im wesentlichen den Kriterien, die in der deutschen Diskussion zur Abgrenzung von formalem und materialem Rechtsstaat ${ }^{2}$ sowie in der amerikanischen "Form and Substance"-Debatte ${ }^{3}$ Verwendung finden. Robert Summers hat zusammenfassend fünf Kriterien zur Abgrenzung eines formalen von einem materialen Rechtssystem herausgearbeitet ${ }^{4}$, anhand derer im folgenden ein erster Überblick über formale und materiale Elemente eines Rechtssystems gegeben wird.

\section{Norm}

\section{a) Die Geltung der Rechtsnorm}

Jedes Rechtssystem muß Regeln über die Geltung von Recht i.S.v. Harts "rule of recognition"5 enthalten. Solche Regeln sind formal, wenn die Geltung ausschließlich von der ordnungsgemäßen Setzung durch eine kompetente Stelle, sie sind material, wenn Rechtsgeltung auch von inhaltlichen Kriterien abhängig gemacht wird. Eine extrem formale rule of recognition ist die englische Regel "What Queen enacts in Parliament is Law". Danach steht den Richtern weder ein formelles noch ein materielles Prüfungsrecht zu, vielmehr gilt als Gesetz alles, was im Gesetzgebungsblatt (parliamentary roll)

1 M.Weber, WuG, Teil 2, Kap.VII, §§ 7 u. 8; Zu Weber vgl. F.Loos, Zur Wert- und Rechtslehre Max Webers, Tübingen 1970; D.M.Trubek, Max Weber on Law and the Rise of Capitalism, Wisconsin Law Review 1972, S.720ff.; J.Habermas, Theorie des kommunikativen Handelns, Bd.1, Kap.II, insbes. S.342ff.

2 I.Maus, Entwicklung, S.33ff. m.w.N.

3 Vgl. R.M.Unger, Law, S.192ff; P.S.Atiyah/R.S.Summers, Form and Substance in Anglo-American Law, Oxford UP 1987.

4 R.S.Summers, On analyzing and characterizing the general style of a legal system as formal or as substantive, Rechtstheorie 1992, S.27-34.

5 H.L.A.Hart, Concept of Law, S. 107. 
veröffentlicht ist. ${ }^{6}$ Demgegenüber gilt in den USA und in Deutschland eine relativ materiale rule of recognition, da Gesetze sowohl in formeller (Kompetenz, Form und Verfahren) als auch in materieller (insbes. Grundrechte) Hinsicht auf ihre Verfassungsmäßigkeit überprüft werden?

\section{b) Normstruktur: Regeln und Prinzipien}

Ein Normensystem kann insgesamt eher formal oder eher material sein. Diese Unterscheidung bezieht sich vornehmlich auf Normen des materiellen Rechts (primary rules). Ein Normensystem ist formal, wenn es dem Richter erlaubt, sein Urteil ausschließlich mit Bezug auf die Norm selbst und das Vorliegen oder Nichtvorliegen der im Tatbestand der Norm bezeichneten Fakten zu begründen, es ist material, wenn das Urteil darüber hinaus auf nicht in der Norm bestimmte Gerechtigkeits- oder Nützlichkeitserwägungen gestützt werden muß $\beta^{8}$. Eine formale Norm muß daher positiv (geschrieben), publik (veröffentlicht), generell (Allgemeinheit des Gesetzes) und inhaltlich bestimmt sein und darf keine rückwirkende Kraft entfalten. ${ }^{9}$ Formale Normen haben den Charakter definitiver Regeln, sie knüpfen das Eintreten einer Rechtsfolge ausschließlich an die Erfüllung eines bestimmten Tatbestands (konditionale Programmierung). Demgegenüber sind materiale Normen wesentlich unbestimmter. Durch Verwendung unbestimmter Rechtsbegriffe auf der Tatbestandsseite sowie Anordnung von Ermessen auf der Rechtsfolgenseite, durch die bloße Definition erstrebenswürdiger Zustände und Ziele bei Offenhaltung der zur Verwirklichung einzusetzenden Mittel (Prinzipien ${ }^{10}$ bzw. Zweckprogrammierung ${ }^{11}$ ) oder den über Generalklauseln vermittelten Verweis auf außerrechtliche Maßstäbe wie Treu und Glauben, gute Sitten, Stand von Wissenschaft und Technik etc. wird der Rechtsanwender zur Rechtfertigung seiner Entscheidung mit Nützlichkeitsund Folgenabwägungen ${ }^{12}$ sowie zur gerechten Abwägung konfligierender Interessen und Güter nach rechtlich nicht definierten Kriterien ermächtigt und gezwungen.

6 Zur Supremacy of Parliament siehe H.L.A.Hart, Concept of Law, S.145f.; ferner M.Allen et al., Cases \& Materials on Constitutional and Administrative Law, 2. Aufl., London 1992, Kap. 2, dort abgedruckt (S.59ff.): Pickin v British Railways Board (1974) AC 765, House of Lords, Lord Reid: "all that a court of justice can look to is the parliamentary roll;.... The court has no concern with the manner in which Parliament or its officers carrying out its Standing Orders perform these functions".

7 In den USA hat das Supreme Court erstmals in Marbury v. Madison (1803) 1 Cranch 137 ein richterliches Prüfungsrecht in Anspruch genommen; in Deutschland nahm das Reichsgericht erstmals 1921 ein Prüfungsrecht in Anspruch (E 102, 161ff), dies blieb aber umstritten und wurde endgültig erst durch das Grundgesetz geklärt, welches in Art. 1 III die Grundrechtsbindung des Gesetzgebers normiert und eine verfassungsgerichtliche Prüfung dieser Bindung vorsieht (Art. 93 GG).

8 R.M.Unger, Law, S.204.

9 F.Neumann, Funktionswandel des Gesetzes, S.37ff.; D.Grimm, Der Wandel der Staatsaufgaben und die Krise des Rechtsstaats, in: ders., Wachsende Staatsaufgaben, 1990, S.291-306, 294; J.Raz, The Rule of Law and its Virtue, (1977) 93 Law Ouarterly Review, S.195ff.; R.S.Summers, A Formal Theory of the Rule of Law, Ratio Juris 1993, S.127-142.

10 Zu Definition von Prinzipien als Ziel-(Aufgaben-)normen U.Penski, Rechtsgrundsätze und Rechtsregeln, JZ 1989, S.105ff m.w.N. in FN 31-33; R.Alexy definiert Prinzipien als Optimienungsgebote, die gebieten, daß etwas in einem relativ auf die rechtlichen und tatsächlichen Möglichkeiten möglichst hohen Maße realisiert wird: R.Alexy, Grundrechte, S.75; ders., Rechtsregeln und Rechtsprinzipien, ARSP Beiheft 25 (1985), S.13, 19.

11 Zur Unterscheidung zwischen konditionaler Programmierung und Zweckprogrammierung: N.Luhmann, Rechtssoziologie, 3.Aufl., Opladen 1987, S.88, 227ff.

12 Zur Folgenberücksichtigung im Recht: N.Luhmann, Rechtssystem und Rechtsdogmatik, S.29ff. 
Als Beispiel für ein formales Normensystem kann der französische Code Civil angeführt werden ${ }^{13}$, aber auch das Allgemeine Preußische Landrecht sowie die systematischen Gesetzgebungswerke der Kaiserzeit wie etwa das RStGB, das BGB und die Prozeßordnungen. Das BGB ist allerdings gleichzeitig ein Beispiel dafür, daß schon wenige Generalklauseln genügen, um ein ganzes Normensystem von einem formalen in ein materiales zu verwandeln. So wurde insbesondere $\S 242$ BGB in der Weimarer Republik zunehmend zur Begründung von Richterrecht auch gegen den Wortlaut der Gesetze verwandt, Richter, aber auch der Gesetzgeber traten die "Flucht in die Generalkläuseln"14 an. Diese Tendenz hat sich weiter fortgesetzt, so daß das Normensystem der Bundesrepublik eher als material zu kennzeichnen ist. Gleiches gilt wohl auch für das amerikanische Recht ${ }^{15}$, während das englische Rechtssystem einen Sonderfall darstellt. Einerseits ist dort selbst das Strafrecht, für dessen Formalität in Deutschland das Bestimmtheitsgebot aus Art. 103 II GG bürgt, zu großen Teilen auf durch richterliches Gewohnheitsrecht entstandenes Common Law gegründet. Vom Parlament erlassene Gesetze verstehen sich nicht als systematische Grundlegung eines Rechtsgebiets, sondern als lediglich partielle Veränderung oder Ergänzung immer schon geltenden Richterrechts. Wenn das Parlament allerdings solche Ergänzungen vornimmt, dann zeichnen sich diese Gesetze andererseits durch relativ hohe Präzision und Klarheit aus, so daß die englischen Gesetze, sofern vorhanden, eher formal sind. ${ }^{16}$

\section{Normanwendung}

\section{a) Norminterpretation (Juristische Methodenlehre)}

Ein weiteres Kriterium der Unterscheidung bilden die Methoden der Gesetzesauslegung und Interpretation. $\mathrm{Zu}$ den klassischen Auslegungsmethoden gehören die grammatikalische (Wortlaut), die systematische (Normzusammenhang), die historische (Wille des Gesetzgebers) sowie die teleologische (Sinn und Zweck des Gesetzes) Auslegung. Hinzu kommt unter dem Grundgesetz die verfassungskonforme Auslegung. ${ }^{17}$ Argumente, die sich auf den Wortlaut oder die Entstehungsgeschichte einer Norm beziehen, sind eher formal, während Argumente, die auf den Zweck des Gesetzes, auf Prinzipien, auf die Gerechtigkeit des Ergebnisses oder auf sonstige Folgen der Entscheidung verweisen, eher material sind. ${ }^{18}$ Darüber hinaus ist eine Methodenlehre eher formal, wenn sie die verschiedenen Auslegungskriterien in ein festes Vorrangverhältnis zueinander bringt, sie ist eher material, wenn die einzelnen Argumente jeweils im Hinblick auf den konkreten Fall gegeneinander abgewogen werden. ${ }^{19}$

Unter dem Gesichtspunkt der Auslegungsmethoden ist das englische Rechtssystem wiederum eher formal, da zur Auslegung im wesentlichen Wortlautargumente herange-

13 So M.Weber, WuG, Teil 2, Kap. VII, $\S 7,1$.

14 J.W.Hedemann, Flucht in die Generalklauseln; F.Neumann spricht vom "Sieg der Generalklausel über die echten Rechtssätze" in der Weimarer Zeit (Funktionswandel des Gesetzes, S.62).

15 R.S.Summers, On analyzing, S.27, 29.

16 R.S.Summers, a.a.O.; M.Allen et al., Constitutional Law, Kap. 6 C.

17 Vgl. K.Engisch, Einführung in das juristische Denken, 8.Aufl., Ffin 1983, S.39ff; K.Larenz, Methodenlehre der Rechtswissenschaft, Studienausgabe, 2.Aufl. 1992, Kap.5, S.208-230.

18 R.S.Summers, On analyzing, S.30; R.M.Unger unterscheidet zwischen "formalistic and purposive or policy-oriented styles of legal reasoning" (Law, S.194).

19 R.S.Summers, a.a.O. 
zogen werden, während schon der Rückgriff auf den Willen des Gesetzgebers mit der Begründung abgelehnt wird, daß dieser nicht eindeutig feststellbar sei. ${ }^{20}$ Das strikte Festhalten am Wortlaut wird zudem als Instrument zur Disziplinierung des Gesetzgebers eingesetzt. Wenn dieser sich nicht klar ausdrückt, wird nicht etwa über objektive Auslegungsmethoden rekonstruiert, was der Gesetzgeber vernünftigerweise gemeint haben könnte, sondern das Gesetz findet keine Anwendung. ${ }^{21}$ Andererseits ist das deutsche Rechtssystem eher material, wofür insbesondere die teleologische Auslegung sowie der über verfassungskonforme Auslegung vermittelte Rückgriff auf die Grundrechte als Werte oder Prinzipien stehen. Ferner ist die zunehmende Folgenorientierung zu erwähnen. ${ }^{22}$ Zudem werden die einzelnen Auslegungsmethoden vielfach nicht in ein Rangverhältnis zueinander gesetzt, und selbst die Frage, ob der mögliche Wortsinn die Grenze der Auslegung bildet, ist nicht unumstritten. ${ }^{23}$

\section{b) Richterliche Rechtsfortbildung}

Neben der Kompetenz zur inhaltlichen Ausfüllung von unbestimmten Rechtsbegriffen, Zweckprogrammen und Generalklauseln sowie einer an Zwecken und Folgen orientierten Form juristischer Argumentation kann den Gerichten in einem Rechtssystem die Kompetenz zufallen, das Recht bei seiner Anwendung auf den konkreten Fall im Hinblick auf substanzielle Erwägungen weiterzuentwickeln oder unter Umständen auch entgegen der bestehenden Regeln zu verändern. Solche richterliche Rechtsfortbildung ${ }^{24}$, die entweder als Lückenschließung etwa im Wege der Analogie eine Regelungslücke voraussetzt ${ }^{25}$ oder als Auslegung contra legem die bewußte Abweichung von einer vorhandenen Regel im Einzelfall unter Rückgriff auf gegenläufige Rechtsprinzipien mein ${ }^{26}$, ist von der abstrakten oder konkreten Normenkontrolle zu unterscheiden, bei

20 M.Allen et al., Constitutional Law, S. $131 \mathrm{ff}$.

21 So führt z.B. Lord Donaldson MR in Merkur Island Shipping Corp. v Laughton an Others, (1983) 2 AC 570, Court of Appeal aus: "In industrial relations it is of vital importance that the worker ... should know what is and what is not offside. And he must be able to find this out for himself by reading plain and simple words of guidance. The judges of this court are all skilled lawyers of very considerable experience, yet it has taken us hours to ascertain what is and what is not offside, even with the assistance of highly experienced counsel. This cannot be right."

22 N.Luhmann, Rechtssystem und Rechtsdogmatik, S.31ff; ders., Das Recht der Gesellschaft (RdG), Ffm 1993, S.195ff; H.Rottleuthner, Zur Methode einer folgenorientierten Rechtsanwendung, ARSP Beiheft 13 (1980), S.97ff; G.Lübbe-Wolff, Rechtsfolgen und Realfolgen; Welche Rolle können Folgenerwägungen in der juristischen Regel- und Begriffsbildung spielen, 1981, S.139ff; M.Kriele, Theorie der Rechtsgewinnung, 2.Aufl., Berlin 1976, S.195ff.

23 Die Wortlautgrenze wird überwiegend noch für das Strafrecht, nicht aber für das Zivilrecht akzeptiert: W.Hassemer, Rechtssystem und Kodifikation, in: A.Kaufmann/W.Hassemer (Hrsg.), Einführung in Rechtsphilosophie und Rechtstheorie der Gegenwart, 5.Aufl., Heidelberg 1989, S.212ff., sowie U.Schroth, Philosophische und juristische Hermeneutik, ebenda, S.306ff; K.Larenz, Methodenlehre, S.233 m.w.N. in FN 69; eine eher formale Methodenlehre dagegen bei H.J.Koch H.Rüßmann, Juristische Begründungslehre, München 1982.

24 Vgl. dazu den Überblick zu Rspr. und Literatur bei R.Wiethölter, Rechtsfortbildung, S.5ff.

25 Zur Analogie vgl. die Ausführungen zur Methodenlehre bei A.Kaufmann, Problemgeschichte der Rechtsphilosophie, in: ders./Hassemer (Hrsg.), Einführung, S.25-139, 103ff; Zum Lückenproblem C.W.Canaris, Die Feststellung von Lücken im Gesetz, 2.Aufl., München 1983.

26 J.Pöyhönen, Auslegung contra legem als dekonstruktives Spiel von Regein und Prinzipien im Recht, Rechtstheorie 1989, S.211-220; K.Larenz, Methodenlehre, Kap.6, der zwischen gesetzesimmanenter (lückenschließender) und gesetzesübersteigender Rechtsfortbildung unterscheidet. 
der die generelle Geltung einer Regel überprüft wird (o.1). Richterliche Rechtsfortbildung hebt die Geltung des geschriebenen Gesetzesrechts nicht auf, sondern beruft sich gegenüber diesem auf ein "Mehr an Recht"27 und schafft dadurch neues Recht. Die Zulässigkeit solcher Rechtsfortbildung wird unter dem Stichwort der Bindung des Richters an das Gesetz diskutiert ${ }^{28}$, im anglo-amerikanischen Case-Law-System spielt zudem die Bindung an Präzedenzfälle eine Rolle ${ }^{29}$. Ein Rechtssystem ist eher formal, wenn es die Kompetenz der Gerichte zur Abweichung von bestehendem Recht (Gesetz, Präjudizien) soweit als möglich einschränkt, es ist eher material, wenn eine solche Abweichung unter Berufung auf allgemeine Rechtsprinzipien, die Einzelfallgerechtigkeit etc. zulässig ist.

Das englische Rechtssystem ist mit der strikten Bindung der Richter an den Wortlaut der Gesetze und mit der restriktiven Handhabung des "overruling of precedent" eher formal, während das amerikanische Recht eher material ist. ${ }^{30} \mathrm{Im}$ deutschen Recht ist die richterliche Rechtsfortbildung auch gegen den Wortlaut des Gesetzes mit Ausnahme des Strafrechts ${ }^{31}$ hingegen prinzipiell anerkannt ${ }^{32}$, weshalb das deutsche Rechtssystem als eher material zu qualifizieren ist. ${ }^{33}$

\section{c) Tatsachenermittlung}

Die Tatsachenermittlung kann in einem Rechtssystem auf einem formalen oder auf einem materialen Wahrheitsbegriff beruhen. Ein Rechtssystem ist in diesem Sinne eher material, wenn es dem Richter die Aufgabe der Ermittlung des tatsächlichen (wahren) Sachverhalts zuweist, wofür z.B. das Inquisitionsprinzip steht. ${ }^{34}$ Der Wahrheitsbegriff des Rechts ist eher formal, wenn das Recht Legalfiktionen ${ }^{35}$ enthält, das Bestehen eines Rechts oder Rechtsverhältnisses lediglich von bestimmten Formen abhängig macht (bes. streng im Wechselrecht, aber auch durch öffentl. Bücher und Urkunden), wenn die Parteien im Prozeß über die Wahrheit verfügen können (Verhandlungsgrundsatz ${ }^{36}$ ), wenn die Anfechtbarkeit einer Entscheidung durch Fristablauf begrenzt wird (Rechtskraft) etc. Das Beweisrecht selbst kann ebenfalls entweder formal (Strengbeweis) oder material

27 So z.B. die Begründung in BVerfGE 34, 269 (286f.), "Soraya".

28 Siehe W.Hassemer, Rechtssystem und Kodifikation.

29 R.S.Summers, On analyzing, S.30f.

30 R.S.Summers, a.a.O.; vgl. auch die Ausfïhrungen zur Bindung der Richter an Gesetz und precedent bei J.Raz, Rule of Law, S.198.

31 Wegen dem aus Art. 103 II GG folgenden Analogieverbot. Vgl. dazu H.-L.Schreiber, Gesetz und Richter, Ffm 1974.

32 BVerGE, 34, 269, 286f: "Die Aufgabe der Rechtsprechung kann es insbesondere erfordern, Wertvorstellungen, die der verfassungsmäßigen Rechtsordnung immanent, aber in den Texten der geschriebenen Sätze nicht oder nur unvollkommen zum Ausdruck gelangt sind, in einem Akt des bewertenden Erkennens, dem auch willenhafte Elemente nicht fehlen, ans Licht zu bringen und in Entscheidungen zu realisieren". Zu den Grenzen: BVerfGE 49, 304; E 65,182.

33 Die Bindung des Richters an das Gesetz ist in der deutschen Methodendiskussion vielfach als utopisch bezeichnet worden: z.B. D.Simon, Die Unabhängigkeit des Richters, 1975, S.88; ein umfassender Überblick über die Diskussion bei K.Larenz, Methodenlehre, Kap.1.

34 Das Inquisitionsprinzip wird auch als Prinzip der materiellen Wahrheit bezeichnet: C.Roxin, Strafverfahrensrecht, 20.Aufl., München 1987, S.76.

35 Dazu K.Larenz, Methodenlehre, S.150-152 m.w.N., der allerdings die Funktion der Legalfiktion i.S.v. beschleunigter Herstellung von Rechtssicherheit durch Beweiserleichterung verkennt.

Vgl. Thomas/Putzo, ZPO, 19.Aufl., München 1995, Einl I R 1ff. 
(freie Beweiswürdigung) ausgerichtet sein. ${ }^{37}$ Eher formal ist weiterhin der Juryprozeß, da die Wahrheitsfindung Laien obliegt, während das Recht lediglich durch formale (bzw. prozedurale) Regeln ${ }^{38}$ sicherstellt, daß der Prozeß der Wahrheitsfindung möglichst objektiv und unparteilich verlaüft. ${ }^{39}$

Eine Einordnung verschiedener Rechtssysteme anhand dieser Kriterien ist äußerst schwierig. Dennoch mag man das englische und amerikanische Rechtssystem wegen des Juryprozesses sowie der Ausgestaltung auch des Strafprozesses als Parteienprozeß unter der Verhandlungsmaxime als eher formal bezeichnen, während das deutsche Rechtssystem mit dem Inquisitionsprinzip, das auch im Zivilprozeß im Vordringen begriffen ist ${ }^{40}$, sowie der freien Beweiswürdigung eher material ist. ${ }^{41}$

\section{Theorien der Gerechtigkeit}

Die soeben dargestellten Kriterien geben anhand der konkreten Beispiele einen ersten Einblick in die Debatte um die formale und materiale Rationalität des Rechts. Die Hintergründe dieser Debatte sind dabei allerdings im Dunkeln geblieben. Worum geht es also, wozu dient die Unterscheidung zwischen formalem und materialem Recht? Es geht um die Rationalität des Rechtssystems als Ganzem, um die Legitimität und Richtigkeit, oder mit anderen Worten um die Gerechtigkeit des Rechts. ${ }^{42}$ Noch genauer kann man sagen: Forderungen nach formaler oder materialer Rationalisierung des Rechts verweisen auf Theorien der Gerechtigkeit und der Entscheidbarkeit normativer Fragen. Solche "Hintergrundtheorien" werden im folgenden dargestellt.

Es ist bereits darauf hingewiesen worden, daß die Prädikate formal und prozedural in diesem Zusammenhang häufig als austauschbar behandelt werden ${ }^{43}$. Demgegenüber soll hier begründet werden, daß zwischen formalen und prozeduralen Theorien der Gerechtigkeit (bzw. Rationalität) unterschieden werden muß. Die fälschliche Gleichsetzung der

37 Ein Überblick über Formstrenge im Verfahrensrecht bei W.Oswald, Formalismus in der Jurisprudenz und materiale Rechtsethik, Freiburg (Schweiz) 1957, S.19-24; zur Tatsachenfeststellung im Prozeß auch K.Larenz, Methodenlehre, Kap. 4, S.193ff.; zu Strengbeweis und freier Beweiswürdigung s.a. Rosenberg/Schwab/Gottwald, Zivilprozeßrecht, 15.Aufl., München 1993, § 4 II; C.Roxin, Strafverfahrensrecht, S.77ff.

38 Z.B. Regeln über die Auswahl unvoreingenommener Geschworener, Verbot der Beeinflussung der Jury durch den Richter, Beweisaufnahme im Verfahren der crossexamination, Verbot sog. leadingquestions etc.: vgl. R.J.Walter/R.Ward, English Legal System, 7th edition, London 1994, ch. 9 (Juries), S.196ff.; W.R.Cornish, The Jury, London 1968.

39 R.S.Summers, On analyzing, S.32; anders M.Weber, WuG, Teil 2, Kap.VII, \& 8, 4., der das Vordringen von Laienelementen im Recht als Gegenbewegung zur fortschreitenden Spezialisierung und Rationalisierung des Rechts begreift.

40 Etwa durch $\S \S 138$ Шl, 139, 141, 273 ZPO: Thomas/Putzo, ZPO, Einl I R 3.

41 So R.S.Summers, On analyzing, S.32; mit vielen Beispielen auch W.Oswald, der die ursprüngliche Formenstrenge des deutschen "gemeinen Prozeßes" als überlebt bezeichnet (Formalismus, S.19).

42 Für die Austauschbarkeit dieser Begriffe A.Kaufmann, Prozedurale Theorien, S.2f.; J.Habermas, FuG, S.190ff. ordnet neuerdings das Prädikat gerecht allen gültigen Handlungsnormen zu, wobei moralisch gerechtfertigte Normen richtig, Rechtsnormen darüberhinaus legitim seien (s.u.). Demgegenüber sind für den Wertrelativisten (z.B. M.Weber, H.Kelsen) die Begriffe gerecht und rational nicht austauschbar, da Gerechtigkeitsfragen gerade nicht für rational entscheidbar gehalten werden. Der dann vertretene Begriff formaler Rationalität wird aber von einer Hintergrundtheorie über Gerechtigkeit getragen.

43 Siehe die oben in der Einleitung genannten Beispiele. Zur Gerechtigkeit vgl. insbes. R.Dreier, Gerechtigkeit; A.Kaufmann, Prozedurale Theorien. 
Prädikate formal und prozedural insbesondere in der deutschen Tradition beruht dabei auf drei Aspekten. Zum einen wird die Unterscheidung zwischen formellem und materiellem Recht (secondary und primary rules) mit der Unterscheidung von formalen und materialen Normen (bestimmt/ unbestimmt) verwechselt. Zweitens wird Kants Philosophie üblicherweise als formal gekennzeichnet, während der von ihm begründeten demokratischen Staatstheorie ein prozedurales Modell der Gerechtigkeit zugrundeliegt. ${ }^{44}$ Drittens besteht insbesondere die Theorie des liberalen (demokratischen) Rechtsstaats aus einer Kombination von formalen und prozeduralen Elementen, weshalb diese in der Regel nicht unterschieden werden. 45

Das Problem der Gerechtigkeit tritt historisch zunächst als Problem der Reziprozität von Leistung und Gegenleistung, Schaden und Ersatz oder Schuld und Strafe auf (ausgleichende Gerechtigkeit). ${ }^{46}$ Von dieser synallagmatischen (seit dem Mittelalter: kommutativen) Gerechtigkeit unterscheidet Aristoteles die distributive Gerechtigkeit (austeilende Gerechtigkeit im Verhältnis Bürger/Staat) ${ }^{47}$. Letztere betrifft die für das Recht besonders wichtige Frage, was einem jeden (rechtlich) zustehen soll. Unter dem Oberbegriff "Jedem das Seine" 48 können hier sehr unterschiedliche Formeln wie "Jedem das Gleiche", "Jedem nach seinem Bedürfnis", "Jedem nach seiner Leistung" usf. Anwendung finden ${ }^{49}$, wobei die letztgenannte Formel wieder die synallagmatische Gerechtigkeit zum Ausdruck bringt. Hans Kelsen hat sechzehn solcher Gerechtigkeitsformeln untersucht, wobei er zu dem Ergebnis kommt, diese seien entweder inhaltsleer oder widersprüchlich ${ }^{50}$. Als Minimum der Gerechtigkeit kann aus den verschiedenen Gerechtigkeitsformeln aber das Prinzip der Gleichheit abstrahiert werden, nach dem wesensmäßig Gleiches gleich und wesensmäßig Ungleiches ungleich behandelt werden muß. Weil dieses Gleichheitsprinzip die für seine Anwendung wesentlichen Kategorien nicht bestimmt, sondern nur Schema für die Suche nach Gründen oder Werten ist, wird diesbezüglich von formaler Gerechtigkeit gesprochen. 51

44 Das hat insbesondere I.Maus herausgearbeitet, die Kants vernunftrechtliche Staatstheorie als prozedurales Naturrecht bezeichnet (Aufklärung, Kap.8 sowie Anhang 1), allerdings selbst nicht hinreichend zwischen formal und prozedural unterscheidet. Dazu näher unten.

45 Anders hingegen R.S.Summers (Rule of Law, S.127ff.), der für eine strikte Trennung von formalem Rechtsstaatskonzept, demokratischer Regierungsform sowie materialen Verfassungsgehalten (Sozialstaat, Menschenrechte) plädiert, weil nur so die spezifischen Rationalitätsleistungen einer formalen Rechtsstaatskonzeption ins Bewußtsein gehoben werden könnten. Allerdings fehlt bei Summers die Unterscheidung zwischen prozeduralen und materialen Gehalten, weshalb er die Demokratie fälschlich einer substantive (materialen) theory zuordnet (a.a.O., S.135).

46 N.Luhmann, RdG, S.226; zu den drei Dimensionen der ausgleichenden Gerechtigkeit R.Dreier, Gerechtigkeit, S.14f.

47 R.Dreier, Gerechtigkeit, S.15; ders., Was ist Gerechtigkeit?, JuS 1996, S.580ff.; vgl. auch E.Tugendhat, Vorlesungen über Ethik, Ffm 1993, Achtzehnte Vorlesung, S.364ff., der anstatt von ausgleichender von korrektiver Gerechtigkeit spricht (S.367). Gemeint ist allemal dasselbe.

48 Das entspricht der platonischen Definition, die durch Ulpian auf die Formel "suum cuique tribuere" gebracht wurde: E.Tugendhat, Vorlesungen über Ethik, S.367; R.Dreier, Was ist Gerechtigkeit?, S.540.

49 Dreier, Gerechtigkeit, S.11f.; ausführlich dazu E.Tugendhat, Vorlesungen über Ethik, S.378ff., der verschiedene Formeln unter dem Begriff der sekundären Diskriminationen entfaltet.

50 H.Kelsen, Gerechtigkeit, S.357ff.

51 Zur formalen Gerechtigkeit: C.Perelmann, Eine Studie über die Gerechtigkeit, in: ders., Gerechtigkeit, S.9-84, 27f.; N.Luhmann, RdG, S.223. 
Was also sind formale, prozedurale und materiale Theorien der Gerechtigkeit? Bevor diese drei Konzepte im einzelnen ausgearbeitet werden, sei für ein erstes Vorverständnis ein Definitionsversuch von R.M.Unger zitiert:

"An ideal of justice is formal when it makes the uniform application of general rules the keystone of justice... It is procedural when it imposes conditions on the legitimacy of the process by which social advantages are exchanged or distributed. It is substantive (material) when it governs the actual outcome of distributive decisions or bargains". 52

\section{Formale Theorien der Gerechtigkeit}

Angesichts der Schwierigkeiten mit der Bestimmung materialer Gerechtigkeit setzen sich formale Theorien der Gerechtigkeit zum Ziel, ein Mindestmaß an Gerechtigkeit durch optimale Verwirklichung der formalen Gleichheit zu erreichen, oder besser, wenigstens offensichtliche Ungerechtigkeit in Form von Willkür auszuschließen. ${ }^{53}$ Dabei wird an das Prinzip der Gleichheit angeknüpft, welches allerdings mangels unstreitiger Kriterien zur Entscheidung der Frage, was wesensmäßig gleich oder ungleich ist, ebenfalls formal interpretiert wird. Formale Gleichheit bedeutet soviel wie Regelhaftigkeit oder Konsistenz des Entscheidens. Regelhaftigkeit des Entscheidens setzt Regeln voraus, Bedingung formaler Gerechtigkeit ist daher die konditionale Programmierung des Rechts ${ }^{54}$ oder in herkömmlicher Formulierung das Vorhandensein positiver, allgemeiner und inhaltlich bestimmter Gesetze. Formale Gerechtigkeit beruht, wie die Definition Ungers besagt, auf zwei Elementen: auf allgemeinen Gesetzen (general rules) und auf deren einheitlicher Anwendung (uniform application).

Die strikte Bindung des Richters an die Gesetze bewirkt die Gleichheit der Menschen vor dem Gesetz und damit Schutz vor richterlicher Willkür. Der Richter soll "ohne Ansehen der Person" entscheiden, also ohne Rücksichten auf soziale Pressionen, FreundFeind- oder Verwandschaft, auf Stand, Status oder Klasse usf. Die besten Gesetze sind daher solche, die dem Richter möglichst wenig Ermessen lassen. ${ }^{55}$ Neben der Gleichheit ermöglicht die Bindung des Richters an inhaltlich bestimmte Gesetze eine weitere fundamentale Forderung der Gerechtigkeit, die Rechtssicherheit. 56

Ist damit die Gerechtigkeit der Rechtsanwendung gesichert, so bleibt die Frage nach der Gerechtigkeit des Gesetzes. Diese soll wiederum durch die Angabe eines formalen Kriteriums gewährleistet sein, nämlich durch die formale Allgemeinheit des Gesetzes. Unabhängig davon, ob der Inhalt eines Gesetzes dem Naturrecht entstammt oder als positives Recht von einem Monarchen, einem demokratischen Gesetzgeber oder gar einem Tyrannen gesetzt ist, gilt als Gesetz nur ein seiner Form nach allgemeines Gesetz. Das Rechtsgesetz wird dabei parallel zu den Naturgesetzen, etwa den Newtonschen Gesetzen

52 R.M.Unger, Law, S.194; substantive = material; Hervorhebungen vom Verf.

53 Vertreter einer formalen Theorie argumentieren allgemein von der Vermeidung groben Unrechts her und betonen, daß damit im Vergleich zu anderen Theorien viel erreicht sei: vgl. nur R.S.Summers, Rule of Law, S.139f; F.Neumann, Funktionswandel des Gesetzes, S.38, 44, $50,54$. N.Luhmann, RdG, S.231f.

55 So begründet schon Aristoteles die Trennung von Gesetzgebung und Rechtssprechung, vgl. N.Luhmann, RdG, S.59 und Kap. 7 II.

56 So formuliert Francis Bacon im 8. Buch von "De Augmentis" (engl. Übersetzung) unter Titel I. Of the Primary Dignity of Laws, that they be certain: Aphorism 8. "Certainty is so essential to law, that law cannot even be just without it". Im Gegensatz dazu wird heute Rechtssicherheit häufig in ein Spannungsverhältnis zur (materialen) Gerechtigkeit gesetzt. 
der Mechanik, definiert als (1.) auf eine unbestimmte Vielzahl von Fällen anwendbar, (2.) an eine unbestimmte Zahl von Adressaten gerichtet sowie als mit (prinzipiell) unbeschränkter räumlicher (3.) und zeitlicher (4.) Geltung ausgestattet..$^{57}$ Die Kriterien der unbegrenzten räumlichen und zeitlichen Geltung sind dabei natürlich nur eingeschränkt auf Rechtsregeln übertragbar, insbesondere wird aber die Stabilität des Rechts in der Zeitdimension eingefordert. ${ }^{58}$ Die formalen Kriterien der Allgemeinheit stellen einen Bezug zur Universalisierbarkeit des Inhalts der Normen her, verweisen in ihrer Idealität also auf deren universelle Geltung. Insbesondere soll die Allgemeinheit des Gesetzes aber individuelle Maßnahmen des Gesetzgebers verhindern. ${ }^{59}$ Die Allgemeinheit wirkt auf der Ebene der Gesetzgebung gleich dem Rawlsschen "Schleier des Nichtwissens", da die künftigen Situationen der Gesetzesanwendung nur schwer vorhersehbar sind. Individuelle Willkür, wie sie auf der Ebene der Einzelfallentscheidung immer möglich ist, ist auf der Ebene der Gesetzgebung damit ausgeschlossen. Da allgemeine Gesetze für und gegen jedermann gelten und ohne Ansehen der Person angewandt werden, bürgt die Allgemeinheit für die Unparteilichkeit der Gesetzgebung. ${ }^{60}$

Formale Gerechtigkeit beschränkt sich folglich nicht auf Rechtssicherheit und bloß formale Gleichheit vor dem Gesetz, sondern enthält mit dem Kriterium der Allgemeinheit des Gesetzes auch ein allerdings wiederum formales Kriterium für die Rechtsinhaltsgleichheit.

\section{Materiale Theorien der Gerechtigkeit}

Demgegenüber sind materiale Gerechtigkeitstheorien auf inhaltlich-konkrete Urteile darüber, was gerecht und was ungerecht ist, gerichtet. Sie sollen einen Urteilenden befähigen zu entscheiden, ob etwa eine bestimmte Verteilung von Gütern, ein bestimmtes Austauschverhältnis (z.B. Preis/Leistung) oder eine bestimmte Norm gerecht ist. ${ }^{61}$ Ausgangspunkt bilden dabei die genannten Gerechtigkeitsformeln. Um aber nicht bei deren abstrakter Inhaltsleere stehenzubleiben, müssen diese mit konkreten Inhalten angereichert werden. Als zentraler Maßstab dafür dient dabei in der Regel der Begriff der Natur, teilweise wird aber auch auf die menschliche Vernunft zurückgegriffen. ${ }^{62}$ Indem materiale Gerechtigkeitstheorien vom Naturrechtstypus eine dem einsichtigen Betrachter erkennbare, objektive und deshalb unverfügbare Rechts- bzw. Gerechtigkeitsordnung behaupten, erfüllen sie gegenüber dem positiven (i.S.v. aktuell wirksamen) Recht eine kritische Funktion ${ }^{63}$. Historisch erlangen sie immer dann besondere Bedeutung, wenn in Zeiten des Wandels und der Krise eine bisher gegebene Rechtsordnung als ungerecht

57 Siehe dazu G. van der Velden, Allgemeinheit, S.329ff.

58 Z.B. J.Raz, Rule of Law, S.197: "Laws should be relatively stable. They should not be changed to often".

59 H.Hofmann, Allgemeinheit des Gesetzes, S.14.

60 Siehe dazu I.Maus, Perspektiven reflexiven Rechts im Kontext gegenwärtiger Deregulierungstendenzen, KJ 1986, S.390ff.; dies., Aufklärung, S.275ff.; N.Luhmann, Gesellschaftliche und politische Bedingungen des Rechtsstaats, in: ders., Politische Planung, Opladen 1971, S.53ff.

61 Mit Beispielen R.Dreier, Gerechtigkeit, S.20-23.

62 Zur Unterscheidung von materialen Gerechtigkeitstheorien vom Naturrechtstypus von solchen vom Vernunftrechtstypus R.Dreier, Gerechtigkeit, S.20ff.

63 N.Luhmann, Positivität des Rechts als Voraussetzung einer modernen Gesellschaft, in Jahrbuch für RSoz und RTheorie Bd 1 (1970), S.175ff, 180. 
empfunden wird. ${ }^{64}$ In Deutschland fand eine solche "Naturrechtsrenaissance" zuletzt nach 1945 als Reaktion auf nationalsozialistisches Unrecht statt. ${ }^{65}$

Nach der Argumentationsrichtung, in der die natürlichen Rechtsinhalte gesucht werden, kann zwischen abstraktem und konkretem Naturrecht unterschieden werden ${ }^{66}$. Abstrakte Naturrechtstheorien leiten Gerechtigkeitsurteile aus obersten Prinzipien oder ewigen Werten, also aus einem gegenüber dem positiven Recht höheren Sollen ab, während konkretes Naturrecht wie etwa in den Lehren von der Natur der Sache in den sachlogischen Strukturen der za regelnden Materie oder den sozialen Institutionen als seienden Ordnungen, also in einem dem positiven Recht zugrundeliegenden Sein, gefunden wird. ${ }^{67}$

Abstrakte Naturrechtstheorien konkretisieren die relativ inhaltsleeren Gerechtigkeitsformeln wie "Jedem das Seine" zunächst durch eine Reihe kategorischer Sätze mittleren Abstraktionsniveaus wie etwa die christlichen Dekalogsätze oder die rationalistisch-aufklärerisch begründeten Menschenrechte. ${ }^{68}$ Sätze wie "Du sollst nicht töten" oder "Jeder hat ein Recht auf Leben" haben zunächst den Vorteil, daß ihnen ein hohes Maß an Konsensfähigkeit zukommt. Obwohl sie ihrem Wortlaut nach bedingungsfeindlich sind, stellt sich bei ihrer Anwendung auf den konkreten Fall hingegen schnell heraus, daß sie einer Reihe von Einschränkungen unterliegen müssen, die allerdings nicht mehr ohne weiteres konsensfähig sind (hier etwa: Krieg, Notwehr, Todesstrafe, Selbsttötung etc.). Mit ihrer grundsätzlichen Einschränkbarkeit verwandeln sich die Dekalog- und Grundrechtsformeln aber von definitiven Regeln in bloße Ziele, Prinzipien oder Werte, die zu ihrer Anwendung wiederum der Konkretisierung bedürfen. ${ }^{69}$

An diese Problemlage schließen die sog. Werttheorien an..$^{70}$ In der Nachkriegszeit besonders einflußreich war in Deutschland die von M.Scheler gegen Kants formale Ethik begründete und von N.Hartmann fortgeführte materiale Wertethik ${ }^{71}$. Danach sind Gerechtigkeitsfragen unter Rückgriff auf eine objektive Wertordnung zu entscheiden ${ }^{72}$. Das Problem einer materialen Wertethik ist allerdings, daß sie nur dann zu einzig richtigen, objektiven Gerechtigkeitsurteilen führt, wenn einerseits ein vollständiger und geschlossener Katalog von gültigen Werten erstellt, und andererseits für den Fall von Wertekollisionen eine harte Vorrangordnung angegeben werden kann. Beide Voraussetzungen haben sich inzwischen, insbesondere auch in der Praxis der Rechtsprechung des

64 A.Baratta, Natur der Sache und Naturrecht (1955), in: ders., Philosophie und Strafrecht, Köln u.a. 1985, S.89ff, 100.

65 Dazu die Beiträge in W.Maihofer (Hrsg.), Naturrecht oder Rechtspositivismus, 3.Aufl., München 1981; A.Kaufmann, Naturrechtslehre nach 1945, in: Anstöße 35 (1988), S.14ff.

66 G.Ellscheid, Das Naturrechtsproblem, Eine systematische Orientierung, in: Kaufmann/Hassemer (Hrsg.), Einführung, S.143ff, 160f, 189ff.

67 G.Ellscheid, Naturrechtsproblem, S.190ff.; A.Baratta, Natur der Sache, S.96-101.

68 Vgl. G.Ellscheid, Naturrechtsproblem, S.165-173.

69 Ders., a.a.O.

70 Dazu ausführlich R.Alexy, Grundrechte, S.125ff.

71 M.Scheler, Wertethik; N.Hartmann, Ethik, Berlin/Leipzig 1926; aufgenommen u.a. von H.Welzel, Naturrecht und materiale Gerechtigkeit (1951), 4.Aufl., Göttingen 1962; W.Oswald, Formalismus; diese Denkart ist insbesondere vom BGH aufgenommen worden.

72 So hat das BVerfG, der Sache nach allerdings nicht im Anschluß an Scheler, sondern an die in der Tradition von Hegel entwickelten Gedanken von Rudolf Smend, den Grundrechts-abschnitt des GG als objektive Wertordnung interpretiert, die für alle Bereiche des Rechts als Grundentscheidung gilt (E 7, 198, 205). 
BVerfG, als unerfüllbar erwiesen. ${ }^{73}$ Eine Werttheorie, die von der prinzipiellen Offenheit des Wertekatalogs ausgeht und Wertekollisionen anhand des konkreten Falles im Wege der Abwägung löst, führt aber nicht in jedem Fall zu genau einem zwingenden Ergebnis $^{74}$ und kann daher nur sehr eingeschränkt als materiale Gerechtigkeitstheorie verstanden werden. ${ }^{75}$

Daneben wurde während besagter Naturrechtsrenaissance insbesondere das Denken aus der Natur der Sache wieder aufgenommen. ${ }^{76}$ Die Lehren von der Natur der Sache wollen ein die Willkür des Gesetzgebers begrenzendes "konkretes Naturrecht"77 ausgehend von der Individualität des Einzelfalles in der materiellen Basis der zu regelnden Materie (Rechtsstoff) finden. ${ }^{78}$ "Natur der Sache ist die objektiv feststellbare, sachlogische Strukturiertheit der Wirklichkeit, deren seinsmäßiger Ordnungscharakter das Recht maßgebend konstituiert."79 Das Anknüpfen an "dem Recht vorgegebene soziale Ordnungen" stellt dabei eine gewisse Nähe zu den institutionellen Rechtstheorien her. ${ }^{80}$ Es sind die Institutionen (bzw. die "seienden Ordnungen"), welche die Rechtsnormen schaffen; nicht etwa umgekehrt. ${ }^{81}$ Mit dieser Vorgehensweise sind nun zwei Probleme verbunden. Zum einen wird bei der Ableitung eines Sollens aus seienden Ordnungen die Frage nach der normativen Richtigkeit des Seienden umgangen (naturalistischer Fehlschluß). Aus der Natur der Sache ist daher die Wirklichkeit nicht kritisierbar, weshalb diesen Lehren zweitens eine konservative Grundhaltung vorgeworfen wird. 82 Unter dem hier interessierenden Aspekt der objektiven Begründbarkeit materialer Gerechtigkeitsurteile wichtiger erscheint jedoch, daß aus der Natur der Sache keine eindeutigen, allgemein konsensfähigen Rechtsinhalte abgeleitet werden können ${ }^{83}$, so daß von diesen Lehren nurmehr "ein Bündel methodischer Anweisungen" übrigbleibt, "die darauf hinauslaufen, die Ordnungsstrukturen der Wirklichkeit, wo immer sie auftauchen, nicht zu verletzen"84.

73 R.Alexy, Grundrechte, S.139, 142.

74 Ders., a.a.O., S.143.

75 Zur Einordnung als prozedurale Gerechtigkeitsbegründungstheorie s.u. 3. und R.Dreier, Gerechtigkeit, S.27f.

76 Insbes. durch G.Radbruch, Die Natur der Sache als juristische Denkform, in: FS f. Rudolf Laun, 1948, S.157ff.; sowie von W.Maihofer, Die Natur der Sache, ARSP 47 (1958), S.145-174. Zur Geschichte des Gedankens vgl. R.Dreier, Zum Begriff der "Natur der Sache", Berlin 1965, Kap. 1 und 2; s.a. A.Baratta, Natur der Sache, S.97, der auf die Ausarbeitung des Gedankens durch Montesquieu verweist.

77 W.Maihofer, a.a.O.

78 A.Baratta, Natur der Sache, S.98ff.

79 Ottmar Ballweg, $\mathrm{Zu}$ einer Lehre von der Natur der Sache, 1960, S.67; zit. nach G.Ellscheid, Naturrechtsproblem, S. 190 .

80 Grundlegend M.Hauriou, Die Theorie der Institution und zwei andere Aufsätze, hrsg. v. Roman Schnur, Berlin 1965; weiterhin das "konkrete Ordnungsdenken" von C.Schmitt, Über die drei Arten des rechtswissenschaftlichen Denkens, Berlin 1934; sowie die institutionelle Methode im Verwaltungsrecht von E.Forsthoff, Die Verwaltung als Leistungsträger, Stuttgart/Berlin 1938; zu den Bezügen zur Natur der Sache vgl. R.Dreier, Natur der Sache, $\S 16$.

81 M.Hauriou, Theorie der Institution, S.65.

82 G.Ellscheid, Naturrechtsproblem, S.195, 203; A.Baratta, Natur der Sache, S.100, sowie eine ausführliche Kritik an Maihofer auf S.125ff.

83 Vgl. dazu das Beispiel bei G.Ellscheid, Naturrechtsproblem, S.193ff.; ein weiteres Beispiel findet sich bei R.Dreier, Gerechtigkeit, S.21.

84 G.Ellscheid, Naturrechtsproblem, S.192. R.Dreier (Natur der Sache, S.126ff.) kommt zu dem Schluß, der Begriff der Natur der Sache sei so vieldeutig, daß er sich nicht als juristischer Fachbe- 
Arthur Kaufmann, ein engagierter Mitstreiter der Naturrechtsrenaissance, kommt rückblickend zu dem Ergebnis: "Eines aber kann mit Sicherheit festgestellt werden: an Kants Kritizismus gibt es kein Vorbeikommen. Inhaltlich erfüllte Naturrechtssätze mit apriorischer ... Gültigkeit lassen sich nicht begründen." 85

\section{Prozedurale Gerechtigkeitstheorien}

Nach allem muß sich die Gerechtigkeitstheorie entweder auf (relativ!) inhaltsleere formale Aussagen zurückziehen oder sich mit der Aufstellung abstrakter Prinzipien und Werte begnügen, will sie sich nicht bei dem Versuch der Konkretisierung materialer Gerechtigkeit hoffnungslos in Widersprüche zwischen vermeintlicher Objektivität und offensichtlich fehlender Konsensfähigkeit ihrer Ergebnisse verstricken. Einen Ausweg aus diesem Dilemma wollen die sog. prozeduralen Theorien der Gerechtigkeit ${ }^{86}$ weisen, nach denen eine Norm oder ein Urteil dann gerecht ist, wenn es Ergebnis eines durch bestimmte Bedingungen und Regeln ausgezeichneten Verfahrens ist.

Die Idee prozeduraler Gerechtigkeit geht auf das privatrechtliche Vertragsmodell zurück, nach dem etwas kraft Übereinkunft (Konsens) gerecht ist, wenn diese Vereinbarung zwischen einsichtsfähigen Partnern unter Ausschluß von Irrtum, Täuschung, Drohung oder Zwang zustande gekommen ist. ${ }^{87}$ Dieses Modell wird in den vernunftrechtlichen Theorien vom Gesellschaftsvertrag (Hobbes, Locke, Rousseau ${ }^{88}$ ) auf die Staatstheorie übertragen ${ }^{89}$. Die eigentlich kopernikanische Wende in der Philosophie wird allerdings erst durch Kants transzendentale Logik begründet..$^{90} \mathrm{Im}$ Gegensatz zu allen traditionellen Naturrechtslehren, welche Gerechtigkeit als etwas Objektives ansehen, rückt Kant das erkennende Subjekt in den Mittelpunkt des Interesses, fragt also nach den Bedingungen der Möglichkeit von Erkenntnis. Alle Inhalte entstammen nach Kant nun der Erfahrung und gelten daher nur "a posteriori". "A priori" gültig sind dagegen nur Aussagen über die Form der Anschauung bzw. die Form des Denkens, also Aussagen über den Erkenntnisprozeß.91 Daraus folgt, da $\beta$ eine objektive, allgemeingültige Theorie der Gerechtigkeit keine Rechtsinhalte, sondern lediglich ein Verfahren der Erkenntnis von Gerechtigkeit umfassen kann. ${ }^{92}$ Solche prozeduralen Theorien der Gerechtigkeit werden im folgenden dargestellt.

griff eigne. Die juristisch nützlichen Gehalte des Begriffs könnten unter dem Titel der empirischfaktischen Schranken des Rechts einerseits, sowie der Wendung vom institutionellen Denken andererseits präziser gefasst werden.

85 A.Kaufmann, Problemgeschichte, S.89; vgl. auch ders., Rechtsphilosophie in der Nach-Neuzeit, München 1990, S.21.

86 Zu dieser Bezeichnung R.Dreier, Gerechtigkeit, S.19, 23ff., A.Kaufnann, Recht und Rationalität, in: FS für Maihofer, Ffm 1988, S.11ff.; ders., Prozedurale Theorien, 1989.

87 So etwa positiviert im BGB AT; vgl. R.Dreier, Gerechtigkeit, S.24f.; andere Formen reiner Verfahrensgerechtigkeit - wie etwa das Losverfahren - erscheinen für eine Rechtsphilosophie hingegen als uninteressant.

88 T.Hobbes, Leviathan (1651), 17.Kap.; J.Locke, Über die Regierung (1689), Kap. 8; J.Rousseau, Vom Gesellschaftsvertrag (1762), 1. Buch, Kap.6.

89 R.Dreier, Gerechtigkeit, S.23f.; A.Kaufmann, Problemgeschichte, S.132.

90 A.Kaufmann, Prozedurale Theorien, S.8; I.Maus, Aufklärung, S.250.

91 Vgl. A.Kaufmann, Problemgeschichte, S.59ff.; ders., Prozedurale Theorien, S.8-10.

92 Das verkennt Kaufmann (Prozedurale Theorien, S.10-18), wenn er allen prozeduralen Theorien unterstellt, daß die Konsenserzielung im Vertrags- oder Diskursmodell von vorneherein ein fiktives Denkverfahren sei, durch das Inhalte aus der Form gewonnen werden sollen und diesen Theorien 


\section{a) Normen und Fakten}

Prozedurale Theorien der Gerechtigkeit in einem weiteren Sinne umfassen neben Verfahren zur Herleitung der normativen Entscheidungsgrundlagen (Leitfrage: Was ist das einem jedem rechtlich Zustehende = prozedurale Gerechtigkeitstheorien i.e.S.) auch Verfahrensregeln über die faire Anwendung dieser Normen auf einen konkreten Fall. Dazu gehören subjektive Justizgrundrechte (gesetzlicher Richter, rechtliches Gehör, right to trial by Jury) ebenso wie eher strukturelle Vorkehrungen (Unabhängigkeit des Richters, Unschuldsvermutung, Beweiserhebungsverbote wie etwa das Verbot der Folter etc.), die als Grundsätze des "fair trial" (bzw. "due process") zusammengefaßt werden können ${ }^{93}$. Diese die Gerechtigkeit des Gerichtsprozesses (bzw. des Verwaltungsverfahrens) regelnden Grundsätze betreffen primär die Ermittlung der tatsächlichen Entscheidungsgrundlage. Sie sind von Theorien prozeduraler Gerechtigkeit i.e.S. zu unterscheiden, die die Herleitung von normativen Entscheidungsgrundlagen durch den Richter (etwa die richterliche Rechtsfortbildung) betreffen. ${ }^{94}$ Erstere treten als eigenständiges Moment zu den Gerechtigkeitstheorien i.e.S. hinzu, sind also sowohl mit prozeduralen, als auch mit formalen oder materialen Theorien der Gerechtigkeit i.e.S. kombinierbar. ${ }^{95}$

Die prozeduralen Gerechtigkeitstheorien i.e.S. beruhen demgegenüber auf dem Konsensprinzip des Vertragsmodells. Zur Übertragung dieses privatrechtlichen Prinzips auf die Erzeugung oder Begründung öffentlich-rechtlicher Normen wird dabei zunächst ein ideales Verfahren begründet, welches jedoch faktisch nicht oder nur annähernd einhaltbar ist. Je nach Zielrichtung der Theorie wird dieses dann auf unterschiedliche reale Bedingungen hin konkretisiert.

dann vorwirft, ihre Inhalte seien allesamt "erschlichen", da Inhalte nie dem Verfahren, sondern immer der Erfahrung enstammten (a.a.O., S.20).

93 Die wichtigsten Justizgrundrechte sind in Art. 101-104 GG sowie in der EMRK positiviert, zur richterlichen Unabhängigkeit vgl. Art. 97 I GG. Weitere Grundsätze des "fair trial" hat das BVerfG aus dem Rechtsstaatsprinzip des Art. 20 GG abgeleitet: vgl. D.Dörr, Faires Verfahren. Gewährleistung im Grundgesetz der Bundesrepublik Deutschland, 1984; P.J.Tettinger, Fairneß und Waffengleichheit. Rechtsstaatliche Direktiven für Prozeß und Verwaltungsverfahren, 1984. Zum "right to trial by jury" vgl. für das englische Recht W.R.Cornish, The Jury, S.56. Zu aus den Grundrechten abgeleiteten Verfahrenstrukturierungsgeboten sowie zu deren Übertragung vom Gerichtsverfahren auf das Verwaltungsverfahren vgl. J.Burmeister, Grundgesetzliche Verfahrensstrukturierungsgebote komplexer Verwaltungsentscheidungen, in: Jahrbuch des Umwelt- und Technikrechts Bd. 5 (UTR), Düsseldorf 1988, S.121-160, 140 m.w.N.; H.Goerlich, Grundrechte als Verfahrensgarantien, 1981.

94 Etwas ungenau dagegen die Unterscheidung von Gerichtsmodell und Vertragsmodell der prozeduralen Gerechtigkeit bei R.Dreier (Gerechtigkeit, S.24f.), der den Eindruck erweckt, es gäbe ein eigenständiges Gerichtsmodell auch bezüglich der normativen Entscheidungs-grundlagen. Da aber alle prozeduralen Theorien i.e.S. an den Konsens anknüpfen, haben Theorien, die auf die Simulation von Konsens im Kopf des Richters abstellen, keinen eigenständigen, sondern einen gegenüber realen Konsensaushandlungsprozessen abgeleiteten Status (s.u.).

95 So sind die Justizgrundrechte (auch das auf rechtliches Gehör) auch dann zu beachten, wenn der Richter nach dem Grundsatz "jura novit curia" die normative Entscheidungsgrundlage ausschließlich formal aus dem Gesetz, oder material aus überpositiven Werten und Prinzipien ableitet. Rechtliches Gehör bedeutet daher primär Anhörung bzgl. der tatsächlichen Seite, höchstens sekundär Anhörung von Rechtsmeinungen der Parteien ("Da mihi factum, dabo tibi jus"). 


\section{b) Ideale Verfahren}

Ein solches ideales Verfahren findet sich zunächst bei Kant. ${ }^{96}$ Kant geht davon aus, daß der Mensch als vernunftbegabtes Wesen kraft dieser Vernunft autonom ist. Autonomie bedeutet dabei Freiheit, und Freiheit ist die Freiheit, nur nach selbstgesetzten Gesetzen zu leben. ${ }^{97}$ In dieser Autonomie sind alle Menschen gleich, womit die Prinzipien der Freiheit und Gleichheit, als deren Ausfluß sich die natürlichen Menschenrechte ergeben $^{98}$, begründet sind. Aus der Gleichheit der Menschen ergibt sich das gleiche Recht eines jeden auf gleiche Freiheit. Sodann stellt sich das Problem der Abstimmung dieser Freiheiten und damit die Frage nach dem Recht. "Das Recht ist also der Inbegriff der Bedingungen, unter denen die Willkür des einen mit der Willkür des andern nach einem allgemeinen Gesetze der Freiheit zusammen vereinigt werden kann." 99 Wann aber ist ein solches Rechtsgesetz gerecht? Kants Antwort ist eine prozedurale:

"Die gesetzgebende Gewalt kann nur dem vereinigten Willen des Volkes zukommen. Denn, da von ihr alles Recht ausgehen soll, so muß sie durch ihr Gesetz schlechterdings niemand unrecht tun können. Nun ist es, wenn jemand etwas gegen einen anderen verfügt, immer möglich, daß er ihm dadurch unrecht tue, nie aber in dem, was er über sich selbst beschließt (denn volenti non fit iniuria). Also kann nur der übereinstimmende und vereinigte Wille aller, so fern ein jeder über alle und alle über einen jeden ebendasselbe beschließen, mithin nur der allgemein vereinigte Volkswille gesetzgebend sein." 100

96 Die folgenden Ausführungen stützen sich insbes. auf die Kantinterpretation von I.Maus, Aufklärung. Die Kantzitate sind der Sonderausgabe der Wissenschaftlichen Buchgesellschaft (I.Kant, Werke in zehn Bänden, hrgg. von W.Weischedel, Darmstadt 1983) entnommen, die von der Seitenzählung der sechsbändigen Studienausgabe (WW I-VI, Darmstadt 1964) entspricht. Es werden die üblichen Abkürzungen (GMS = Grundlegung zur Metaphysik der Sitten; MdS = Metaphysik der Sitten; ZeF = Zum ewigen Frieden; Gemeinspruch = Über den Gemeinspruch: Das mag in der Theorie richtig sein, taugt aber nicht für die Praxis) verwendet.

97 Kant, GMS, WW IV, S. 86: "...Freiheit und eigene Gesetzgebung des Willens sind beides Autonomie, mithin Wechselbegriffe...". Für das öffentliche Recht expliziert Kant dieses Prinzip durch die Prinzipien der Freiheit als Mensch, der Gleichheit als Untertan und der Selbständigkeit als Staatsbürger ( MdS, WW IV, S. 432; Gemeinspruch, WW VI, S. 145ff; bzw. Freiheit, Abhängigkeit, Gleichheit, ZeF, WW VI, S. 204ff.), diese liegen aber alle schon in dem einzigen, angeborenen Recht der Freiheit begrindet (MdS, WW IV, S. 345f.).

98 I.d.S. sagt R.Dreier (Rechtsbegriff und Rechtsidee. Kants Rechtsbegriff und seine Bedeutung für die gegenwärtige Diskussion, Ffm 1986, S.23 mit FN 44), daß bei Kant die wesentlichen materiellen Prinzipien des Grundgesetzes (neben Freiheit und Gleichheit vor allem die Menschenwürde) begründet sind; ebenso A.Kaufmann, Problemgeschichte, S.64f. Diese Feststellung bedarf allerdings insofern der Ergänzung, als bei Kant Freiheit und Gleichheit nicht material i.S.d. Grundgesetzes, sondern formal definiert sind: "Vielmehr ist meine äußere (rechtliche) Freiheit so zu erklären: sie ist die Befugnis, keinen äußeren Gesetzen zu gehorchen, als zu denen ich meine Beistimmung habe geben können. - Eben so ist äußere (rechtliche) Gleichheit in einem Staate dasjenige Verhältnis der Staatsbürger, nach welchem keiner den anderen wozu rechtlich verbinden kann, ohne daß er sich zugleich dem Gesetz unterwirft, von diesem wechselseitig auf dieselbe Art auch verbunden werden zu können.", Kant, ZeF, WW VI, S. 206 FN *.

99 Kant, MdS, WW IV, S.337; dazu ausführlich R.Dreier, Rechtsbegriff, S.11-15.

100 Kant, MdS, WW IV, S.432; vgl, auch Gemeinspruch, WW VI, S.150; ebenso Rousseau, Gesellschaftsvertrag, II. Kap.6: "noch (ist es nötig, zu fragen,) ob das Gesetz ungerecht sei, da niemand gegen sich ungerecht ist". 
Bei Kant ist das Konsensprinzip also als Demokratieprinzip begründet. ${ }^{101}$ Dessen Gerechtigkeit ergibt sich ausschließlich aus der Autonomie des Menschen.

Demgegenüber knüpfen Argumentationstheorien der Gerechtigkeit an das Modell wissenschaftlicher Wahrheitsfindung an. ${ }^{102}$ So soll der Philosoph nach Perelmann versuchen, ein gedachtes "universales Auditorium" der Wissenden im Wege der rationalen Argumentation zu überzeugen. Aus der rationalen Begründung folge zwar nicht die Richtigkeit der vom einzelnen Philosophen vorgeschlagenen Wertungen, hingegen könne der andauernde philosophische Dialog eine fortschreitende Annäherung an die Erkenntnis universeller Werte bewirken. ${ }^{103}$ Ein ähnliches Konzept findet sich schon Ende des 19. Jahrhunderts bei Peirce, der Wahrheit als rationale Akzeptabilität definiert. Wahr ist demnach, was sich in einem offenen, aber zielgerichteten Interpretations- und Lernprozeß vor einem ideal erweiterten Auditorium urteilsfähiger Interpreten in the long run als "final opinion", als unter idealen Bedingungen erreichter Konsens einstellen würde ${ }^{104}$. Habermas hat dieses Modell der wissenschaftlichen Wahrheitsfindung als Konsensustheorie der Wahrheit bezeichnet ${ }^{105}$, wobei er das Kriterium der Argumentationspraxis einer vorgestellten Gelehrtenrepublik durch die Bezugnahme auf eine unbegrenzte Kommunikationsgemeinschaft erweitert ${ }^{106}$. Für normative Fragen hat er dieses Modell durch das Diskursprinzip präzisiert, nach dem eine Norm gültig ist, wenn ihr alle möglicherweise Betroffenen als Teilnehmer an rationalen Diskursen zustimmen

101 Dieses ideal-prozedurale Modell der äußeren Gesetzgebung von äußeren Gesetzen (= mit Zwang durchsetzbaren Rechtsgesetzen im Gegensatz zu ethischen Gesetzen der Tugend) bei Kant blendet R.Dreier (Einheit, S.286ff.) aus, indem er sich auf die vom kategorischen Imperativ geleitete innere Gesetzgebung von äußeren Gesetzen, also von vorneherein auf die hypothetische Verallgemeinerung in einem gedanklichen Verfahren beschränkt (a.a.O., S.289f.). Richtig ist zwar, daß Kant neben dem ethischen auch einen juridischen Gebrauch des kategorischen Imperativs kennt (a.a.O., S.294; dazu s.u.), das Rechtsprinzip und damit das Konsensprinzip leiten sich aber nicht aus dem kategorischen Imperativ (so aber a.a.O., S.295, 299f,), sondern aus dem Prinzip der Selbstgesetzgebung (Autonomie, Freiheit) ab, weil ein Rechtsgesetz nur dann als Freiheitsgesetz (also als selbstgesetzt) gerecht sein kann, wenn die betroffenen Menschen tatsächlich zugestimmt haben (Kant, Gemeinspruch, WW VI, S.144, 150). Demgegenüber hat der juridische Gebrauch des kategorischen Imperativs als bloße Simulation von Selbstgesetzgebung (Probierstein) nur eine untergeordnete, abgeleitete Stellung, was auch daraus folgt, daß im Gemeinspruch vom "Probierstein" nicht in der Theorie der bürgerlichen Verfassung a priori, sondern erst unter dem Abschnitt der Folgerung für die Praxis die Rede ist (Gemeinspruch , S.153; vgl. auch I.Maus, Aufklärung, Kap. 8 und 9, sowie im Anhang S.271ff.). Demgegenüber stellen auch A.Kaufmann (Prozedurale Theorien, S.8f.) und G.Ellscheid (Naturrechtsproblem, S.177f.) fälschlich nur auf das hypothetische Verfahren des kategorischen Imperativs ab.

102 R.Dreier, Gerechtigkeit, S.27f;; Ausführlich zu den Argumentationstheorien R.Alexy, Theorie der juristischen Argumentation, Ffm 1983.

103 C.Perelmann, Fünf Vorlesungen über die Gerechtigkeit, in: ders., Gerechtigkeit, S.85-163; vgl. R.Alexy, Argumentation, S.197ff.

104 Peirce vollzieht in kritischer Rekonstruktion der Kantschen Kritik der reinen Vernunft den Schritt vom Subjekt (Bewußtsein) zur Intersubjektivität (Sprache). Mit dem Konzept der final opinion sind Grundsätze a priori nicht mehr Voraussetzung sondern Ziel wissenschaftlicher Erkenntnis, weshalb alle wissenschaftlichen Sätze (auch Kants Prinzipien a proiri) prinzipiell fallibel werden.Vgl. dazu K.-O.Apel, Von Kant zu Peirce, in: ders., Transformation der Philosophie Bd.2 (1973), 5.Aufl., Ffm 1993, S.157-177 m.w.N.; J.Habermas, Charles S. Peirce über Kommunikation, in: ders., Texte und Kontexte, Ffm 1991, S.9-33;

105 J.Habermas, Wahrheitstheorien, in: Wirklichkeit und Reflexion, FS f. W.Schulz, Pfullingen 1973, S.211-265.

106 Ders., FuG, S.31f. 
könnten. ${ }^{107}$ Die Argumentationstheorien (Diskursmodell) greifen damit ebenso wie Kant (Vertragsmodell) auf den Konsens als Kriterium der Gerechtigkeit zurück. Das Konsensprinzip wird jedoch nicht aus der Autonomie der Person (niemand kann sich selbst Unrecht zufügen), sondern aus der sich in Kommunikationsprozessen jenseits subjektiver Einsichten einstellenden Intersubjektivität begründet. 108

Ebenfalls an das Konsensprinzip, allerdings in einer entscheidungstheoretisch rekonstruierten Form des in einem fiktiven Urzustand geschlossenen Gesellschaftsvertrages, knüpft Rawls in seiner Theorie der Gerechtigkeit an. ${ }^{109}$ Nach dem Grundgedanken der "Gerechtigkeit als Fairneß" ist gerecht, worauf sich freie Bürger unter fairen Bedingungen einigen. 110

\section{c) Konsens und Vernunft}

Gehen alle prozeduralen Theorien vom Konsensprinzip aus, so werden unterschiedliche Bedingungen genannt, die die Entstehung eines vernünftigen Konsenses sicherstellen sollen. Damit ist das Problem angesprochen, wie aus der Vielfalt der empirischen, von egoistischen Motiven getragenen Willen der einzelnen Menschen ein vernünftiger Gesamtwille entstehen kann, wie - mit Rousseaus Worten - aus der "volonté de tous" eine "volonté générale" entsteht. ${ }^{111}$

Nach Kant entspringt die Vernunft des allgemeinen Volkswillens nun einem Automatismus des demokratischen Verfahrens. ${ }^{112}$ "Der Wille aller ist jeder Zeit gut. Der Willen der einzelnen mag noch so böse seyn. Denn das Böse hat darin etwas Besonderes, daß es unter allen Zusammen nicht einstimmig ist und sich so aufhält, daß es kein resultat herausbringt, als nach der Regel des Guten."113 Die Allgemeinheit der Beteiligung aller am Gesetzgebungsverfahren führt einerseits zur formalen Allgemeinheit der Gesetze i.d.S., "daß das Gesetz die Untertanen als Gesamtheit und die Handlungen als abstrakte betrachtet, nie jedoch einen Menschen als Individuum oder eine Einzelhandlung"114: denn einer individuellen Maßnahme, die sich gegen einen einzelnen richtete, würde zumindest der Betroffene nicht zustimmen, weshalb sich der Grundsatz der Gewaltenteilung und damit der Ausschluß einer auch individuelle Maßnahmen treffenden (despotischen) Demokratie bei Kant wie von selbst ergibt. ${ }^{115}$ Andererseits bewirkt die

107 Ders., FuG, S.138; ausführlich zur Diskurstheorie s.u. Kap. 2 II.

108 Vgl. dazu A.Kaufmann, Prozedurale Theorien, S.11, 16ff.; K.-O.Apel, Das Apriori der Kommunikationsgemeinschaft, in: ders., Transformation der Philosophie Bd.2, S. $358 \mathrm{ff}$.

109 J.Rawls, Theorie der Gerechtigkeit; ders., Die Idee des politischen Liberalismus, Ffm 1994; dazu die Beiträge in: L.Kern, H.P.Müller (Hrsg.), Gerechtigkeit, Diskurs oder Markt? Die neuen Ansätze in der Vertragstheorie, 1986.

110 W.Hinsch, Vorwort zu J.Rawls, Idee, S.11.

111 Rousseau, Vom Gesellschaftsvertrag, II., Kap. 3.

112 Zum Folgenden I.Maus, Aufklärung, Kap.9.

113 Kant R 7687 AA XIX 491(zit. nach I.Maus, Aufklärung, S.180 FN 447); ebenso Rousseau, Gesellschaftsvertrag, II Kap. 3: "...der Gemeinwille immer auf dem rechten Weg ist...".

114 Rousseau, Gesellschaftsvertrag, II Kap. 6.

115 Die Gewaltenteilung ergibt sich bei Kant aus einer Unterscheidung zwischen Regienungsart und Herrschaftsform. Die Herrschaftsform betrifft die Frage, wem die oberste Staatsgewalt (Souveränität = gesetzgebende Gewalt) zukommt. Hier unterscheidet Kant zwischen Autokratie (Fürstengewalt), Aristokratie (Adelsgewalt) und Demokratie (Volksgewalt). Die Regierungsart betrifft hingegen die Frage, wer die Gesetze vollzieht, und ist entweder republikanisch (repräsentativ = Absonderung der ausführenden Gewalt (Regierung) von der gesetzgebenden) oder despotisch (Gesetzgebung und 
Generalität der Zustimmungsbedürftigkeit auch die inhaltliche Allgemeinheit der Gesetze i.S. ihrer Universalisierbarkeit. Die partikularen Egoismen der Individuen heben sich nämlich im demokratischen Verfahren von selbst gegenseitig auf ${ }^{16}$, weil das Konsensprinzip zu einem universalen Rollentausch und in Folge dessen zu einer allgemeinen Perspektivenverschränkung nötigt ${ }^{117}$. Verlangt die Moral - wie etwa nach Kants kategorischem Imperativ (s.u.) - die Universalisierbarkeit des Inhalts von Gesetzen, so verbürgt das demokratische Organisationsprinzip deren faktische Univeralisierung ${ }^{118}$. Die Struktur des Gesetzgebungsverfahrens wirkt mithin wie eine "ins Systemische übersetzte Moral"119, so daß dies Prinzip "selbst für ein Volk von Teufeln" taugt. ${ }^{120}$

Auf eben diesen sich aus dem Konsensprinzip ergebenden Zwang zum Perspektivenwechsel setzt auch Habermas. Danach können sich in rationalen Diskursen nur solche partikularen Interessen durchsetzen, die von einer Partikularität sind, wie sie einem jedem Betroffenen zugestanden werden kann, alle anderen werden im Verlauf des Diskurses ausgeschieden ${ }^{121}$. Darüber hinaus führt er als Kriterium der Unterscheidung eines "wahren" von einem "bloß faktischen" Konsens die ideale Sprechsituation ein. Ein wahrer Konsens liegt demnach nur vor, wenn im Verlauf des Diskurses jeder Beteiligte die gleichen Chancen hatte, Sprechakte seiner Wahl zu vollziehen, d.h. wenn der Konsens unter Abwesenheit von Täuschung, Drohung oder Zwang und frei von Zeitdruck (handlungsentlastet) entstanden ist. 122

Demgegenüber vertraut Rawls nicht der "invisible hand" des Konsensprinzips, sondern versetzt seine Kontrahenten des Gesellschaftsvertrags hinter einen "Schleier des Nichtwissens". Die Menschen im Urzustand sollen ein gerechtes Gesellschaftsmodell beschließen, ohne Kenntnis von ihrem Platz in der Gesellschaft (Klasse, Status), von ihren individuellen Fähigkeiten (Intelligenz, Körperkraft), Eigenschaften (Alter) oder Neigungen (Risikofreude, -scheu, etc.) zu haben ${ }^{123}$. Nach Festlegung der Grundstrukturen der Gesellschaft ${ }^{124}$ werden die Plätze der Individuen in der Gesellschaft ausgelost. Mit diesem "Schleier der Unwissenheit" will Rawls die Vertragspartner von der Not-

\footnotetext{
Vollziehung sind in einer Person vereinigt). Eine demokratische Vollziehung ist nun "notwendig ein Despotism, weil sie eine exekutive Gewalt gründet, da alle über und allenfalls auch wider Einen (der also nicht mit einstimmt), mithin alle, die doch nicht alle sind, beschließen" (Kant, ZeF, WW VI, S. 206f). Kant votiert also zunächst für eine republikanische Verfassung (a.a.O., S.208) und erst innerhalb dieser für eine demokratische Gesetzgebung. Die Vollziehung (sowie davon getrennt die Rechtsprechung) soll frei gewählten Repräsentanten des Volks obliegen (Kant, MdS, WW IV, S.434-437, 461-465).
}

116 Kant, ZeF, WW VI, S.223-225; ähnlich Rousseau, Gesellschaftsvertrag, II Kap.3, nach dem sich die "volonté générale" ergibt, indem man von der Summe von Sonderwillen das Mehr oder Weniger wegnimmt, das sich gegenseitig aufhebt.

117 I.Maus, Aufklärung, S.158.

118 I.Maus, Aufklärung, S.170.

119 I.Maus, Aufklärung, S.184.

$120 \mathrm{Kant}, \mathrm{ZeF}, \mathrm{WW}$ VI, S.224.

121 J.Habermas, Diskursethik - Notizen zu einem Begründungsprogramm, in: ders., Moralbewußtsein und kommunikatives Handeln, Ffm 1983, S.53-125, $75 \mathrm{ff}$.

122 Ders., Vorbereitende Bemerkungen zu einer Theorie der kommunikativen Kompetenz, in: ders./ N.Luhmann, Theorie der Gesellschaft oder Sozialtechnologie - Was leistet die Systemforschung, Ffm 1971, S.101-141, 136ff.

123 J.Rawls, Theorie der Gerechtigkeit, S.160ff.

124 Nur um diese geht es in Rawls Gesellschaftsvertrag: J.Rawls, Die Grundstruktur als Gegenstand, in: ders., Idee, S.45ff. 
wendigkeit des eigenverantwortlich vollzogenen, universellen Rollentauschs befreien, indem er diesen in die Strukturen des Urzustandes einläßt. ${ }^{125}$

Auf einem Mißtrauen gegen den beschriebenen Automatismus demokratischer Verfahren beruht auch die Einschränkung des Kreises derjenigen, auf deren Zustimmung es ankommt, nach einem Kompetenzkriterium ${ }^{126}$. Ist etwa der Ausschluß von Kindern oder geistig nicht Einsichtsfähigen noch unmittelbar einleuchtend, so sind Einschränkungen des Wahlrechts auf Männer sowie auf "Besitz und Bildung" historisch bekannte Beispiele. ${ }^{127}$ Darüber hinaus wird etwa bei Perelmann oder bei Peirce nicht auf die Zustimmung aller Menschen, sondern auf das wissenschaftliche Auditorium einer Gelehrtenrepublik abgestellt. Im Juristischen Diskurs kommt es letztlich auf die entscheidenden Richter an, die ihre Entscheidung allerdings vor dem ideal erweiterten Auditorium der am juristischen Diskurs teilnehmenden Rechtsöffentlichkeit begründen müssen ${ }^{128}$. Im Extremfall der Entscheidungstheorien der Gerechtigkeit obliegt die Entscheidung hingegen nur noch einem einzigen, besonders qualifizierten Subjekt. ${ }^{129}$ So kommt es nach Trapps Gerechtigkeitsutilitarismus ${ }^{130}$ nicht mehr auf die Zustimmung der Individuen an, sondern diese haben nur einen Anspruch auf Mitbilanzierung der von ihnen artikulierten Präferenzen, wobei der Entscheidende über einen hypothetischen Rollentausch (Anonymitätsprinzip) nur die "wohlverstandenen" Interessen der Individuen berücksichtigt. ${ }^{131}$

\section{d) Angewandte Verfahren}

Sind damit unter dem Gesichtspunkt der Vernunft des Konsens schon erste Abweichungen beschrieben, so ergeben sich deutliche Unterschiede hinsichtlich der Umsetzung und Anwendung dieser Verfahren unter praktischen Gesichtspunkten. Dabei kann zwischen monologischen und dialogischen Verfahrensmodellen unterschieden werden ${ }^{132}$.

125 Vgl. dazu J.Habermas, FuG, S.79ff.

126 H.Rüßmann, Normative Begründungsmöglichkeiten jenseits der Gesetzesbindung, in: Theorien der Gerechtigkeit, ARSP-Beiheft 56, Stuttgart 1994, S.24-40, 35; zu solchen Einschränkungen vgl. auch R.Alexy, Die Idee einer prozeduralen Theorie der juristischen Argumentation (1981), in: ders., Recht, Vernunft, Diskurs (RvD), Ffm 1995, Kap. 4, S.96f.

127 Eine solche Einschränkung folgert Kant aus dem Prinzip der bürgerlichen Selbständigkeit, nach dem stimmberechtigte (aktive) Staatsbürgerschaft Selbständigkeit voraussetzt. "Die dazu erforderliche Qualität ist, außer der natürlichen (daß es kein Kind, kein Weib sei), die einzige: daß er sein eigener Herr (sui iuris) sei.", (Gemeinspruch, WW VI, S.151; vgl. auch MdS, WW IV, S.432f.).

128 Richterliche Urteile erheben (allerdings nur im Rahmen der geltenden Rechtsordnung) einen Anspruch auf Richtigkeit, der sich nicht nur auf ein rechtswissenschaftliches Auditorium (höhere Instanz, rechtswissenschaftliche Literatur), sondern über die prinzipielle Öffentlichkeit von Verhandlung und Begründung vermittelt auch auf das universale Auditorium der Gesamtheit der Menschen bezieht (R.Alexy, Argumentation, S.263-272). Der Zugang zum wichtigeren rechtswissenschaftlichen Diskurs ist allerdings durch das Merkmal der wissenschaftlichen Qualifikation strikt begrenzt.

129 Diese Definition bei R.Dreier, Gerechtigkeit, S.28.

130 R.Trapp, Nicht-klassischer Utilitarismus, Habil. Frankfurt 1992; ders., Politisches Handeln im wohlverstandenen Allgemeininteresse, ARSP-Beiheft 56, 1994, S.54-77.

131 Vgl. dazu auch H.Rüßmann, Begründungsmöglichkeiten, S.37f.

132 Diese Unterscheidung knüpft an R.Dreiers (Gerechtigkeit, S.23, 25ff.) Unterscheidung zwischen Gerechtigkeitserzeugungs- und Gerechtigkeitsbegründungstheorien an, ist aber nicht mit dieser identisch. Während Dreier die Gerechtigkeitbegründungstheorien gegenüber dem Konsensprinzip eigenständig aus dem Modell wissenschaftlicher Wahrheitsfindung ableitet, wird hier angenommen, daß 
Während im dialogischen Modell ein zwar unter faktischen Einschränkungen stehendes, aber dem Ideal der intersubjektiven Verständigung aller Betroffenen möglichst angenähertes Verfahren institutionalisiert wird, dient das ideale Verfahren im monologischen Modell nur als Denkverfahren, nach dem der universale Rollentausch und die daraus folgende Verallgemeinerung eines Gesetzes im Kopf eines Entscheidenden simuliert wird. Bei Kant finden sich beide Modelle, als Gesetzgebungsmodell einerseits und als kategorischer Imperativ andererseits.

Kants ideales Verfahren beinhaltet nicht mehr als den Grundsatz der Volkssouveränität, ist also ein Gesetzgebungsmodell der Gerechtigkeit. ${ }^{133}$ Dieses ideale Verfahren gilt bei Kant a priori, es ist daher auch als prozedurales Naturrecht bezeichnet worden ${ }^{134}$. Alles, was in diesem Verfahren beschlossen wird, gilt, da es der Erfahrung entstammt, hingegen nur a posteriori, d.h. es ist in eben diesem Verfahren wieder änderbar. Das einzige, was in diesem Verfahren nicht beschlossen werden kann, ist die Aufhebung dieses Verfahrens der Volkssouveränität selbst. ${ }^{135}$ Das Problem dieses idealen Verfahrens ist nun, daß es in der Praxis ausgeschlossen erscheint, daß einem Gesetz, selbst wenn es sich lediglich um ein allgemeine Grundsätze festlegendes Verfassungsgesetz handelte, tatsächlich alle Menschen zustimmen. Kant schränkt dieses Verfahren deshalb unter dem pragmatischen Gesichtspunkt der Einigungsfähigkeit durch die Mehrheitsregel sowie (jedenfalls für große Völker) durch das Prinzip der repräsentativen Demokratie ein ${ }^{136}$. Während nun Rousseau sagt: "Das Gesetz der Stimmenmehrheit beruht selbst auf Übereinkunft und setzt zumindest einmal Einstimmigkeit voraus"137, führt Kant aus: "... so wird doch selbst der Grundsatz, sich diese Mehrheit genügen zu lassen, als mit allgemeiner Zustimmung, also durch einen Kontrakt, angenommen, der oberste Grund der Errichtung einer bürgerlichen Verfassung sein müssen"138. Die Mehrheitsregel wird also nicht tatsächlich einstimmig beschlossen, sondern der sie begründende Kontrakt wird von Kant als notwendige Bedingung der Errichtung einer Verfassung unterstellt, weil die Zustimmung zu diesem Kontrakt zur Verwirklichung des Rechtsprinzips nötig und damit vernünftig ist. ${ }^{139}$ Der die bürgerliche (republikanische) Verfassung begründende ursprüngliche Kontrakt wird also nicht als faktisch beschlossen vorausgesetzt, sondern ist eine bloße Idee der Vernunft. ${ }^{140}$

diese in ihrer monologischen oder eingeschränkt dialogischen Form eine unselbständige Ableitung aus dem Konsensprinzip sind.

133 Kant, MdS, WW IV, S.464.

134 Zunächst hatte Max Weber die Demokratietheorien der Aufklärung als Umstellung von materialem auf formales Naturrecht begriffen (WuG Teil 2, Kap. VII, § 7). Weber unterschied allerdings nicht zwischen formalen und prozeduralen Theorien. Wenn auch dasselbe gemeint ist, ist nach der hier vertretenen Abgrenzung die bei I.Maus (Aufklärung, Kap. 8) zu findende Bezeichnung "prozedurales Naturrecht" treffender.

135 Kant, MdS, WW IV, S.465: "Das Recht der obersten Gesetzgebung ... ist kein veräußerliches ... Ein Vertrag, der das Volk verpflichtete, seine Gewalt wiederum zurückzugeben, würde demselben nicht als gesetzgebender Macht zustehen..." Dieser Gundsatz findet sich heute in der Ewigkeitsklausel des Art. 79 III GG wieder. Vgl. I.Maus, Aufklärung, Kap.3, und S. $280 \mathrm{ff}$.

136 Kant, Gemeinspruch, WW VI, S.152f.

137 Rousseau, Gesellschaftsvertrag, I Kap. 5 a.E.

138 Kant, Gemeinspruch, WW VI, S. 152f. (Hervorhebung vom Verf.).

139 Dahinter steht die Überlegung, daß ansonsten etwa ein einziger Anarchist durch Verweigerung der Zustimmung zur Mehrheitsregel die Errichtung einer funktionstüchtigen Verfassung und damit den Eintritt in den bürgerlichen Zustand verhindern könnte.

140. Kant, Gemeinspruch, WW VI, S.153; MdS, WW IV, S.462f. 
Damit bedient sich Kant einer Methode, die - für viele Theorien prozeduraler Gerechtigkeit typisch - auf den tatsächlichen Konsens zu Gunsten einer bloßen Simulation von Selbstgesetzgebung im Kopf des Philosophen verzichtet. Da die monologisch begründete republikanische Verfassung aber lediglich prozedurale Voraussetzungen (Demokratie und Gewaltenteilung) enthält, alle inhaltlichen Festsetzungen hingegen dem faktischen Gesetzgebungsprozeß selbst überlassen bleiben, ist Kants Gesetzgebungsmodell noch als dialogisch einzustufen. Mit der Einführung der Mehrheitsregel wird allerdings genau der demokratische Automatismus aufgehoben, der Kant zufolge die formale als auch die inhaltliche Allgemeinheit des Gesetzes garantiert. Mit bloßer Mehrheit und dazu eventuell bloß von einem kleinen Kreis von Delegierten beschlossene Gesetze sind nicht mehr automatisch kraft allgemeiner Zustimmung gerecht, und können darüber hinaus auch individuelle Maßnahmen enthalten. Damit wird die sich aus dem idealen Verfahren ergebende Allgemeinheit der Gesetze zu einer normativen Anforderung, anhand welcher faktische Gesetzgebungsprozesse kritisiert werden können.

Subsidiär zu diesem Gesetzgebungsmodell der Gerechtigkeit, das als Grundmodell des demokratischen Rechtsstaats bezeichnet werden kann ${ }^{141}$, hat Kant dem idealen Verfahren der Selbstgesetzgebung des Volkes eine monologische Fassung gegeben, die immer dann greift, wenn demokratische Gesetze nicht vorliegen. Dies gilt zunächst für den Bereich des Rechts, solange die Gesetzgebungsmacht im Obrigkeitsstaat de facto beim Monarchen liegt. Für diesen gilt das ideale Verfahren als "Probierstein der RechtmäBigkeit". Er muß seine Gesetze so geben, "als (ob) sie aus dem vereinigten Willen eines ganzen Volkes haben entspringen können"142. Dieses Simulationsprinzip gilt allerdings nur subsidiär bis zum Zeitpunkt der Errichtung der reinen Republik ${ }^{143}$, weil nach Kant auch "Engelsweisheit" eines Monarchen den beschriebenen Automatismus demokratischer Verfahren nicht ersetzen kann und die autokratische Staatsform "die gefährlichste fürs Volk (ist), in Betracht des Despotismus, zu dem sie so sehr einladet"144. Gleiches gilt auch für den kategorischen Imperativ, der von jedem einzelnen die Prüfung fordert, ob er wollen könne, daß die Maxime seines beabsichtigten Handelns ein allgemeines Gesetz werde. ${ }^{145}$ Die Frage nach der Verallgemeinerbarkeit der Maxime verweist auf die Struktur des demokratischen Gesetzgebungsverfahrens, das im Kopf des einzelnen simuliert werden muß ${ }^{146}$, weshalb der kategorische Imperativ als monologisch einzuordnen ist. 147

Darüber hinaus tritt Kant in seiner Rechtslehre selbst als Experte für Gerechtigkeit auf, indem er die Ergebnisse eines monologisch simulierten Verallgemeinerungstests, der das demokratische Prozedere im Kopf des Philosophen vor sich gehen läßt, nieder-

141 I.Maus, Aufklärung, Anhang I, S.271ff.; R.Dreier, Gerechtigkeit, S.25f.

142 Kant, Gemeinspruch, WW VI, S.153.

143 Kant, MdS, S.464.

144 Kant lehnt aus diesem Grunde die Auffassung, derzufolge die Monarchie die beste Staatsverfassung ist, wenn nur der Monarch gut ist, ab: MdS, WW IV, S.462. Mit Despotismus meint Kant hier das Problem, daß in der Monarchie Gesetzgebung und Vollzug in einer Person vereinigt sind: vgl. Kant, ZeF, WW VI, S.206f.

145 Verschiedene Ausformulienungen des kategorischen Imperativs, der hier nur in seinem juridischen Gebrauch, also in Bezug auf äußere Gesetze (bzw. äußere Handlungen) interessiert, finden sich bei R.Dreier, Einheit, S.290f.

146 I.Maus, Aufklärung, S.263f.

147 J.Habermas, Moralität und Sittlichkeit, in: ders., Erläuterungen zur Diskursethik, Ffm 1991, S.9ff, $24 \mathrm{ff}$. 
legt ${ }^{148}$. Wenn Kant deshalb ein Rückfall in eine material-naturrechtliche Betrachtungsweise vorgeworfen wird ${ }^{149}$, ist $\mathrm{zu}$ beachten, daß Kant seinen materialen Ausführungen einen bloß provisorischen Charakter gegenüber jeder demokratischen (öffentlichen) Rechtssetzung einräumt. ${ }^{150}$ Kants diesbezügliche Ausführungen dürften daher im Sinne der Argumentationstheorien als Vorschlag zu verstehen sein, der sich vor dem Auditorium eines demokratischen Gesetzgebers zu bewähren hat. ${ }^{151}$

In diesem Sinne ist auch die Argumentationstheorie Chaim Perelmanns zu verstehen, wenn ausgeführt wird, der Philosoph solle seine Gerechtigkeitsvorstellungen so gut begründen, daß angenommen werden könne, diese würde vor einem universalen Auditorium Konsens finden (s.o.). Ebenso hat der Gesellschaftsvertrag bei Rawls einen hypothetischen, nicht-historischen Status, was schon aus dem idealen Charakter des Schleiers der Unwissenheit hervorgeht. Die Übereinkunft im Urzustand dient Rawls nur als gedankliches Verfahren, mithilfe dessen er unter Hinzunahme von analytischen Überlegungen zu möglichst einleuchtenden (d.h. konsensfähigen) Aussagen über Gerechtigkeit kommen will. Diese Inhalte der Gerechtigkeit sind dann nicht mehr durch reine Verfahrensgerechtigkeit begründet, sondern durch Vernunft entdeckt. ${ }^{152}$ Für den Juristen sind diese eine bloß hypothetische Einigungsprozedur (Simulation) voraussetzenden Theorien deshalb besonders interessant, weil sie auf eine Entscheidungssituation zugeschnitten sind, in der nur einer oder einige wenige für und über andere entscheiden, die mithin der richterlichen Entscheidungssituation entspricht, soweit diese Entscheidung nicht gesetzlich gebunden ist. ${ }^{153}$ Die Übertragung dieser auf der Simulation von Konsensaushandlungsprozessen im Kopf des Philosophen beruhenden Theorien auf die Rechtsprechung sprengt allerdings in gewisser Weise die strikte Unterscheidung von monologischen und dialogischen Theorien, weil die richterliche Entscheidung als Teil eines, wenn auch nicht allgemeinen, so doch juristischen Diskurses rekonstruiert werden kann. ${ }^{154}$

Demgegenüber hat Habermas in seiner Diskurstheorie auf die Ableitung materialer Inhalte durch monologische Simulation des vom Diskursprinzip vorgeschriebenen Ver-

148 Nämlich in der Privatrechtslehre: Kant, MdS, Rechtslehre 1. Teil, WW IV, S.353ff.; vgl. dazu I.Maus, Aufklärung, S.164ff.

149 Vgl. I.Maus, Aufklärung, S.168; A.Kaufmann, Problemgeschichte, S.60, 77ff. m.w.N.

150 Dies ergibt sich trotz Kants Unterscheidung von natürlichen Gesetzen, zu denen die Verbindlichkeit auch ohne äußere Gesetzgebung a priori durch die Vernunft erkannt werden kann, von positiven Gesetzen, die ohne äußere Gesetzgebung gar nicht verbinden (MdS, WW IV, S.331), aus Kants Bestimmung des öffentlichen Rechts. Denn "obgleich (im natürlichen Zustand der Rechtlosigkeit) nach jedes seinen (also der inneren Gesetzgebung nach dem kategorischen Imperativ entspringenden G.C.) Rechtsbegriffen etwas Äußeres durch Bemächtigung oder Vertrag erworben werden kann, diese Erwerbung nur provisorisch ist, so lange sie noch nicht die Sanktion eines öffentlichen Gesetzes für sich hat, weil sie durch keine öffentliche (distributive) Gerechtigkeit, und durch keine dies Recht ausübende Gewalt gesichert ist." (a.a.O., S.430f.). Im bürgerlichen Zustand bestimmt sich die Gerechtigkeit also ausschließlich durch äußere Gesetzgebung, dem Staatsbürger steht gegen diese kein Widerstandsrecht, sondern nur ein Recht zur Teilnahme am Gesetzgebungsprozeß zu.

151 In diesem Sinne bleibt auch im Vergleich zu John Rawls Theorie, die auf dieselbe Art vorgeht, eine Einordnung von Kant in die Gruppe der materialen Gerechtigkeitstheorien vom Vernunftrechtstyp bei R.Dreier (Gerechtigkeit, S.22) unzutreffend.

152 So ausdrücklich J.Rawls, Die Grundstruktur als Gegenstand, in: ders., Idee, S.45ff, 62; früher hat Rawls auch von moralischer Intuition gesprochen, was zu Mißverständnissen führte: vgl. die Kritik bei E.Tugendhat, Vorlesungen über Ethik, S.365 FN 2.

$153 \mathrm{Vgl}$. dazu ausführlich H.Rüßmann, Begründungsmöglichkeiten, S.24ff, 37.

154 R.Alexy, Argumentation, S.263ff. 
fahrens verzichtet. 155 Gewisse auch inhaltlich aufgeladene Diskursregeln leitet er lediglich aus unvermeidlichen Unterstellungen (Präsuppositionen) ab, auf die sich Diskursteilnehmer einlassen müssen, weil sie Bedingungen von Kommunikation überhaupt sind (Universalpragmatik) ${ }^{156}$. In seiner Rechtstheorie hat er vielmehr den Prozeß der demokratischen Gesetzgebung als einen rationalen Entscheidungsprozeß rekonstruiert, wobei er umfangreiche prozedurale Bedingungen für diese Rationalität nicht nur in dessen institutionalisierten Teil, sondern vor allem in einer nicht institutionalisierbaren kritischen Öffentlichkeit (civil society) findet. ${ }^{157}$ Gleichzeitig findet sich bei Habermas eine Theorie der Rationalität des juristischen (richterlichen) Diskurses sowie dessen Verhältnisses zum demokratischen Diskurs ${ }^{158}$, so daß weder ein reines Gesetzgebungsmodell, noch ein reines Gerichtsmodell der Gerechtigkeit vorliegt. 159

\section{Entwicklung des Rechtsstaatsbegriffs}

Die Entwicklung des Rechtsstaatsbegriffs wird allgemein in drei Phasen unterteilt. ${ }^{160}$ In der ersten Hälfte des 19. Jahrhunderts dient er zunächst als politischer Kampfbegriff 161 gegen den absolutistischen Polizeistaat mit dem Ziel, diesen durch eine den Grundsätzen der vernunftrechtlichen Staatstheorie (Locke, Montesquieu, Rousseau, Kant) entsprechende bürgerliche Verfassung rechtlich zu binden. In dem Maße, in dem dieses Ziel zumindest teilweise durch die Errichtung einer konstitutionellen Monarchie erreicht ist, tritt der politische Gehalt des Rechtsstaatsgedankens in den Hintergnund, die Lehre konzentriert sich zunehmend auf die dogmatische Durchdringung und Umsetzung des Rechtsstaatsprinzips, insbesondere auf die Gesetzmäßigkeit der Verwaltung und den

155 Die Inhalte entstammen daher auch bei Habermas der Erfahrung der Diskursteilnehmer, das Thema wird dem Diskurs von der Lebenswelt gegeben (z.B. J.Habermas, Über Moraltät und Sittlichkeit Was macht eine Lebensform rational?, in: H.Schnädelbach (Hrsg.), Rationalität, Ffm 1984, S.218ff, 220f.), weshalb die Einwände von A.Kaufmann (Prozedurale Theorien, S.18f.) ins Leere zielen.

156 J.Habermas, Was heißt Universalpragmatik, in: K.-O.Apel (Hrsg.), Sprachpragmatik und Philosophie, Ffm 1976, S.201ff. Ähnlich K.-O.Apel, Apriori, S.295ff.

157 J.Habermas, FuG, insbes. Kap. 7 und 8; nur am Rande sei hier auf die diskurstheoretische Begründung eines Systems der Rechte sowie der Prinzipien des Rechtsstaats hingewiesen (a.a.O. Kap. 3 und 4).

158 Ders., a.a.O., Kap. 5 und 6.

159 Ausführlich zu Habermas s.u. Kap. 2. I. 2. und II. 2.

160 U.Scheuner, Entwicklung des Rechtsstaats, S.461ff.; K.Hesse, Der Rechtsstaat im Verfassungssystem des Grundgesetzes (1960), in: M.Tohidipur (Hrsg.), Der bürgerliche Rechtsstaat Bd. 1, Ffm 1978, S. 290-314; E.R.Huber, Rechtsstaat und Sozialstaat in der modernen Industriegesellschaft, O1denburg 1962; E.-W.Böckenförde, Entstehung und Wandel des Rechtsstaatsbegriffs, in FS f. A.Andt, Ffm 1969, S.53-76; A.Baratta, Zur Entwicklung des inodernen Rechtsstaatsbegriffs (1970), in: ders., Philosophie und Strafrecht, Köln u.a. 1985, S.213-228; K.Stern, Der Rechtsstaat, Krefeld 1971; E.Denninger, Staatsrecht Bd.1, Reinbek 1973, S. 91 ff.; M.Kriele, Einführung in die Staatslehre, Reinbek 1975, S. 104ff.; D.Merten, Rechtsstaat und Gewaltmonopol, Tübingen 1975; R.WeberFas, Rechtsstaat und Grundgesetz, Pfullingen 1977; I.Maus, Entwicklung; E.Benda, Der soziale Rechtsstaat, in: Benda/Maihofer/Vogel (Hrsg.), Handbuch des Verfassungsrechts, 2.Aufl., Berlin/New York 1994, S.719-798; E.Schmidt-Aßmann, Rechtsstaat, in: Isensee/Kirchhof (Hrsg.), Handbuch des Staatsrechts, Bd.1, Heidelberg 1987, § 24, S.987-1045; R.Dreier, Rechtsstaat, S.73ff.; U.Karpen, Die geschichtliche Entwicklung des liberalen Rechtsstaats, Mainz 1985, wiederveröffentlicht in: ders., Der Rechtsstaat des Grundgesetzes, Baden-Baden 1992, Abschnitt I-IV; P.Kunig, Das Rechtsstaatsprinzip, Tübingen 1986; D.Grimm, Wandel, S.291ff.

161 E.R.Huber, Rechtsstaat, S.8f; A.Baratta, Entwicklung, S.216; U.Scheuner, Entwicklung des Rechtsstaats, S.461; R.Weber-Fas, Rechtsstaat, S.20. 
Rechtsschutz. Diese zweite Phase der Formalisierung des Rechtsstaatsbegriffs erreicht zu Beginn des 20. Jahrhunderts ihren Höhepunkt. Beginnend mit der Weimarer Zeit werden dann eher materiale Momente des Rechtsstaatsprinzips betont. Diese materielle Interpretation des Rechtsstaatsprinzip bleibt zwar zunächst umstritten, setzt sich aber im Grundgesetz angesichts der Erfahrungen mit dem nationalsozialistischen Unrechtsstaat durch. Die Unterscheidung zwischen formalem und materiellem Rechtsstaat ist hier vor dem Hintergrund der These der generellen Entwicklung des Rechtssystems von formaler zu materialer Rationalität von Interesse und wird deshalb im folgenden im Hinblick auf die zugrundeliegenden Annahmen über Rationalität untersucht.

Als Kerngedanke des Rechtsstaats kann zunächst die Bindung und Mäßigung der Staatsgewalt um des Schutzes der Freiheit und Gleichheit der Menschen willen bezeichnet werden. ${ }^{162}$ Der materielle Kern der Menschen- bzw. Grundrechte soll dabei durch eine bestimmte Form der Staatsorganisation gesichert werden. ${ }^{163}$ Oberstes Prinzip dieser Staatsorganisation ist die Gewaltenteilung, also die Trennung der Funktionen von Legislative, Exekutive und Judikative. ${ }^{164}$ Der Primat des Rechts soll durch die Herrschaft des Gesetzes gesichert werden. ${ }^{165}$ Die Gesetze sollen allgemein, inhaltlich bestimmt und positiv (geschrieben und veröffentlicht) sein und dürfen keine rückwirkende Kraft entfalten. Sie müssen zudem unter Zustimmung einer Volksrepräsentation zustande gekommen sein. ${ }^{166}$ An diese Gesetze soll die Exekutive strikt gebunden sein (GesetzmäBigkeit der Verwaltung), was in den Prinzipien des Vorrangs des Gesetzes vor allen anderen Regelungen (z.B. Verordnungen) sowie des Vorbehalts des Gesetzes, nach dem Eingriffe in die Freiheit (Grundrechte) einer gesetzlichen Ermächtigung bedürfen, zum Ausdruck kommt. ${ }^{167}$ Abgesichert wird diese Bindung durch ein System umfassenden Rechtsschutzes gegen Maßnahmen der Exekutive durch unabhängige, nur dem Gesetz unterworfene Gerichte sowie durch das Prinzip öffentlich-rechtlicher Entschädigung, nach dem der Staat für Eingriffe in die Freiheiten der Bürger haftet. ${ }^{168}$

\section{Der liberale Rechtsstaat}

In der Entstehungsphase ${ }^{169}$, zu deren Kennzeichnung der Rechtsstaat auch mit den Zusätzen liberal oder bürgerlich versehen wird ${ }^{170}$, ist die Forderung nach der Herrschaft

162 Vgl. U.Scheuner, Entwicklung des Rechtsstaats, S.470; E.R.Huber, Rechtsstaat, S.10, 12; E.W.Böckenförde, Entstehung, S.55, 57; U.Karpen, Rechtsstaat, S.19ff, $33 \mathrm{ff}$.

163 E.R.Huber, Rechtsstaat, S.10-12; E.W.Böckenförde, Entstehung, S.56.

164 Vgl. R.Dreier, Rechtsstaat, S.74; K.Hesse, Rechtsstaat, S.292; A.Baratta, Entwicklung, S.218.

165 K.Hesse, Rechtsstaat, S.293; R.Weber-Fas, Rechtsstaat, S.25f.

166 U.Scheuner, Entwicklung des Rechtsstaats, S.464; E.W.Böckenförde, Entstehung, S.56, 58f.; I.Maus, Entwicklung, S.19ff; E.Denninger, Staatsrecht Bd.1, S.111ff.; D.Grimm, Wandel, S.293.

167 E.W.Böckenförde, Entstehung, S.59; D.Grimm, Wandel, S.293; U.Karpen, Entwicklung, S.24ff.; vgl. auch J.Pietzcker, Vorrang und Vorbehalt des Gesetzes, JuS 1979, S.710ff.; P.Kunig, Rechtsstaatsprinzip, S.316ff.

168 E.R.Huber, Rechtsstaat, S.9; K.Stem, Rechtsstaat, S.8; E.Denninger, Staatsrecht Bd.1, S.107f.; ein Überblick über die Diskussion bei P.Kunig, Rechtsstaatsprinzip, S.9-35.

169 Der Begriff Rechtsstaat wird wohl zuerst 1809 von Adam Müller verwendet. In die juristische Diskussion wird er von Robert v.Mohl eingeführt: vgl. U.Scheuner, Entwicklung des Rechtsstaats, S.461 mit FN 1; P.Kunig (Rechtsstaatsprinzip, S.21 mit FN 92) weist aber schon auf die Verwendung des Begriffs "Rechts-Staatslehre" bei J.W.Placidus (1798) hin. Die erste Verwendung des Begriffs ist aber insofern von untergeordneter Bedeutung, als die damit gemeinten Ideen der Sache nach schon in den vernunftrechtlichen Staatslehren enthalten sind. 
des Gesetzes mit einem rationalistischen Gesetzesbegriff verknüpft, der dem Gesetzgebungsmodell prozeduraler Gerechtigkeit entspricht. Ein Gesetz ist danach vernünftig (gerecht), wenn es den in einem demokratischen Gesetzgebungsverfahren entstandenen Willen der Allgemeinheit zum Ausdruck bringt (s.o.). Im Anschluß an Montesquieu und Rousseau hat Kant dabei ausgeführt, daß das Volk nur allgemeine Gesetze beschließen dürfe, da der Erlaß individueller Maßnahmen zu einer despotischen Demokratie (i.S.v. Willkürherrschaft) führe, und so das Prinzip der Gewaltenteilung begründet. ${ }^{171}$ Diese Verschränkung von Demokratie und Rechtsstaat, in der die demokratische Genese des Gesetzes die Gerechtigkeit, und die von unabhängigen Gerichten überwachte Bindung der Exekutive an das Gesetz zugleich die Rechtssicherheit gewährleistet ${ }^{172}$, ist Kennzeichen des liberalen Rechtsstaats. Der Schutz von Freiheit und Gleichheit wird der Volksvertretung anvertraut. ${ }^{173}$ Diese muß jeder Beschränkung von Grundrechten durch die monarchische Exekutive in Form eines Gesetzes zustimmen. Den Grundrechten kommt im Rahmen der Lehre vom Vorbehalt des Gesetzes lediglich die Funktion von Kompetenzabgrenzungsregeln zu. ${ }^{174}$ Vorherrschaft des Rechts meint hier deshalb Herrschaft des Parlamentsgesetzes. ${ }^{175}$ Insofern der Gesetzesbegriff des liberalen Rechtsstaats formelle und materielle Elemente vereinigt ${ }^{176}$, kann von einem einheitlichen Gesetzesbegriff gesprochen werden. ${ }^{177}$ Zusammenfassend besteht der liberale Rechtsstaat aus drei Komponenten. Seine materielle Komponente besteht darin, daß der Staat vom Subjekt und dessen Autonomie (Freiheit) her begründet wird. Der Staatszweck ist auf den Rechtszweck, i.e. die formale Kompatibilisierung der Freiheit des einen mit der gleichen Freiheit aller anderen, beschränkt. Darüber hinausgehende Zwecke der Wohlfahrt oder Glückseligkeit darf der Staat jedenfalls nicht mit Zwangsmitteln verfolgen. ${ }^{178}$ Die prozedurale Komponente besteht im Schutz der Freiheit und Gleichheit (Grundrechte)

170 R.Dreier, Rechtsstaat, S.75; M.Tohidipur (Hrsg.), Der bürgerliche Rechtsstaat; U.Karpen, Rechtsstaat; F.Neumann, Funktionswandel des Gesetzes, S.31f.

$171 \mathrm{Zu}$ Kants Begründung s.o. und I.Maus, Aufklärung, Kap. 10; Zu den entsprechenden Konstruktionen bei Montesquieu und Rousseau vgl. W.Maihofer, Prinzipien freiheitlicher Demokratie, in: Benda/Maihofer/Vogel, Handbuch des Verfassungsrechts, 2.Aufl., Berlin/New York 1994, S.427-536, $440 \mathrm{ff}$.

172 Zur Verschränkung von Gerechtigkeit und Rechtssicherheit A.Baratta, Entwicklung, S.225f.

173 So steht bei R.v.Mohl (Das Staatsrecht des Königreichs Württemberg, Tübingen 1829, S.451) das Kapitel über die Stellung und Befugnisse der Volksvertretung unter der Überschrift: "Von der Verteidigung der Volksrechte durch die Ständeversammlung" (zit. nach E.W.Böckenförde, Entstehung, S.58 FN 23).

174 A.Baratta, Entwicklung, S.222f.; U.Scheuner, Die rechtliche Tragweite der Grundrechte in der deutschen Verfassungsentwicklung des 19. Jahrhunderts (1973), in: ders., Staatstheorie und Staatsrecht, 1978, S. 633-663; D.Grimm, Die Entwicklung der Grundrechtstheorie in der deutschen Staatsrechtslehre des 19. Jahrhunderts, in: ders., Recht und Staat der bürgerlichen Gesellschaft, Ffm 1987, 308-346; I.Maus, Entwicklung, S.18ff.; E.Denninger, Staatsrecht Bd. 1, S.115.

175 F.Neumann, Funktionswandel des Gesetzes, S.41, 46ff.; U.Scheuner, Entwicklung des Rechtsstaats, S.464; E.W.Böckenförde, Entstehung, S.58, 65; D.Grimm, Wandel, S.293f.; I.Maus, Entwicklung, S.16ff.

176 Zur Unterscheidung von formellem und materiellem Gesetz vgl. C.Starck, Gesetzesbegriff; H.Hofmann, Allgemeinheit des Gesetzes; E.W.Böckenförde, Gesetz und gesetzgebende Gewalt, Von den Anfängen der deutschen Staatsrechtslehre bis zur Höhe des staatsrechtlichen Positivismus, Berlin 1958, 2.Aufl. 1981, S.226ff; R.Dreier, Rechtsstaat, S.78f.

177 E.W.Böckenförde, Entstehung, S.58 m.w.N. in FN 25.

178 S.o. und I.Maus, Aufklärung, S.270ff.; P.Koslowski, Staat und Gesellschaft bei Kant, Tübingen 1975, S.26ff., der Kants Rechtsstaatstheorie deshalb als formal bezeichnet (S.38). 
durch die demokratische Genese der Gesetze (Gesetzgebungsmodell der Gerechtigkeit). Seine formale Komponente findet sich in der Allgemeinheit der Gesetze und deren einheitlicher Anwendung (formale Gleichheit, Rechtssicherheit), also in der Idee der Gewaltenteilung und den daraus folgenden Prinzipien der Gesetzesbindung und des Rechtsschutzes durch unabhängige Gerichte. ${ }^{179}$

\section{Der formale Rechtsstaat}

Während der zweiten Hälfte des 19. Jahrhunderts bis in die Weimarer Zeit hinein wird dieser Rechtsstaatsbegriff zunehmend formalisiert. Der Rechtsstaatsbegriff wird dabei von seiner vernunftrechtlich-philosophischen Fundierung gelöst, erhält aber als unpolitisches Formelement, das vornehmlich die Gesetzmäßigkeit der Verwaltung und deren gerichtsförmige Sicherung betrifft, zugleich eine tiefgreifendere dogmatische Präzision. ${ }^{180}$ Diese Vernachlässigung der Grundlagen des Rechtsstaats wird zum Teil darauf zurückgeführt, daß mit der Errichtung der konstitutionellen Monarchie die wesentlichen verfassungspolitischen Forderungen erfüllt waren, während eine rechtsstaatliche Durchstrukturierung der Verwaltung noch ausstand. ${ }^{181}$ Die Bewegung zum formalen Rechtsstaat ist allerdings nicht einheitlich, sondern wird von unterschiedlichen, teilweise gegensätzlichen Motiven getragen. ${ }^{182} \mathrm{Ihr}$ Kern besteht aber in der Abkehr vom rationalistischen Gesetzesbegriff. ${ }^{183}$ Dessen ursprüngliche Einheit wird dabei zunächst in zwei Richtungen verkürzt.

Auf der einen Seite gerät das prozedurale Element der demokratischen Genese der Gesetze aus dem Blick. Gesetz ist dann jede abstrakt-generelle Regel, wer immer diese erlassen hat (Gesetz im materiellen Sinne). Der so verstandene Rechtsstaat ist politisch neutral und unabhängig von der Staatsform (Monarchie, Demokratie etc.). Im Sinne der formalen Theorien der Gerechtigkeit (s.o.) gewährleistet er ein Minimum an Gerechtigkeit in Form von formaler Gleichheit und Rechtssicherheit ${ }^{184}$. Dieses Auseinanderreißen von Demokratie und Rechtsstaat ist schon in Kants Formel vom "Probierstein" (s.o.) angelegt und gründet darin, daß der deutsche Liberalismus angesichts der Folgen der fran-

179 In diesem ursprünglichen liberalen Rechtsstaatsbegriff ist hingegen keine rechtliche Bindung des Gesetzgebers an die Grundrechte enthalten gewesen (so aber R.Dreier, Rechtsstaat, S.75f.), es galt vielmehr als selbstverständlich, daß das Parlament als Vertreter der Gesellschaft gegenüber dem monarchischen Staat die Grundrechte schützen werde, im Grundrechtsschutz bestand sogar dessen einzige Aufgabe. Ein richterliches Prüfungsrecht wurde demgegenüber - wenn überhaupt - nur in formeller Hinsicht befürwortet: vgl. D.Grimm, Wandel, S.294; U.Scheuner, Entwicklung des Rechtsstaats, S.476f., 485f.; E.W.Böckenförde, Entstehung, S.58; E.Denninger, Staatsrecht 1, S.99.

180 E.W.Böckenförde, Entstehung, S.64f.; R.Dreier, Rechtsstaat, S.76; D.Merten, Rechtsstaat, S.11.

181 U.Scheuner, Entwicklung des Rechtsstaats, S.483; E.W.Böckenförde, Entstehung, S.60; R.Thoma, Rechtstaatsidee und Verwaltungsrechtswissenschaft (1910), in: M.Tohidipur (Hrsg.), Rechtsstaat, Bd.2, S.499-524, unterscheidet in diesem Sinne Rechtsstaat und Verfassungsstaat, wobei sich ersterer nurmehr auf das Verwaltungsrecht bezieht.

182 E.W.Böckenförde, Entstehung, S.59f.

183 Ders., a.a.O., S.65.

184 Eine gute Darstellung findet sich bei R.S.Summers (Rule of Law, S.127ff.), der ausdrücklich darauf hinweist, daß weder Demokratie noch soziale Gerechtigkeit Bestandteil einer formalen Rechtsstaatstheorie sind (a.a.O., S.135). Die "ethische Funktion" der Allgemeinheit des Gesetzes in Form der Garantie eines Minimums an Freiheit und Gleichheit wird auch bei F.Neumann (Funktionswandel des Gesetzes, S.43f., 50f.) betont. In rigoroser Weise hat auch G.Radbruch (Rechtsphilosophie, 8.Aufl., Stuttgart 1973, S.289f.) die "Eigengesetzlichkeit der Rechtsform" herausgearbeitet, die, der Inhalt des Rechts sei welcher er wolle, immer gerade den Unterdrückten diene. 
zösischen Revolution eine republikanische Verfassung auf dem Wege von Reformen erreichen wollte. Wo Demokratie nicht zu erreichen war, wollte man ein Mindestmaß an Freiheit auch ohne diese durch den Rechtsstaat erreichen ${ }^{185}$. Während in England und den USA die "Rule of Law" die spezifische Verfassung der Demokratie blieb, trat die deutsche Rechtstaatstheorie nach dem Zusammenbruch von 1849 aus der gemeineuropäischen Naturrechtstradition des Parlamentarismus heraus. ${ }^{186}$ Die ursprüngliche Einheit der liberalen Bewegung mit ihren drei Zielen (Einheit, Rechtsstaat, Demokratie) zerfiel infolge ständiger Demütigungen durch die deutschen Fürsten. Mit der Zuteilung der Reichsverfassung von 1871 "als Gnadengeschenk von oben" durch den größten Feind der Liberalen, Bismarck, distanzierte sich das deutsche Bürgertum zunehmend vom demokratischen Liberalismus und begann seinen Bezwinger Bismarck zu verehren ${ }^{187}$. Nach Herstellung der Einheit der Nation wurde dann zur Garantie der aus wirtschaftsliberaler Sicht nötigen Rechtssicherheit ein formaler Rechtsstaat auch ohne demokratische Fundierung für ausreichend befunden. ${ }^{188}$

Eine Verkürzung des rationalistischen Gesetzesbegriffs in umgekehrter Richtung stellt hingegen der spätkonstitutionelle formale Gesetzesbegriff dar. Gesetze sind demnach alle, aber auch nur die mit Zustimmung der Volksvertretung ergangenen Anordnungen ${ }^{189}$. Damit wird die Allmacht des, alferdings noch demokratisch gedachten, Gesetzgebers behauptet ${ }^{190}$. Insofern dadurch die Beschränkung des Staatszwecks auf Rechts- und Friedensbewahrung ("liberaler Nachtwächterstaat") aufgegeben wird, durch die Beschränkung der Rechtsstaatsidee auf die bloße Form also die Sozialpolitik des späten 19. Jahrhunderts erst ermöglicht wird ${ }^{191}$, dient der formale Gesetzesbegriff durchaus progressiven, sozialen Zwecken ${ }^{192}$. Mit der Aufgabe des Allgemeinheitspostulats werden allerdings auch individuelle Maßnahmen des Gesetzgebers möglich. Der formale Gesetzesbegriff stellt insofern die Gewaltenteilung als Grundlage des Rechtsstaats selbst in Frage und birgt die von Kant beschworene Gefahr einer despotischen (bzw. totalitären ${ }^{193}$ ) Demokratie in sich ${ }^{194}$. Darüber hinaus ist in der These von der auch

185 So führt schon Kant (ZeF, WW VI, S. 208) aus: "Es ist aber an der Regierungsart (d.h. Gewaltenteilung G.C.) dem Volk ohne alle Vergleichung mehr gelegen, als an der Staatsform (d.h. Demokratie bzw. Monarchie G.C.)". Kant hält aber an der Idee der Demokratie als Ziel der Entwicklung fest: "Aber der Geist jenes ursprünglichen Vertrages ... enthält die Verbindlichkeit der konstituierenden Gewalt, die Regierungsart ..., wenn es nicht auf einmal geschehen kann, allmählich und kontinuierlich dahin zu verändern, daß sie mit der einzig rechtmäßigen Verfassung, nämlich der einer reinen Republik, ... zusammenstimme, ... Alle wahre Republik aber ist und kann nichts anders sein, als ein repräsentatives System des Volks, um ... durch alle Staatsbürger vereinigt, vermittelst ihrer Abgeordneten (Deputierte) ihre Rechte zu besorgen." (MdS, WW IV, S. 464).

186 M.Kriele, Staatslehre, § 27; vgl. auch N.MacCormick, Rechtsstaat und rule of law, JZ 1984, S.67ff; J.Harvey, L.Bather, Über den englischen Rechtsstaat. Die "rule of law", in: M.Tohidipur (Hrsg.), Rechtsstaat, S.359ff.

187 M.Kriele, Staatslehre, $\S \S 74-76$, S.307f.; Vgl. auch den Roman "Der Untertan" von K.Mann.

188 M.Kriele, a.a.O.; F.Neumann, Funktionswandel des Gesetzes, S.48f.

189 So die Definition bei Georg Jellinek, Gesetz und Verordnung, Freiburg 1887, S.115, zit. nach I.Maus, Aufklänung, S.335 FN 68. Dort auch weitere Nachweise.

190 Vgl. dazu E.W.Böckenförde, Entstehung, S.65; I.Maus, Entwicklung, S.38f.; beide m.w.N.

191 So R.Thoma, Rechtsstaatsidee, S.499ff., 501f.

192 So - allerdings etwas einseitig - I.Maus, Entwicklung, S.38f.

193 So W.Kägi, Rechtsstaat und Demokratie, Antinomie und Synthese (1953), in: M.Tohidipur (Hrsg.), Rechtsstaat Bd.1, S.127ff. 
verfassungsändernden Allmacht des Gesetzgebers die Möglichkeit zur Selbstabschaffung des demokratischen Rechtsstaats enthalten, wie sie sich später im Ermächtigungsgesetz realisierte. Hatte Kant die Volkssouveränität zu den notwendigen Bedingungen einer bürgerlichen Verfassung gezählt, und deren Veräußerung durch einen Herrschaftsvertrag (etwa i.S.v. Hobbes) für unmöglich erklärt (s.o.), so ist der formalen Rechtsstaatstheorie das Bewußtsein für das Unabstimmbare, für die nichtvertraglichen Grundlagen eines (Gesellschafts-) Vertrags abhandengekommen. 195

Die völlige Entkleidung des rechtsstaatlichen Gesetzesbegriffs wird allerdings erst durch eine Verbindung beider Linien im wertrelativistischen Gesetzespositivismus bewirkt. Dieser Gesetzespositivismus ist zu unterscheiden vom älteren Rechtspositivismus, welcher wie etwa schon bei Montesquieu, Kant und Feuerbach die strikte Bindung von Verwaltung und Justiz an das rational gedachte, positive Gesetz meint und Rechtsanwendung als bloße logische Subsumtion versteht ${ }^{196}$. Während letzterer wesentlicher Bestandteil der liberalen Rechtsstaatstheorie ist, bezieht sich ersterer im Anschluß an den philosophischen Positivismus auf die Wissenschaftlichkeit der Rechtswissenschaft. ${ }^{197}$ Im Anschluß an Kants Vernunftkritik trennen die "Neukantianer" das Sein strikt vom Sollen, wobei ein Schluß vom Sein auf ein Sollen für unzulässig erklärt wird (Methodendualismus) ${ }^{198}$. Innerhalb des Sollens wird dann nach Form und Inhalt unterschieden, wobei wissenschaftliche Erkenntnis nur im Bereich formal-logischer, zweckrationaler und wertvergleichender Aussagen für möglich gehalten wird, während alle inhaltlichen Aussagen über Werte, Moral und Ethik nur subjektive, nichtwissenschaftliche Bekenntnisse sind und dem Bereich der Politik oder der Metaphysik zugerechnet werden (Wertrelativismus) ${ }^{199}$. Rechtswissenschaft kann danach nur entsprechend den Naturwissenschaften als Kausalwissenschaft, entsprechend der Mathematik als Logik oder (auf der Basis des südwestdeutschen Neukantianismus) als Kulturwissenschaft betrieben werden. Demgemäß kann zwischen einem rechtssoziologischen und einem juristischen Positivismus unterschieden werden. Für ersteren steht etwa Theodor Geigers Rechtssoziologie, für letzteren Hans Kelsens Reine Rechtslehre als Normlogik sowie Gustav Radbruchs Rechtsphilosophie als Kulturwissenschaft. ${ }^{200}$ Hieraus ergeben sich ein soziologischer und ein juristischer Begriff der Rechtsgeltung. Eine Norm gilt sozial, wenn

194 I.Maus (Aufklärung, S.222) sieht den rein formalen Gesetzesbegriff ebenfalls nicht mehr so positiv (wie oben in FN 223), wenn sie ausfihirt. "Was Kant noch als Despotismus bezeichnete ist die Signatur der Gesetzgebung des 20. Jahrhunderts."

195 M.Kriele, Staatslehre, S.114f.; I.Maus, Aufklärung, S.281.; E.W.Böckenförde, Entstehung, S.65.

196 A.Kaufmann, Problemgeschichte, S.79f; i.d.S. auch A.Baratta, Rechtspositivismus und Gesetzespositivismus, in: ders., Philosophie und Strafrecht, S.229-249.

197 Vgl. A.Kaufmann, Problemgeschichte, S.77-84; der Begriff "Positivismus" wird in der Literatur teils recht widersprüchlich mit verschiedenen Zusätzen wie "philosophisch", "wissenschaftlich", "juristisch" versehen. Mit philosophischem Positivismus soll hier die Denkart des Empirismus bezeichnet sein.

198 Ders., a.a.O., S.80-84, 90, der als prominente Neukantianer u.a. R.Stammler, G.Radbruch, M.Weber und H.Kelsen nennt.

199 Vgl. z.B. H.Kelsen, Reine Rechtslehre, 2.Aufl., Wien 1960, S.3ff.; sowie ders., Gerechtigkeit, S.364ff; Zur neukantianischen Rechtstheorie und zum gesellschaftlichen Kontext vgl. H.Dreier, Rechtslehre, Staatssoziologie und Demokratietheorie bei Hans Kelsen, Baden-Baden 1986, S.56112.

200 Vgl. dazu A.Kaufmann, Problemgeschichte, S.80, 83, 111ff., 118ff., m.w.N.; zum Rechtspositivismus von Kelsen und Radbruch vgl. auch R.Dreier, Gustav Radbruch, Hans Kelsen, Carl Schmitt, in: H.Haller et.al. (Hrsg.), Staat und Recht, FS für G.Winkler, Wien, New York 1997, S.193-215. 
sie entweder befolgt oder ihre Nichtbefolgung sanktioniert wird. Eine Norm gilt rechtlich, wenn sie von einem dafür zuständigen Organ in der dafür vorgesehenen Weise erlassen worden ist und nicht gegen höherrangiges Recht verstößt, kurz: wenn sie ordnungsgemäß gesetzt ist ${ }^{201}$. Der positivistische Rechtsbegriff ist also eher wirksamkeitsoder eher setzungsorientiert ${ }^{202}$, in jedem Falle aber frei von ethischen Anforderungen jeder $\mathrm{Art}^{203}$, weshalb "jeder beliebige Inhalt Recht sein (kann)"204. Da der soziologische Rechtsbegriff Geltung nur relativ (prozentual) nach dem Grad der Befolgung oder Sanktionierung bestimmen kann ${ }^{205}$, ist aus juristischer Sicht nur das eindeutige Kriterium der ordnungsgemäßen Setzung brauchbar ${ }^{206}$. Dem wertrelativistischen Gesetzespositivismus ist also ein Gesetzesbegriff zu eigen, der zwar ebenso wie der beschriebene formale Gesetzesbegriff ausschließlich auf das formal korrekte Zustandekommen eines Gesetzes abstellt. Allerdings wird die Gesetzgebungskompetenz nicht mehr automatisch der Volksrepräsentation zugestanden ${ }^{207}$. Da für den Wertrelativismus Gerechtigkeitsfragen nicht rational entscheidbar sind, wird die Rechtssicherheit zum Höchstwert des Rechts. "Wer Recht durchzusetzen vermag, beweist damit, daß er Recht zu setzen berufen ist", heißt es deshalb beim frühen Radbruch ${ }^{208}$. Durch diese Verflechtung der Aufgabe des Allgemeinheitspostulats ${ }^{209}$ mit der Verabschiedung der rechtlichen Fundierung der Volkssouveränität wird der Gesetzesbegriff derart formell, daß er als rein voluntaristischer wehrlos gegen gesetzliches Unrecht macht.

\section{Der materielle Rechtsstaat}

Vor dem Kontrastbild dieses extrem formellen Gesetzespositivismus, der in der Nachkriegszeit verdächtigt wird, zum Untergang der Weimarer Republik und zu deren legaler Umformung in eine autoritäre Diktatur beigetragen $z u$ haben ${ }^{210}$, begründet das Grundgesetz der Bundesrepublik Deutschland einen materiellen Rechtsstaat. Dessen Materialität besteht in der Festlegung von unabänderlichen Rechtsinhalten in der Verfassung, die

201 R.Alexy, Begriff und Geltung des Rechts, Freiburg/München 1992, S.139 und 143.

202 Ein Überblick über die verschiedenen positivistischen Rechtsbegriffe (Ross, Weber, Geiger, Holmes, Bierling, Luhmann, Austin, Kelsen, Hart) bei R.Alexy, Begriff, S.31ff. m.w.N.

203 Vgl. R.Dreier, Rechtsstaat, S.80.

204 H.Kelsen, Reine Rechtslehre, S.201.

205 R.Alexy, Begriff, S.140f.

206 So auch M.Weber, WuG, S.17.

207 H.Kelsen hatte zwar versucht, die Demokratie aus dem Wertrelativismus zu begründen (Vom Wesen und Wert der Demokratie (1920), 2. Aufl., Tübingen 1929), trennte diese Ausführungen aber strikt von seiner gegenüber der Staatsform neutralen Rechtslehre. Zudem konnte er nicht die Illegalität der legalen Selbstpreisgabe der Demokratie begründen. Vgl. dazu: H.Dreier, Rechtslehre, Kap.V, insbes. S. 269.

208 G.Radbruch, Rechtsphilosophie, S.175. Vgl. dazu A.Kaufmann, Problemgeschichte, S.82, 90ff.

209 Bei Kelsen wird die Aufgabe der Unterscheidung zwischen allgemeiner Regel und individueller Maßnahme besonders deutlich, weil im Stufenbau der Rechtsordnung jeder Rechtsakt (ob Gesetzgebung oder Urteil) zum Teil Kognition, d.h. Vollziehung einer übergeordneten Norm, und zum Teil Dezision, d.h. Normerzeugung ist. Kelsens Positivismus unterscheidet sich also auch insofern vom herkömmlichen Rechtspositivismus, als in gewisser Nähe zur Freirechtsschule das Ideal vom Richter als "Subsumtionsautomat" aufgegeben ist. Vgl. H.Dreier, Rechtslehre, S.146f.

210 W.Kägi, Rechtsstaat und Demokratie, S.127 ff; K.Stern, Rechtsstaat, S.7; U.Karpen, Rechtsstaat, S.91ff.; R.Dreier, Rechtsstaat, S.76; kritisch dazu I.Maus, Bürgerliche Rechtstheorie und Faschismus. Zur sozialen Funktion und aktuellen Wirkung der Theorie Carl Schmitts, 2.Aufl., München 1980; D.Merten, Rechtsstaat, S.12ff. 
auch den Gesetzgeber binden, also im Einbau eines Qualitätsmaßstabs in den Gesetzesbegriff211. Recht wird nicht mehr nur durch eine Kombination von Gesetztheit und Wirksamkeit, sondern darüber hinaus durch seine materiale Richtigkeit (d.h. Gerechtigkeit) definiert ${ }^{212}$. Rechtstechnisch kommt dies in der ausdrücklichen Bindung des Gesetzgebers an die Grundrechte (Art. $1 \mathrm{III} \mathrm{GG)}$ ) und die verfassungsmäßige Ordnung (Art. 20 III GG), in der Sozialstaatsklausel (Art. 20 I, 28 I 1 GG) sowie in der Überprüfbarkeit dieser Bindung durch ein Verfassungsgericht (Art. 92-94 GG) zum Ausdruck. Im Gegensatz zur einfachen "Herrschaft des Gesetzes" wird dadurch eine "zweistufige Legalität" begründet, wobei über den Vorrang der Verfassung vor einfachem Gesetzesrecht hinaus die grundlegenden Strukturprinzipien der Verfassung (Demokratie, Rechtsstaat, Sozialstaat und Föderalismus: Art. $20 \mathrm{GG}$ ) sowie der Wesenskern der Grundrechte (Art.1 I (Menschenwürde) und Art. 19 II GG) auch dem verfassungsändernden Gesetzgeber entzogen werden (Art. $79 \mathrm{III} \mathrm{GG).} \mathrm{"Hüter} \mathrm{der} \mathrm{Grundrechte"} \mathrm{ist} \mathrm{damit} \mathrm{nicht} \mathrm{mehr}$ in erster Linie das Parlament, sondern die neu geschaffene Institution des Verfassungsgerichts. ${ }^{213}$

Hatte Kant jede nochmalige Überprüfung des gesetzgebenden Souveräns wegen eines regressus ad infinitum abgelehnt ${ }^{214}$, so ist das der liberalen Rechtsstaatstheorie eigene Vertrauen in den demokratischen Gesetzgeber im materiellen Rechtsstaat durch ein prinzipielles Mißtrauen gegen diesen abgelöst. ${ }^{215}$ Die materiale Interpretation der Grundrechte, die ihren Ursprung schon Ende des 19. Jahrhunderts findet, bedeutet eine Abwendung von Kants rein formaler Definition der Prinzipien der Freiheit und Gleichheit als Teilhaberechte an der Gesetzgebung ${ }^{216}$. Mit der zunehmenden Industrialisierung der Gesellschaft und der damit einhergehenden Verelendung des Proletariats zeigte sich, daß die rein formale Freiheit nur denjenigen dient, die sich im Besitz der materiellwirtschaftlichen Grundlagen für die Wahrnehmung dieser Freiheiten befinden ${ }^{217}$. Die der liberalen Staatstheorie zugrundeliegende Annahme, daß der formal-rechtlich abgesicherte freie Markt automatisch zu distributiver Gerechtigkeit führe, hatte sich damit als falsch erwiesen. Das neu erwachte Bewußtsein für soziale Gerechtigkeit verlangte somit nach einem in die gesellschaftliche Güterverteilung intervenierenden Staat, der auch

211 D.Grimm, Reformalisierung, S.704.

212 R.Dreier, Rechtsstaat, S.79f.; ders., Der Begriff des Rechts, in: ders., Recht-Staat-Vernunft, Studien zur Rechtstheorie 2, Ffm 1991, Kap. 4, S.95-119; R.Alexy, Begriff, Kap. 4, S.201.

213 D.Grimm, Reformalisierung, S.705; ders., Wandel, S.294, 296.

214 "Ja es kann auch selbst in der Konstitution kein Artikel enthalten sein, der es einer Gewalt im Staat möglich machte, sich, im Fall der Übertretung der Konstitutionalgesetze durch den obersten Befehlshaber (d.i. der Gesetzgeber G.C.), ihm zu widersetzen, mithin ihn einzuschränken. Denn der, welcher die Staatsgewalt einschränken soll, muß doch mehr, oder wenigstens die gleiche Macht haben, als derjenige welcher eingeschränkt wird, und ... in jedem vorkommenden Fall rechtskräftig urteilen, ... Alsdann ist aber nicht jener (d.i. der Gesetzgeber, G.C.), sondern dieser (hier also das BVerfG, G.C.) der oberste Befehlshaber; welches sich widerspricht." Kant, MdS, S. 438f.; ebenso ders., Gemeinspruch, S.146f.: "Denn, könnte dieser auch gezwungen werden, so wäre er nicht das Staatsoberhaupt, und die Reihe der Unterordnung ginge aufwärts ins Unendliche."

215 Vgl. U.Scheuner, Entwicklung des Rechtsstaats, S.491 mit FN 102; R.Dreier, Rechtsstaat, S.86; E.W.Böckenförde, Entstehung, S.72f. m.w.N.

216 S.o. FN 127; I.Maus, Aufklärung, Anhang, S.298ff.

217 Diese materiell wirtschaftlichen Voraussetzungen von Freiheit hat Kant als "bürgerliche Selbständigkeit" umschrieben, folgerte daraus allerdings nicht die Notwendigkeit von Sozialpolitik, sondern schloß alle Unselbständigen mangels "bürgerlicher Persönlichkeit" schlicht vom Stimmrecht aus (Kant, MdS, WW IV, S.432-434). 
rechtlich auf das Ziel materieller Gerechtigkeit verpflichtet war. ${ }^{218}$ Anstelle der Begrenzung des Staates auf den Rechtszweck, die formale Kompatibilisierung der Freiheiten eines jeden Menschen mit den Freiheiten aller anderen Menschen, stand nunmehr der soziale Zweck des Staates im Vordergrund. Anstelle des Kampfes der bürgerlichen Gesellschaft gegen den Staat trat der Kampf der Industriegesellschaft um den Staat ${ }^{219}$. Die Rechtswissenschaft entdeckte in diesem Zusammenhang den Zweck im Recht und konzentrierte sich weniger auf die rein begriffliche Durchstrukturierung des Rechts als vielmehr auf die hinter dem Recht stehenden Interessenkonflikte ${ }^{220}$.

Neben diesem sozialen Aspekt wurde die Inhaltsleere des Formalismus, der jegliche Zwecksetzung ausschließlich dem Individuum überläßt, auch generell als unbefriedigend empfunden. Insbesondere nach dem 2. Weltkrieg verlangte das Rechtsgefühl nach objektiven Zwecken, nach nichtindividualistischen Rechtsinhalten, nach einem Ethos von Recht und Staat, kurz: nach Halt anstatt von wertrelativistischer Haltlosigkeit221. Ein erster Ansatz zu einer nichtindividualistischen, objektiven Begründung des Staats findet sich schon in Hegels Rechtsphilosophie ${ }^{222}$. Der endgültige Abschied vom "Formalismus in der Ethik" wird aber erst zu Beginn des 20. Jahrhunderts vom Neothomismus, vom Heidelberger Neukantianismus, vom Neuhegelianismus und von der materialen Wertethik vollzogen ${ }^{223}$. Die neue materiale Philosophie wird von den Juristen gegen Ende der Weimarer Republik rezipiert, indem insbesondere der Grundrechtskatalog der Weimarer Verfassung als Wertsystem ${ }^{224}$ bzw. als substanzhafte Ordnung ${ }^{225}$ verstanden wird. Vor allem der Grundsatz der Gleichheit vor dem Gesetz wird dabei in einen materielle Rechtsinhaltsgleichheit gebietenden Satz uminterpretiert.226 Das Reichsgericht nimmt zudem seit 1925 ein materielles Prüfungsrecht für sich in Anspruch, wodurch die materielle Verfassungsinterpretation erstmals auch aktuelle Wirksamkeit entfalten $\mathrm{kann}^{227}$. Diese Uminterpretation der Verfassung, die die rechtsstaatlichen Grundsätze weniger gegen die Exekutive als gegen den Gesetzgeber selbst zur Wirksamkeit bringt, ist teilweise auf die Wandlung der Staatsform von der Monarchie zur Demokratie zurückgeführt worden. Da mit Weimar ein freigewähltes Parlament, in dem zunächst die Sozialisten die Mehrheit stellen, zum ersten Mal die Möglichkeit zur legalen Umge-

218 D.Grimm, Wandel, S.296f;; E.W.Böckenförde, Entstehung, S.66ff.; B.Willms, Gesellschaftsvertrag und Rollentheorie, Jahrbuch zur RSoz und RTh 1 (1970), S.275-298.

219 E.R.Huber, Rechtsstaat, S.8, $11 \mathrm{ff}$.

220 Rudolf v.Jehring, Der Zweck im Recht, 1877/1883, sowie die Interessenjurisprudenz (insbes. Phillip Heck): vgl. A.Kaufmann, Problemgeschichte, S.113f.; K.Larenz, Methodenlehre, S.9ff.

221 Exemplarisch sei hier W.Oswald (Formalismus, S.48ff. m.w.N.) zitiert: "Die heutige Welt und vor allem die akademische Jugend ist des ethischen Formalismus müde. Erfültt von einem neuen Werterlebnis ... sehnt sie sich nach allgemeingültigen Werten ... (S.48). Das Ethos des Rechts, nämlich die Gerechtigkeit, ist Wille zur reinen Objektivität (S.54)." Oswald verlangt nach "geistiger Stellungnahme" des Rechts (S.57) und befürwortet im Anschluß an W.Kägi (Rechtsstaat und Demokratie) einen "materialen Verfassungsbegriff" (S.97ff.).

222 Im $\S 75$ seiner Rechtsphilosophie lehnt Hegel eine Begründung des Staats aus einem Vertragsverhältnis ab: vgl. B.Willms, Gesellschaftsvertrag, S.282.

223 Vgl. A.Kaufmann, Problemgeschichte; H.Welzel, Naturrecht, S. $183 \mathrm{ff}$.

224 R.Smend, Verfassung und Verfassungsrecht, München/Leipzig 1928, S. 163; kritisch dazu E.Forsthoff, Umbildung, S.40ff.

225 C.Schmitt, Legalität und Legitimität, Berlin 1932, S.40.

226 E.Kaufmann, Die Gleichheit vor dem Gesetz im Sinne des Art. 109 der Reichsverfassung, VVDStRL 3 (1927), S.1ff.; C.Schmitt, Verfassungslehre, München/Leipzig 1928, S.138ff.

227 RGZ 111, 320. 
staltung der Gesellschaft im Sinne sozialer Gerechtigkeit erhält, werden die Grundrechte von konservativen Kräften als Gewährleistung der kapitalistischen Gesellschafts- und Eigentumsordnung gegen den Gesetzgeber gewendet, weshalb eher linksgerichtete Verfassungsrechtler zur gleichen Zeit um so deutlicher auf den Formalismus pochen. ${ }^{228}$

Diese materiale Verfassungsinterpretation, die zu einer Relativierung der formalen Verfassungsgewährleistungen insofern führt, als die materialen Gehalte der Verfassung gegenüber den formalen verabsolutiert werden ${ }^{229}$, spielt später auch eine Rolle bei der Umwandlung der Weimarer Republik in eine faschistische Diktatur. Von nationalsozialistischen Juristen wird nämlich der als bürgerlich-besitzindividualistisch und deshalb als veraltet qualifizierte materiale Gehalt der Grundrechte schlicht durch einen neuen materialen Gehalt, das gesunde Volksempfinden, ersetzt und gegen die formalen Qualitäten des Gesetzesstaates ausgespielt. Mit den Methoden der materialen Verfassungsinterpretation, jetzt mit neuem, völkischen Inhalt, wird der schnelle Wandel zum faschistischen Rechtsstaat vollzogen. ${ }^{230}$ Dort, wo vorvölkisches, demokratisch gesetztes Recht dem neuen Rechtsideal hindernd entgegensteht, wird die formale Gesetzesbindung mit Bezug auf das neue materiale Rechtsdenken außer Kraft gesetzt.231

Dagegen meint die materielle Interpretation des Rechtsstaats des Grundgesetzes zweierlei. Zum einen wird der materielle Rechtsstaat als Rückbesinnung auf die prozeduralen Elemente der liberalen Rechtsstaatstheorie verstanden, womit die Einheit von Demokratie und Rechtsstaat gemeint ist. ${ }^{232}$ Als Gesetz wird wieder nur das mit Zustimmung einer frei gewählten Volksvertretung entstandene Gesetz bezeichnet ${ }^{233}$. Insofern im Grundgesetz also die Nichtabschaffbarkeit der Demokratie und der Gewaltenteilung festgelegt wird (Art. 20 I, II, 79 III GG) sowie weitere prozedurale Vorkehrungen zum Schutz der Grundrechte durch den Gesetzgeber festgelegt werden (etwa das Bestimmtheitsgebot, insbesondere für das Strafrecht gem. Art. 103 II GG, die Bindung des Gesetzgebers an Art. $3 \mathrm{GG}$, soweit dieser als Gebot der formalen Allgemeinheit der Gesetze verstanden wird, das Verbot von grundrechtsbeschränkenden Einzelfallgesetzen gem. Art. 19 I 1, oder etwa das Zitiergebot gem. Art. 19 I 2, das Verbot der generellen Ermächtigung der Exekutive gem. Art. $80 \mathrm{GG}$, das Gebot der Publizität der Gesetze gem. Art. 82 GG usf.), bedeutet dies eine Rückbesinnung auf die schon von Kant herausgearbeiteten Unverfügbarkeiten und prozeduralen Bedingungen des Verfassungsstaates, die von den extrem formellen Theorien des Rechtsstaats vernachlässigt oder übersehen und im Führerstaat allesamt mißachtet wurden.234 Nach der oben vorgenommenen Unterscheidung zwischen materialen und prozeduralen Theorien der Gerechtigkeit sind diese

228 F.Neumann, Funktionswandel des Gesetzes, S.55ff.; H.Heller, Rechtsstaat oder Diktatur? (1930), in: Tohidipur (Hrsg.), Rechtsstaat Bd. 1, S.159ff.; I.Maus, Entwicklung, S.40ff. Zur Parallele der Verhinderung von Sozialgesetzgebung durch eine besitzindividualistische Interpretation der Verfassung durch den amerikanischen Supreme Court vgl. M.Kriele, Staatslehre, $§ \S 54,55$.

229 Bei C.Schmitt (Legalität und Legitimität, S.40) wird die "substanzhafte Ordnung" gegen die parlamentarische Staatsorganisation verabsolutiert: vgl. I.Maus, Entwicklung, S.43f.

230 C.Schmitt, Der Führer schützt das Recht, in: ders., Positionen im Kampf um Weimar, Genf, Versailles, Hamburg 1940, S.199ff.; H.Lange, Vom Gesetzesstaat zum Rechtsstaat, Tübingen 1934.

231 Vgl. I.Maus, Bürgerliche Rechtstheorie; B.Rüthers, Die unbegrenzte Auslegung. Zum Wandel der Privatrechtsordnung im Nationalsozialismus, Tübingen 1968; E.W.Böckenförde, Enstehung, S.74; D.Merten, Rechtsstaat, S.12-16.

232 Z.B. W.Kägi, Rechtsstaat und Demokratie, S.148.

233 U.Scheuner, Entwicklung des Rechtsstaats, S.490 mit FN 99.

234 D.Merten, Rechtsstaat, S.12ff mit Beispielen. 
Prinzipien allerdings als prozedurale Prinzipien nicht dem Rechtsstaat im materiellen Sinne zuzuordnen. 235

Dem materiellen Rechtsstaat ist vielmehr die erwähnte materiale Interpretation der Grundrechte eigen, die in der Wertordnungstheorie des BVerfG aufgenommen wurde ${ }^{236}$. Danach kommt den Grundrechten ein Doppelcharakter zu: sie sind einerseits subjektive Rechte des Bürgers gegenüber dem Staat, andererseits wertentscheidende Grundsatznormen, die zusammengenommen als objektive Werteordnung für alle Bereiche des Rechts Geltung beanspruchen. ${ }^{237}$ Diese Interpretation der Grundrechte führt nun zu einem dreifachen Spannungsverhältnis zwischen Gesetz und Recht. Einerseits besteht ein Spannungsverhältnis zwischen einfachem Gesetz und Verfassungsrecht, das sich darin äußert, daß nicht nur jedes Gesetz formell und materiell verfassungsgemäß sein muß, sondern auch jede Auslegung und Anwendung der Gesetze im Einzelfall im Lichte der Grundrechte vorzunehmen ist. Darüber hinaus besteht aber eine Spannung zwischen den verschiedenen, mitunter kollidierenden Verfassungsprinzipien selbst sowie zwischen der Prinzipienebene und der Regelebene der Verfassung. Diese Spannungen sind im Einzelfall durch eine am Verhältnismäßigkeitsgrundsatz orientierte Güterabwägung aufzulösen. ${ }^{238}$ Dieses Verfassungsverständnis führt zu einer Verschiebung im Gewaltenteilungssystem zugunsten der Judikative, insofern deren Bindung an das Gesetz durch Bezugnahme auf die allgegenwärtige materiale Wertordnung in jedem Einzelfall relativiert werden kann. Es birgt zudem die Gefahr, die Gesetzgebung nur noch als wertverwirklichenden Verfassungsvollzug zu verstehen. ${ }^{239}$ Der so begründete Wandel vom Gesetzesstaat zum Richterstaat ${ }^{240}$ hebt den materiellen Rechtsstaat nicht nur vom formalen, sondern auch vom liberalen Rechtsstaat ab.

\section{Gesellschaft und Staatsaufgaben}

Bisher wurde gezeigt, daß die zunächst an fünf rechtsinternen Kriterien festgemachte Unterscheidung zwischen formal- und material-rationalen Rechtssystemen durch die Dreiteilung der Gerechtigkeitstheorien in formale, materiale und prozedurale in gewisser Weise gesprengt wird. Bei der Erörterung der Entwicklung des Rechtsstaatsbegriffs wurde dann herausgearbeitet, daß der liberale Rechtsstaat auf einer Umstellung von materialem Naturrecht auf prozedural-formales Vernunftrecht beruht. Der Prozeß der Formalisierung des Rechtsstaatsbegriffs wurde als Entwicklung interpretiert, in der das Recht ganz aus seiner naturrechtlichen Fundierung gelöst wurde. Dabei wurde der wert-

235 So aber U.Scheuner (Entwicklung), der unter materiellem Rechtsstaat die Einbettung der formalen Garantien des Rechtsstaats in die europäische Naturrechtstradition des Parlamentarismus versteht, eine Prüfungsbefugnis der Gerichte gegenüber dem Gesetzgeber dagegen zwar für möglich, nicht aber für nötig hält, sondern die Verwirklichung der materialen Gerechtigkeit dem Gesetzgeber zuweist (S. 490f.), und insbes. die Anwendung des Verhältnismäßigkeitsgrundsatzes auf die Gesetzgebung ablehnt (S. 496). Auch Böckenförde kritisiert die Deutung der Grundrechte als materiale Wertordnung und betont demgegenüber die "materiale Eigenbedeutung formaler rechtlicher Garantien und geordneter Verfahren" (Entstehung, S. 74). Den von Scheuner und Böckenförde vertretenen Ansatz kann man daher als prozedurales Rechtsstaatsverständnis verstehen.

236 So zuerst in BVerfGE 6, 32 (Elfes-Urteil); E 7, 198 (Lüth-Urteil).

237 R.Dreier, Rechtsstaat, S.81ff.; R.Alexy, Grundrechte, S.75ff.

238 Vgl. dazu R.Dreier, Rechtsstaat, S.81ff.

239 R.Dreier, a.a.O.

240 R.Marcic, Vom Gesetzesstaat zum Richterstaat, Wien 1957; E.Forsthoff, Rechtsstaat oder Richterstaat?, in ders., Rechtsstaat im Wandel, 1976, S.243ff. 
relativistische Positivismus als eine Denkhaltung bestimmt, die mit der Annahme der Nichtentscheidbarkeit von Gerechtigkeitsfragen den drei genannten Gerechtigkeitstheorien als vierte, negative Kategorie gegenübersteht, insofern selbst der minimale Gerechtigkeitsbezug der formalen Gerechtigkeitstheorien aufgegeben wird. ${ }^{241}$ Schließlich wurde bezüglich der Wende zum materiellen Rechtsstaatsbegriff des Grundgesetzes unterschieden zwischen Konzepten, die den prozeduralen Gehalt der Verfassung betonen, und solchen, die insbesondere die Grundrechte als materiale, substanzhafte Vorgaben interpretieren. Wenn im Rahmen von Evolutionstheorien des Rechts die Rechtsentwicklung zunächst als Prozeß zunehmender Formalisierung beschrieben wird, der dann von einem Prozeß der Materialisierung des Rechts abgelöst wird, so kommt den prozeduralen Elementen dabei keine eigenständige Bedeutung zu. Die formal-prozedurale Theorie des liberalen Rechtsstaats scheint sich im Grundgesetz zu einer materialprozeduralen Theorie weiterentwickelt zu haben. ${ }^{242}$ Wie läßt sich dann aber ein eigenständiges prozedurales Rechtsparadigma begründen, welches in einem Drei-StadienModell der Rechtsentwicklung das bestehende materiale Rechtsparadigma ablösen soll?

Ein Rechtsparadigma kann als "Sozialmodell des Rechts"243, also als internes Modell des Rechts von seiner Außenwelt, das handlungsleitende Kraft entfaltet, verstanden werden $^{244}$. Ein Rechtsparadigma ist mit anderen Worten ein im Rechtssystem wirksames Gesellschaftsbild. Paradigmen verweisen daher nicht nur, wie bisher dargestellt, auf philosophische und wissenschaftstheoretische Hintergrundannahmen des Rechts, sondern auch auf die Gesellschaft in ihrer historischen Ausformung mit ihren spezifischen Problemlagen. Eine Evolutionstheorie des Rechts ist damit immer eingebunden in eine Evolutionstheorie der Gesellschaft. Das formale und das materiale Rechtsparadigma werden deshalb als Reaktionen des Rechts auf bestimmte gesellschaftliche Problemlagen und daraus resultierende Vorstellungen vom Staat und dessen Aufgaben verstanden. Das Paradigma des bürgerlichen Formalrechts wird danach aufgrund der mit der Industrialisierung entstehenden sozialen Frage durch ein material-wohlfahrtsstaatliches Paradigma ersetzt. Der Übergang zu einem prozeduralen Paradigma wird nun mit dem Wandel zur wissenschaftlich-technischen Informationsgesellschaft und der daraus resultierenden Ausweitung der Staatsaufgaben auf umfassende Risikovorsorge begründet. Angesichts dieses gesellschaftlichen Wandels und der damit einhergehenden Zunahme von Staatsaufgaben, so die These, gerät das vom materialen Paradigma geleitete Recht in eine dreifache Krise, die den Übergang zu einem prozeduralen Paradigma zur Folge hat. ${ }^{245}$ Bevor im nächsten Teil diese dreifache Krisenlage erläutert wird, soll zunächst kurz auf die Entwicklung der Staatsaufgaben vor dem Hintergrund gesellschaftlicher Problemlagen eingegangen werden.

241 Zur Erosion der Allgemeinheit des Gesetzes durch Maßnahmegesetze s.u. V. 1.

242 Zur Einstufung des Grundgesetzes als material-prozeduraler Konzeption vgl. R.Dreier, Rechtsstaat, S.78.

243 F.Wieacker, Das Sozialmodell der klassischen Privatrechtsgesetzbücher und die Entwicklung der modernen Gesellschaft, in: ders., Industriegesellschaft und Privatrechtsordnung, Ffm 1974, S.5ff.

244 Vgl. G.Teubner, Recht als autopoietisches System, S.86ff;; J.Habermas, FuG, S.472: "Gemeint sind ... diejenigen impliziten Bilder von der eigenen Gesellschaft, die der Praxis der Rechtsetzung und Rechtsanwendung eine Perspektive ... geben". Systemtheoretisch formuliert wäre ein Rechtsparadigma "Die Gesellschaft des Rechts".

245 Vgl. nur G.Teubner, Reflexives Recht; ders., Recht als autopoietisches System, Kap. 4 u. 5; H.Willke, Ironie, Kap. 2.4; J.Habermas, FuG, Kap. IX. 


\section{Bürgerliche Gesellschaft und liberaler Staat}

Ausgehend von der Epoche der Religionskriege kann die Wahrung des inneren und äuBeren Friedens als der neuzeitliche Staatszweck bestimmt werden. ${ }^{246}$ Unter dem Eindruck des "Krieges aller gegen alle" begründet z.B. Hobbes das staatliche Gewaltmonopol durch einen Herrschafts- bzw. Unterwerfungsvertrag unter einen absoluten Staat. 247 Sobald mit der Durchsetzung des staatlichen Gewaltmonopols der Frieden gesichert ist, stellt sich aber das Problem der Begrenzung des so errichteten "Leviathan". Weil die Menschen die Unterdrückung durch das "Recht" des Stärkeren nicht gegen willkürliche staatliche Unterdrückung eintauschen wollen, muß die staatliche Macht auf das zur Friedensbewahrung Notwendige beschränkt werden. ${ }^{248}$ Dieses Problem findet seine Lösung in der Theorie des Rechtsstaats. Der Herrschaftsvertrag wird dabei durch einen Gesellschaftsvertrag ersetzt, der als bürgerliche Verfassung den Staat nicht nur begründet, sondern zugleich auf die Verfolgung des Rechtszwecks, d.i. die formale Koordinierung der Freiheit des einen mit der gleichen Freiheit jedes anderen, beschränkt.249

Freiheit wird in diesem Zusammenhang formal verstanden: positiv als Freiheit, nur nach selbstgesetzten Zwecken und Gesetzen zu leben, und negativ als Freiheit von jeder staatlichen Bevormundung. Der Staat soll lediglich den formal-rechtlichen Rahmen zur Verfügung stellen, innerhalb dessen die Subjekte ihre Zwecke autonom setzen und verfolgen können ${ }^{250}$, was in der liberalen Formel "Jeder soll nach seiner Fasson glücklich werden"25ı zum Ausdruck kommt. Das aufklärerische Verständnis von Freiheit als Selbermachendürfen schließt dabei gleichzeitig ein Selbermachenmüssen, also eine Theorie der Eigenverantwortlichkeit ein.252 Jede staatliche Wohlfahrtspolitik wird daher einerseits als "der größte denkbare Despotismus" abgelehnt, weil sie notwendig eine staatliche Definition von Wohlfahrt voraussetzt und damit die Behandlung der Bürger als "unmündige Kinder" zur Folge hätte (imperium paternale = Verfassung, die alle Freiheit aufhebt) ${ }^{253}$; andererseits aber auch deshalb, weil "unter einer zu ausgedehnten Sorgfalt des Staates" für das physische und moralische Wohl der Bürger "die Energie des Handelns überhaupt leidet", das Prinzip der Eigenverantwortlichkeit also aufgehoben würde.254 Der Staat hat Sicherheit nicht als soziale Sicherheit, sondern nur in Form von

246 C.Starck, Frieden als Staatsziel, in: FS fiur Karl Carstens, 1984, S.867ff.

247 Hobbes, Leviathan, Kap. 14, 17; vgl. dazu M.Kriele, Staatslehre, §§ 30-36.

248 C.Starck, Die Bedeutung der Rechtsphilosophie für das positive Recht, ARSP Beiheft 44, 1991, S.376ff, 384 .

249 Zum Übergang vom Herrschafts- zum Gesellschaftsvertrag s. I.Maus, Aufklärung, Kap. 2.

250 So heißt es in Kants Rechtsdefinition (MdS, WW IV, S. 337): "in diesem wechselseitigen Verhältnis der Willkür kommt auch gar nicht die Materie der Willkür, d.i. der Zweck, ... , in Betrachtung, ... sondern nur (die) Form in Verhältnis der beiderseitigen Willkür, sofern sie als frei betrachtet wird ...".

251 Z.B. bei Kant, Gemeinspruch, WW VI, S. 145: "Niemand kann mich zwingen, auf seine Art ... glücklich zu sein, sondem ein jeder darf seine Glückseligkeit auf dem Wege suchen, welcher ihm selbst gut dünkt ...".

252 H.M.Sass, Zielkonflikte im Wohlfahrtsstaat, in: Sachße/Engelhardt (Hrsg.), Sicherheit und Freiheit, S.71-105, 89f.

253 Kant, Gemeinspruch, S. 145f.

254 Wilhelm v.Humboldt, Ideen zu dem Versuch, die Grenzen der Wirksamkeit des Staates zu bestimmen (1792), in: W. v.Humboldt: Eine Auswahl seiner politischen Schriften, hrsg.v. Siegfried Köhler, Berlin 1922, S. 24f.: "Wer zu oft und viel geleitet wird, kommt leicht dahin, den Überrest seiner Selbsttätigkeit gleichsam freiwillig zu opfern. Er glaubt sich der Sorge überhoben, die er in fremden 
Rechtssicherheit zu gewährleisten 255 . Gleich sind die Menschen nur "dem Rechte nach", während faktische Ungleichheit dem "Besitztum nach" mit der rechtlichen Gleichheit unter der Bedingung von Chancengleichheit vereinbar ist. ${ }^{256}$

Die liberale Staatstheorie begründet mit der Begrenzung der Staatsaufgaben auf den Schutz gegen Gewalt, Diebstahl und Betrug sowie die Durchsetzung von Verträgen, die Konzeption eines minimalen Staates 257 , der von seinen Kritikern auch als "liberaler Nachtwächterstaat" verspottet wurde 258 . Zur Verteidigung dieser Staatskonzeption, die außer von Kant und Humboldt vor allem vom englischen Liberalismus ${ }^{259}$ vertreten wurde, wäre vorzubringen, daß zumindest ein Minimum an durch staatliche Zwangsabgaben (Steuern) finanzierter Armenfürsorge vorgesehen war ${ }^{260}$ und der Exekutive darüber hinaus die Verfolgung wohlfahrtsstaatlicher Zwecke zugestanden wurde, soweit sie diese Zwecke nicht mit Zwangsmitteln durchsetzt. ${ }^{261}$ Insgesamt beruht die liberale Staatstheorie mit ihrem rein formalen Verständnis von Freiheit und Gleichheit aber auf der Vorstellung einer Gesellschaft von bäuerlichen und kaufmännischen Kleineigentümern, die durch Abwesenheit von Monopolbildung und sozialer Machtkonzentration gekennzeichnet ist. Nur unter der Voraussetzung von - jedenfalls ursprünglich - relativ gleicher Verteilung von Besitz und Bildung konnte die Annahme einleuchten, der freie Markt führe automatisch zu distributiver Gerechtigkeit. ${ }^{262}$ Besitz und Bildung als Voraussetzung der Wahrnehmung formal-rechtlicher Freiheit sind dabei schon von den liberalen Staatstheoretikern erkannt worden, woraus allerdings etwa Kant - im Gegensatz zu Rousseau ${ }^{263}$ - nicht die Notwendigkeit einer Bildungspolitik oder der Verhinderung allzu ungleicher Verteilung des Eigentums folgert, sondern im Gegenteil den Ausschluß aller "Unselbständigen" von der aktiven Staatsbürgerschaft (Stimmrecht). ${ }^{264}$ Den passi-

Händen sieht, und genug zu tun, wenn er ihre Leistung erwartet ... Wie jeder sich selbst auf die sorgende Hilfe des Staates verläßt, so und noch weit mehr übergibt er ihr das Schicksal seines Mitbürgers". Ebenso schreibt Kant (MdS, S.447), das Armsein dürfe nicht zum Erwerbmittel für faule Menschen gemacht werden.

255 E.Denninger, Der Präventions-Staat, KJ 1988, 1ff.; U.Preuß, Verfassungstheoretische Überlegungen zur normativen Begründung des Wohlfahrtsstaates, in: Sach/3e/Engelhardt (Hrsg.), Sicherheit und Freiheit, S.106ff.

256 Wobei Chancengleichheit unter Ausschluß materieller Voraussetzungen nur auf Talent, Fleiß und Glück bezogen wird: Kant, Gemeinspruch, S.147.

257 Eine neuere Konzeption eines minimalen Staates findet sich bei R.Nozick, Anarchy, State, and Utopia, New York 1974; Neoliberale Staatskonzepte finden sich auch bei Friedrich A. Hayek, The Constitution of Liberty, London 1960; ders., Law, Legislation, and Liberty, London 1982; sowie bei M.Friedman, Capitalism and Freedom, Chicago UP 1962; J.M.Buchanan, The Limits of Liberty, Chicago 1975.

258 Diese Bezeichnung geht auf Lasalle zurück; vgl. F.Neumann, Funktionswandel des Gesetzes, S.32.

259 Nach Locke vor allem Adam Smith und John Stuart Mill: vgl. H.Willke, Ironie, S.17ff.; B.Peters, Rationalität, Recht und Gesellschaft, Ffm 1991, S.59f.

260 Z.B. Kant, MdS, WW IV, S.446f.

261 Vgl. dazu P.Koslowski, Staat und Gesellschaft bei Kant, S.33ff. m.w.N.

262 D.Grimm, Bürgerlichkeit im Recht, in: ders., Recht und Staat der bürgerlichen Gesellschaft, Ffm 1987, S.11-49; ders., Wandel, S.291ff., 296.

263 Rousseau, Gesellschaftsvertrag, 2. Buch, Kap. 11

264 Stimmrecht setzt bei Kant "bürgerliche Selbständigkeit" bzw. "bürgerliche Persönlichkeit" voraus. "Der Geselle ...; der Dienstbote ...; der Unmündige ...; alles Frauenzimmer, und überhaupt jedermann, der nicht nach eigenem Betrieb, sondern nach der Verfügung anderer ..., genötigt ist, seine Existenz (Nahrung und Schutz) zu erhalten, entbehrt der bürgerlichen Persönlichkeit, und seine Existenz ist gleichsam nur Inhärenz." (Kant, MdS, WW IV, S. 433). 
ven Staatsbürgern bleibt nur ein Recht auf die Möglichkeit, "sich aus diesem passiven Zustande zu dem aktiven empor arbeiten zu können"265. Wenn der liberalen Staatstheorie aus heutiger Sicht deshalb "soziale Blindheit" vorgeworfen wird, so ist zu beachten, daß der "liberale Minimalstaat" in seiner reinen Form nie Wirklichkeit war ${ }^{266}$, sondern lediglich ein - sicherlich einseitiges - theoretisches Modell bezeichnet, das zu einer Zeit entworfen wurde, in der es galt, dem bürgerlichen Leistungsprinzip in einer starren, von ständischen Privilegien gekennzeichneten Gesellschaft und gegenüber einem übermächtigen, absolutistischen "Polizeystaat" überhaupt Raum zu verschaffen.

\section{Industriegesellschaft und Sozialstaat}

Die "soziale Frage" in ihrer uns bekannten Form existierte zu Kants Zeiten noch nicht. Not, Armut und Hunger gab es zwar auch in der ständischen Gesellschaft, der moderne Sozialstaat entstand aber erst vor dem Hintergrund der Klassengesellschaft. ${ }^{267}$ Diese aber ist Produkt der - jedenfalls teilweisen - Verwirklichung der liberalen Freiheiten, insbesondere der Wirtschafts- und Vertragsfreiheit. "Enrichez vous", Aufforderung des französischen Königs an das Bürgertum, steht sprichwörtlich für die staatliche Freisetzung der Industrialisierungsdynamik, in deren Gefolge sich die neue Arbeiterklasse herausbildete. Mit der zunehmenden Verelendung dieses "Proletariats" stellte sich dann auch die soziale Frage. ${ }^{268}$ Während in Frühliberalismus in Anlehnung an den aristotelischen Begriff der zivilen Gesellschaft die bürgerliche Gesellschaft als der zentrale Ort, an dem distributive Gerechtigkeit sich verwirklicht, bestimmt wurde, definierte Hegel die bürgerliche Gesellschaft als das System der partikularen Bedürfnisse und Interessen, als Sphäre des universalen Egoismus, der er den Staat als die Sphäre des universellen Altruismus gegenüberstellte. ${ }^{269}$ In dieser Staatsdefinition ist die Zuständigkeit des Staates für die Herstellung von sozialer Gerechtigkeit bereits angelegt. ${ }^{270}$ Noch ohne den Begriff zu benutzen, werden die auch heute noch wesentlichen Merkmale des Sozialstaats dann bei Lorenz v.Stein herausgearbeitet. ${ }^{271} \mathrm{Im}$ Gegensatz zu der schon bei Kant erwähnten Armenfürsorge wird mit dem Sozialstaat das Programm eines aktiven Staates begründet ${ }^{272}$, dem die Globalverantwortung für die wirtschaftliche, soziale und kulturelle Entwicklung zukommt. ${ }^{273}$ Der Sozialstaat mit seinen Grundwerten der Existenzsi-

265 Kant, MdS, S.434.

266 B.Peters, Rationalität, S.58.

267 D.Grimm, Die sozialgeschichtliche und verfassungsrechtliche Entwicklung zum Sozialstaat, in: ders, Recht und Staat der bürgerlichen Gesellschaft, Ffm 1987, S. 138-161.

268 Kritisch dazu G.Habermann, Der Wohlfahrtsstaat. Die Geschichte eines Irrwegs, Berlin 1994, der die Wurzeln des Sozialinterventionismus im "eudämonistischen Polizeistaat" am Beispiel Preussens unter Friedrich dem Großen herausarbeitet.

269 Georg W.F. Hegel, Philosophie des Rechts (1819/20), hrsg. v. Dieter Henrich, Ffm 1983, S. 208ff;; vgl. H.Willke, Ironie, S.28.

270 Vgl. T.Blanke, Sozialer Rechtsstaat: Verfassungsgebot für soziale Sicherheit?, in: Sachße/Engelhardt (Hrsg.), Sicherheit und Freiheit, S.133-157, $145 \mathrm{ff}$.

271 Lorenz v.Stein, Der Sozialismus und Kommunismus des heutigen Frankreich, 1842; vgl. dazu E.R.Huber, Rechtsstaat und Sozialstaat, S.12; auf den Ursprung der Formel vom demokratischen und sozialen Rechtsstaat in der französischen Revolution von 1848 verweist W.Abendroth, Der demokratische und soziale Rechtsstaat als politischer Auftrag, in: Tohidipur (Hrsg.), Rechtsstaat, Bd.1, S.265-289, 268.

272 Zum Konzept des aktiven Staates vgl. H.Willke, Ironie, S.107-143 m.w.N.

273 D.Grimm, Verfassungsrechtliche Anmerkungen zum Thema Prävention, KritV 1986, S.38-54, 43. 
cherheit, der Vollbeschäftigung und der Erhaltung der Arbeitskraft soll soziale Integration durch ein Programm umfassender Sozialreform verwirklichen. ${ }^{274}$

Die Verwirklichung der Sozialstaatsidee kann als mehrstufiger Prozeß verstanden werden, in welchem sich der Schwerpunkt staatlicher Politik vom Medium Macht zum Medium Geld verlagert. ${ }^{275}$ Zunächst wurde Formen des offensichtlichen Freiheitsmißbrauchs entgegengewirkt, indem die mit dem Eigentum verbundenen Verfügungsbefugnisse eingeschränkt oder bestimmte Verträge (Arbeitsrecht, Mietrecht) inhaltlichen Anforderungen unterworfen wurden. Sodann galt es, den verschiedensten Formen von Marktversagen entgegenzuwirken. Einerseits mußte das durch die industrielle Revolution und die spätere Entwicklung zum Monopolkapitalismus in Frage gestellte gesellschaftliche Kräftegleichgewicht als Grundlage der Marktwirtschaft durch staatliche Ordnungspolitik (z.B. Wettbewerbs- und Kartellrecht) gesichert oder aktiv hergestellt werden. Andererseits wurden, beginnend mit den Bismarckschen Sozialversicherungsgesetzen, bestimmte Bereiche dem Marktmechanismus ganz entzogen. Damit setzte ein Prozeß der immer umfassenderen Zwangsversicherung gegen soziale Risiken ein, der erst kürzlich mit der Pflegeversicherung einen - jedenfalls vorläufigen - Abschluß gefunden $z u$ haben scheint ${ }^{276}$.

Mit der Idee der Sozialversicherung beginnt, auch wenn es sich dabei im strengen Sinne noch nicht um staatliche Leistungen handelt, der Übergang zum geldbasierten Leistungs- und Interventionsstaat. Der Staat übernimmt in immer stärkerem Maße die Verantwortung für Engpässe, Notlagen und Krisen, denen er zunächst reaktiv durch Sach- und Geldleistungen, dann aber zunehmend auch durch präventives Krisenmanagement (z.B. Subventionen) entgegenwirkt, um schließlich die Rahmenbedingungen für Wachstum und Entwicklung aus eigener Initiative zu verbessern. ${ }^{277}$ Die zunehmende Bedeutung des Geldes als Medium staatlicher Politik kann am "revolutionären Umbruch" der Steuergesetzgebung verdeutlicht werden: Während die preußische Einkommensteuerreform von 1891 sich mit einem Stufentarif von 0,67 bis 4 Prozent begnügte, galt in der Weimarer Republik schon 1920 eine Progression von 10 bis 60 Prozent ${ }^{278}$. Über das Medium Geld verfügt der Sozialstaat - im Gegensatz zum Medium Macht (staatliches Gewaltmonopol) - zwar nicht ausschließlich, aber bei einer Staatsquote von über 50 Prozent doch in ganz erheblichem Maße. 279

Diese Ausweitung der Staatsaufgaben im Sozialstaat wird in der Regel mit einer Argumentation gerechtfertigt, die sich als bloßes konsequentes Weiterdenken der bürgerlich-liberalen Verfassungsprinzipien versteht: Freiheit und Gleichheit, individuelle Selbstbestimmung und freie Entfaltung der Persönlichkeit seien nur da verwirklicht, wo

274 E.R.Huber, Rechtsstaat und Sozialstaat, S.13.

275 H.Willke, Ironie, S.239ff, 246.

276 Zur Entwicklung von der Arbeiterversicherung des Reichs zur umfassenden Volksversicherung in der Bundesrepublik: P.Koslowski, Der soziale Staat der Postmoderne. Ethische Grundlagen der Sozialpolitik und Reform der Sozialversicherung in: Sachße/Engelhardt (Hrsg.), Sicherheit unf Freiheit, S.28-70, $43 \mathrm{ff}$.

277 D.Grimm, Prävention, S.38, 42f.; H.Willke, Ironie, S.246ff.; N.Luhmann, Politische Theorie im Wohlfahrtsstaat, München/Wien, 1981, S.25ff.; U.Beck, Risikogesellschaft. Auf dem Weg in eine andere Moderne, Ffm 1986, Teil II, S.67ff.

278 In den USA und Großbritannien galten zeitweise sogar Sätze bis zu 97 Prozent: vgl. R.Weber-Fas, Finanzgerichtsbarkeit im freiheitlichen Rechtsstaat, in: Tohidipur (Hrsg.), Rechtsstaat, Bd.2, S.548564,549 m.w.N.

279 H.Willke, Ironie, S.248. 
jenseits bürgerlicher Formalprinzipien auch die materiellen Voraussetzungen der Wahrnehmung dieser Freiheiten gewährleistet seien. ${ }^{280}$ Sozialpolitik wird deshalb als Grundrechtsverwirklichungspolitik oder auch als Staatsbürgerqualifikationspolitik legitimiert ${ }^{281}$. In Kants Begriffen hat also jeder einen Anspruch auf bürgerliche Selbständigkeit, der Staat hat die Bürger vom passiven in den aktiven Stand der Staatsbürgerschaft zu versetzen. Diese Argumentation kann allerdings nur dann als bloßes $\mathrm{Zu}$-EndeDenken der Kantschen Prinzipien verstanden werden, wenn die fehlende Qualifikation der bürgerlichen Selbständigkeit nicht mehr als selbstverschuldet dem Einzelnen, sondern als strukturell bedingt der Gesellschaft zugerechnet werden kann. Hegel hat diesen Schritt vollzogen, wenn er schreibt: "Die Entstehung der Armut ist überhaupt eine Folge der bürgerlichen Gesellschaft, und sie ergibt sich im ganzen notwendig aus derselben"282. Voraussetzung dieser Erkenntnis ist aber die Industrialisierung selbst, weil erst infolge der diese begleitenden Landflucht, Verstädterung, Auflösung der bäuerlichen Großfamilie, Arbeitsteilung etc., also infolge des rapiden gesellschaftlichen Wandels und der funktionalen Differenzierung die gesellschaftlichen Verhältnisse, und damit auch die Armut, nicht mehr als Naturzustand, sondern als künstlich, von Menschen gemacht, begriffen werden können. So wie sich der liberale Staat als Schutz vor physischer Gewalt legitimiert, kann dann staatliche Sozialpolitik als Schutz vor "struktureller Gewalt" legitimiert werden. ${ }^{283}$

\section{Risikogesellschaft und Präventionsstaat}

Ist der Sozialstaat die politische Antwort auf die mit der industriellen Klassengesellschaft entstandene soziale Frage, so findet in jüngster Zeit eine "Neubelebung der Staatsdiskussion"284 vor dem Hintergrund eines gesellschaftlichen Wandels statt, der abermals zu einer Ausdehnung der Staatsaufgaben führt. Da dieser Wandel der Gesellschaft noch nicht abgeschlossen ist, haben sich noch keine einheitlichen Begrifflichkeiten zur Umschreibung der modernen Gesellschaft, ihrer spezifischen Probleme und der zu deren Lösung angemessenen Idee vom Staat herausgebildet. Die konkurrierenden Beschreibungen der Gesellschaft als Wissenschafts-285, Informations-286, Kommunikations ${ }^{287}$ oder Risikogesellschaft ${ }^{288}$, und die korrespondierenden Konzepte vom gärt-

280 Diese inzwischen "klassische" verfassungsrechtliche Legitimation des Sozialstaats findet sich bei W.Abendroth, Zum Begriff des demokratischen und sozialen Rechtsstaates im Grundgesetz der Bundesrepublik Deutschland (1954), in: Forsthoff (Hrsg.), Rechtsstaatlichkeit und Sozialstaatlichkeit, Darmstadt 1968, S.114ff;; vgl. auch D.Grimm, Die sozialgeschichtliche und verfassungsrechtliche Entwicklung zum Sozialstaat, S.138ff.; aus amerikanischer Sicht R.E.Goodin, Reasons For Welfare. The Political Theory of the Welfare State, Princeton UP 1988, S.153ff.

281 U.Preuß, Überlegungen, S.124ff.

282 Hegel, Philosophie des Rechts (1819/20), hrgg. v. D.Henrich, Ffm 1983, S.193.

283 H.Willke, Ironie, S.242-245.

284 D.Fürst, Die Neubelebung der Staatsdiskussion: Veränderte Anforderungen an Regienung und Verwaltung in westlichen Industriegesellschaften, JBzStuVwWiss 1987, S.261-284.

285 Z.B. R.Kreiblich, Die Wissenschaftsgesellschaft. Von Galilei zur High-Tech-Revolution, Ffm 1986.

286 Z.B. K.T.Schröder et.al., Die Bundesrepublik Deutschland auf deın Weg zur Informationsgesellschaft?, Aus Politik und Zeitgeschichte B 15/89.

287 Z.B. G.Wersig, Die kommunikative Revolution, Strategien zur Bewältigung der Krise der Moderne, Opladen 1985; R.-P.Calliess, Strafzwecke und Strafrecht, NJW 89, S.1338ff.; Theoretisch gut ausgearbeitete Beschreibungen der Gesellschaft als Kommunikationsgesellschaft finden sich immerhin 
nernden ${ }^{289}$, sorgenden ${ }^{290}$ oder präzeptoralen ${ }^{291}$ Staat, vom Sicherheits-292, Präventions${ }^{293}$ und Schutzstaat ${ }^{294}$ treffen jeweils für sich nur Teilaspekte der Entwicklung und unterliegen der Gefahr, als modische Schlagwörter zu Leerformeln zu verkommen ${ }^{295}$. Unabhängig von der Begriffswahl ${ }^{296}$ sollen im folgenden einige wesentliche Merkmale herausgearbeitet werden, die den der neuen Staatsdebatte zugrundeliegenden gesellschaftlichen Wandel charakterisieren.

Vorweg erwähnt sei, daß der Sozialstaat mit dem Wandel der Industrie- zur Dienstleistungsgesellschaft und von der Klassen- zur "nivellierten Mittelstandsgesellschaft" seine traditionelle Ausgangsbasis verloren hat. ${ }^{297}$ Dieser Wandel ist u.a. auf den Erfolg sozialstaatlicher Politik selbst zurückzuführen, hat indessen keinesfalls die Überflüssigkeit von Sozialpolitik zur Folge, wie die Diskussion um "neue Armut" und "ZweiDrittel-Gesellschaft" beweist ${ }^{298}$. Auch soweit der Sozialstaat etwa unter dem Gesichtspunkt der "over-protection" und des "Paternalismus" in die Kritik geraten ist ${ }^{299}$, betrifft dies nicht den hier interessierenden gesellschaftlichen Wandel, der zu neuen Staatsaufgaben führt.

Entscheidend ist vielmehr ein steigendes Sicherheitsbedürfnis der Gesellschaft, das an den Staat als schützende Instanz weitergegeben wird. ${ }^{300}$ Dieses Sicherheitsbedürfnis

bei J.Habermas, Theorie des kommunikativen Handelns, 2 Bde, Ffm 1981, und bei N.Luhmann, Soziale Systeme, Ffm 1984: dazu ausführlich unten Kap. 2 II.

288 U.Beck, Risikogesellschaft; ders., Gegengifte, Die organisierte Unverantwortlichkeit, Ffm 1988.

289 Z.Bauman, Modernity and Ambivalence, London 1991, deutsch: Moderne und Ambivalenz, Ffm 1995, S.43ff.

290 A.de Swaan, Der sorgende Staat, Ffrn/New York 1993; vgl. auch F.Ewald, Der Vorsorgestaat, Ffm 1993; ders., Die Versicherungs-Gesellschaft, KJ 1989, 385-393.

291 U.Di Fabio, Grundrechte im präzeptoralen Staat am Beispiel hoheitlicher Informationstätigkeit, JZ 1993, S.689ff.; vgl. auch Willke, Ironie, S.144ff m.w.N.

292 J.Hirsch, Der Sicherheitsstaat, Köln 1980.

293 E.Denninger, Präventions-Staat, S.1ff; ähnlich schon D.Grimm, Prävention, S.38ff.

294 H.A.Hesse, Der Schutzstaat, Baden-Baden 1994; ders., Der Schutzstaat geht um, JZ 1993, S.741748.

295 Als Beispiel mag die Karriere des Begriffs der "Postmoderne" und des Gegenbegriffs der "reflexiven Modernisierung" genommen werden: kritisch dazu N.Luhmann, RdG, S.538f. Dem Begriff der "Risikogesellschaft" scheint ein ähnliches Schicksal bevorzustehen: vgl. etwa den Beitrag von M.Bock, Vorüberlegungen zur rechtlichen Bewältigung der Risikogesellschaft, ZfRSoz 1989, S.255-264. Daniel Bell, der den Wandel zur Wissenschaftsgesellschaft schon früh beschrieben hat (The Cultural Contradictions of Capitalism, London 1976), fuhrt deshalb aus: "I rejected the temptation to label these emergent features as ... the 'information society' or the 'knowledge society', ... since such terms are only partial, or they seek to catch a fashionable wind and twist it for modish purposes" (aaO, S. IX); vgl. Willke, Ironie, S.283.

296 Die Wahl der Ü̉berschrift dieses Abschnitts ("Präventionsstaat") ist im Hinblick auf diese Problemlage eine Verlegenheitswahl. Gleichzeitig liegt diese Begriffswahl aber aus rechtstheoretischer Sicht nahe, da Prävention die rechtliche Grundproblematik der beschriebenen Entwicklungen ausmacht.

297 Dementsprechend ist eine traditionelle "Arbeiterpolitik" heute weder mehrheitsfähig (mangels Masse) noch sozial (da bloß Besitzstände der Arbeiter auf Kosten der Arbeitslosen verteidigt würden); ein Problem mit dem SPD und Gewerkschaften zu kämpfen haben.

298 Vgl. U.Beck, Jenseits von Klasse und Schicht, in: ders., Risikogesellschaft, Kap.III; S.Leibfried, Zeit der Armut, Lebensläufe im Sozialstaat, Ffm 1995.

299 Vgl. dazu unten V. 2. : Krise des Wohlfahrtsstaats.

300 S.Murck, Soziologie der öffentlichen Sicherheit, Ffm 1980; W.Zapf, Individualisierung und Sicherheit, Schriftenreihe des Bundeskanzleramts Bd. 4, 1987; R.-P.Calliess, Strafzwecke und Straf- 
entsteht vor dem Hintergrund von Kontingenz und Ambivalenz als menschlicher Grunderfahrung unserer Zeit. ${ }^{301}$ Es kann an drei Aspekten beleuchtet werden, die je für sich mit der gestiegenen Bedeutung von Wissenschaft und Technik für die moderne Gesellschaft in Zusammenhang stehen.

Am deutlichsten wird dies erstens für den Bereich des Umweltschutzes. Wissenschaft und Technik bilden zwar von jeher die Grundlage der Aufklärung und der Industrialisierung, aber erst im Verlauf des 20. Jahrhunderts werden sie mehr und mehr zur unverzichtbaren Grundlage der Ökonomie, wobei die Grenzen zwischen Wissenschaft und Technik durch einen zunehmenden Handlungsbezug von Forschung verschwimmen. ${ }^{302} \mathrm{Ab}$ der Mitte des 20. Jahrhunderts werden dann die negativen externen Effekte der technologischen Entwicklung sichtbar, die Gesellschaft gefährdet sich selbst in einem Ausmaß, das die Fortexistenz der Menschheit in Frage stellt. ${ }^{303}$ Hatte die Industrialisierung die Entzauberung der bürgerlichen Gesellschaft zur Folge, weil die sozialen Verhältnisse nicht mehr als naturgegeben, sondern als strukturell bedingt und damit entscheidungsabhängig (kontingent) gedacht werden konnten, so hat die wissenschaftlich-technische Revolution die Situation insofern radikalisiert, als die Natur selbst entzaubert wurde und es damit prinzipiell nichts mehr gibt, was nicht entscheidungsabhängig wäre. Die Globalverantwortung des Sozialstaats für die wirtschaftliche, kulturelle und soziale Entwicklung erweitert sich dadurch um eine Globalverantwortung für die Sicherung der natürlichen Lebensgrundlagen - und zwar auch gegenüber zukünftigen Generationen. ${ }^{304}$ Bei der Lösung dieser Aufgabe ist der Staat zunehmend selbst auf Wissenschaft und Technik angewiesen. Denn diese gefährden nicht nur die natürlichen Lebensgrundlagen, sondern die Gefährdungen sind auch nur aufgrund von Wissenschaft und Technik wahrnehmbar und bearbeitbar. Das Schicksal des Staates wird dadurch unmittelbar mit dem Schicksal der modernen Wissenschaft verknüpft. ${ }^{305}$

Eine Steigerung des Sicherheitsbedürfnisses der Gesellschaft ergibt sich zweitens aus der zunehmenden funktionalen Differenzierung. Die Bildung hochspezialisierter Funktionssysteme (Wissenschaft, Wirtschaft, Recht, Politik, Erziehung, Gesundheit etc.) in der Gesellschaft führt einerseits zu einem Auseinanderdriften der Gesellschaft, also zu gesteigerten Independenzen, die die gesamtgesellschaftliche Integration zunehmend erschweren ${ }^{306}$. Gleichzeitig begründet die funktionale Differenzierung aber neue Interdependenzen, insofern die Subsysteme nicht nur intern immer höhere Komplexitätsstrukturen aufbauen, sondern auch die von ihrer Umwelt vorstrukturierte Komplexität voraussetzen und benutzen ${ }^{307}$. Die Wirtschaft kann nur deshalb immer unwahrscheinlichere Strukturen aufbauen, weil sie ein für sie in seiner Komplexität zwar nicht durchschaubares, für ihre Bedürfnisse aber funktionierendes Rechts-, Wissenschafts-, Gesundheitsoder politisches System voraussetzen kann, und gleiches gilt jeweils umgekehrt. In die-

recht, S.1338; N.Luhmann, Soziologie des Risikos, Berlin/New York 1991, Kap. 8; Willke, Ironie, S.291.

301 R.Rorty, Contingency, Irony, and Solidarity, Camebridge 1988, ch. 1; Z.Baumann, Moderne und Ambivalenz, Kap. 2 u. 3.

302 H.Willke, Ironie, S.273.

303 A.Gore, Earth in the Balance, Ecology and the Human Spirit, New York, London 1993.

304 Vgl. den durch Gesetz v. 27.10.1994 eingefügten Art. 20 a GG.

305 U.Beck, Risikogesellschaft, S.254ff.; ders., Gegengifte, S.115ff.

306 B.Peters, Die Integration moderner Gesellschaften, Ffm 1994.

307 H.Willke, Ironie, S. 60. 
sem komplex strukturierten System der funktionalen Differenzierung wird Information zu Macht und Kommunikation zur Überlebensstrategie. Die sich so herausbildende Informations- und Kommunikationsgesellschaft wird nicht nur immer sensibler gegenüber jeder Art von Gewalt (als Negation von Kommunikation), sondern insgesamt störanfälliger, soweit sich jedes spezialisierte Teil der Gesellschaft auf das Funktionieren jedes anderen Teils der Gesellschaft verlassen können muß308. Die "Funktionsfähigkeit des Gesamtsystems" bzw. einzelner Teilsysteme ist damit zu einem neuen - mitunter verfassungsrechtlich geschützten - Rechtsgut geworden, für dessen Sicherung der Staat einzustehen hat. ${ }^{309}$

Ein zunehmendes Sicherheitsbedürfnis ergibt sich drittens aus individueller Sicht aus der mit dem rapiden gesellschaftlichen Wandel und der Entwicklung von Wissenschaft und Technik einhergehenden Pluralisierung der Lebenswelten und Individualisierung der Lebensformen. Dort, wo alles nur noch entscheidungsabhängig gilt, wird Zukunft als Risiko erfahren ${ }^{310}$. Bei der Suche nach Entscheidungsmaßstäben hilft dem Individuum aber auch der Blick auf die Wissenschaft nicht mehr weiter. Denn nachdem diese zunächst alle überlieferten Werte und Autoritäten in Frage stellte, ist mit der Durchsetzung von Wissenschaft und Technik als generellem Problembewältigungsmuster die Wissenschaft selbst als objektive Instanz entzaubert worden, was als Zeichen eines Übergangs zur "Postmoderne" gewertet wird ${ }^{311}$. Die Wissenschaftsgesellschaft hat eine "Explosion des Wissens" bewirkt, wobei sich jeder einzelne im Rahmen der Spezialisierung auf den Punkt zubewegt, wo er "alles von nichts" weiß. Die Zunahme gesellschaftlichen Wissens hat aber entgegen aller Erwartung nicht zu mehr Sicherheit, sondern zu mehr Unsicherheit geführt, weil mehr Wissen auch mehr Wissen über das, was man nicht weiß, also mehr Unwissenheit zur Folge hat ${ }^{312}$. Mit der Zunahme von Wissen widerspricht sich die Wissenschaft zunehmend selbst. Wo etwa Experten und Gegenexperten über Risiken und Sicherheit streiten, wird die Kontextabhängigkeit allen Wissens offenbar. Die Erkenntnistheorie des radikalen Konstruktivismus ${ }^{313}$ wird so wie von selbst zum gesellschaftlichen Alltagswissen und Ironie zur Überlebensstrategie ${ }^{314}$. Wem aber die Ironie nicht liegt, der erfährt die Kontingenz der Wahrheit und die Ambivalenz der Werte, die Nichtfeststellbarkeit von Täterschaft, das Versagen der klassischen $\mathrm{Zu}-$

308 Das hat inzwischen auch der Terrorismus erkannt, der diese zunehmende Interdependenz ausnutzt, wenn nicht nur Strommasten abgesägt, sondern durch einige wenige Schnitte ins Datenkabelnetz ganze Flughäfen oder Wirtschaftszweige lahmgelegt werden.

309 So finden sich insbesondere im Strafrecht kollektive Rechtsgüter wie die "Funktionsfähigkeit des Kreditwesens" (§ 265b StGB), und die "Funktionstüchtigkeit der Strafrechtspflege" (BVerfGE 33, 367, 383; E 38, 105, 116), der Bundeswehr (E 28, 243 LS 2; E 32, 40, 46, E 48, 127, 159) etc. ist zum Verfassungsrechtsgut erhoben worden. Auch in der Wirtschaftspolitik ist staatliche Globalverantwortung für das Funktionieren von Systemen modern: Steuerungsobjekt ist der "Finanzplatz" (1.-3. Finanzmarktförderungsgesetz) oder gleich der "Standort Deutschland" insgesamt (Standortsicherungsgesetz).

310 Vgl. N.Luhmann, Soziologie des Risikos, Kap. 2.

311 J.F.Lyotard, Das postmoderne Wissen, Ffm 1986.

312 U.Beck, Risikogesellschaft, Kap. VII; E.Denninger, Technologische Rationalität, ethische Verantwortung und postmodernes Recht, KritV 1992, S.123-139, $131 \mathrm{f}$.

313 Eine Einfuihrung bei S.J.Schmidt, Der Radikale Konstruktivismus: Ein neues Paradigma im interdisziplinären Diskurs, in: ders. (Hrsg.), Der Diskurs des Radikalen Konstruktivismus, Ffm 1987, S.11-88.

314 R.Rorty, Contingency, Irony, and Solidarity, ch. 2. 
rechnungskategorien von Kausalität und Schuld, die "organisierte Unverantwortlichkeit"315 als "neue Unübersichtlichkeit"316 oder auch einfach als Chaos und gibt sein Bedürfnis nach einfachen Antworten, zuweilen philosophisch eingekleidet in die Wiederentdeckung des "Prinzip Verantwortung"317, oder verfassungstheoretisch über die Erfindung eines "Grundrechts auf Sicherheit"118, an einen starken Staat weiter, der angesichts des hilflosen Ertragenmüssens systemisch produzierter Risiken Abhilfe schaffen soll 319 .

Mit dieser Aufgabenbeschreibung verändert sich das Verhältnis zwischen Staat und Gesellschaft in radikaler Weise. Gab der liberale Staat Rahmenregelungen vor und sorgte der Sozialstaat für sozialen Ausgleich, so muß der Staat nunmehr in ungekanntem Ausmaß steuernd in die Gesellschaft eingreifen: Einen eingeschränkten Katalog von Staatsaufgaben gibt es nicht mehr ${ }^{320}$, prinzipiell jeder Sachverhalt ist der gesellschaftlichen (Re-) Konstruktion als Risiko zugänglich, und damit politisierbar ${ }^{321}$. Dem umfassenden Bedürfnis nach Sicherheit kann der Staat weder repressiv noch restitutiv, sondern nur präventiv begegnen. Sicherheit soll der Staat zum einen nicht mehr in Form von Rechtssicherheit durch nachträgliche Schadensregulierung (Strafe/Schadensersatz) bewirken, sondern in Form von Rechtsgütersicherheit ${ }^{322}$, indem er jegliche Rechtsgutgefährdung schon im Ansatz aufspürt und vorbeugend verhindert. Repression und Restitution versagen als Mittel staatlicher Politik zum anderen dort, wo entweder Täter und Kausalitäten nicht feststellbar sind oder aber die Schäden ein Ausmaß erreichen, das entweder vom Täter oder generell nicht finanziell ersetzbar ist. Wo die Institution des Schadensersatzes versagt, muß der Staat schon den Eintritt eines Schadens präventiv verhindern. Die mit dem so konstitutierten Präventionsstaat verbundene Eingriffsintensität ist erst ersichtlich, wenn man sich den Gegenstandsbereich präventiver Staatstätigkeit vor Augen führt. Einerseits werden die natürlichen Lebensgrundlagen potentiell von jedermann zu jeder Zeit gefährdet, Umweltverschmutzung ist die - häufig nichtintendierte - Nebenfolge nicht nur erlaubten, sondern prinzipiell erwünschten Verhaltens. Gleiches gilt für die Produktion anderer Risiken. Objekt präventiver Staatstätigkeit ist damit potentiell jedes mögliche Verhalten, und jedermann ist potentiell verdächtig. Andererseits ist im Bereich der Hochtechnologie (z.B. Atom- und Biotechnologie) sowie beim Schutz der Funktionsfähigkeit bestimmter Systeme (z.B. Datennetze) zwar der Kreis potentiell schädlicher Handlungen eingrenzbar, aber die Schadenshöhe erreicht

315 U.Beck, Gegengifte, S.96ff.

316 J.Habermas, Die neue Unübersichtlichkeit, Ffm 1985.

317 H.Jonas, Das Prinzip Verantwortung, Ffm 1979.

318 J.Isensee, Das Grundrecht auf Sicherheit, Berlin/New York 1983; G.Robbers, Sicherheit als Menschenrecht, Baden-Baden 1987.

319 So wird etwa im Anschluß an die Verantwortungsethik ein "Dispens der Demokratie" im Anschluß an die römische Institution der Diktatur auf Zeit, allerdings in weiser Nichterwähnung des Ermächtigungsgesetzes, diskutiert: H.Jonas, Philosophie. Rückschau und Vorschau am Ende des Jahrhunderts, Ffm 1993, S.41f.; vgl. auch die Beiträge in D.Böhler (Hrsg.), Ethik für die Zukunft. Im Diskurs mit Hans Jonas, München 1995.

320 Mangels materieller Abgrenzungskriterien ist deshalb vom "System der offenen Staatsaufgaben" die Rede, in welchem allein der Gesetzgeber darüber entscheidet, welche Aufgaben und gegebenenfalls in welcher Form er diese wahrnehmen will: vgl. dazu Zwischenbericht des Sachverständigenrats der Bundesregierung "Schlanker Staat" vom Januar 1996, S.6.

321 N.Luhmann, Soziologie des Risikos, S.171ff.

322 E.Denninger, Präventions-Staat, S.1. 
ein inakzeptables Ausmaß, so daß die staatliche Prävention so weit ins Vorfeld potentiell schädigender Handlungen verlegt wird, daß ebenfalls ganze Personengruppen und ganze Handlungsbereiche ins Blickfeld der Prävention geraten. Im Gegensatz zur traditionellen repressiven und restitutiven Staatstätigkeit, die auf vergangene Ereignisse, auf konkrete Angriffe gegen die Rechtsordnung und auf einzelne Personen (Störer) gerichtet war, ist Prävention zukunftsgerichtet, flächendeckend und gruppenrelevant ${ }^{323}$. Dabei ist der Staat häufig auf die Mitwirkung der Adressaten seiner Schutzpolitik angewiesen, weshalb er sich neben Macht und Geld zunehmend der Medien Information (Aufklärung) und Kommunikation (Verhandlungen) bedient ${ }^{324}$. Das rechtsstaatliche Problem der Begrenzung des Staates erhält mit der Prävention eine neue Aktualität. ${ }^{325}$

\section{Krisen des Rechts}

Aus dem so beschriebenen Wandel von Gesellschaft und Staatsaufgaben ergeben sich eine Reihe von Problemen, die hier unter den Begriffen der Krise des Rechtsstaats, der Krise des Sozialstaats und der Steuerungskrise des Rechts zusammengefaßt werden sollen. Diese Krisenphänomene zusammen münden in ein "regulatorisches Trilemma", welches Ausgangslage und Ursache der Umstellung auf ein prozeduralistisches Rechtsparadigma bildet.

\section{Die Krise des Rechtsstaats}

Eine sog. "Krise des Rechtsstaats" ist verschiedentlich ausgerufen worden, wenn die aktuelle Politik zu einer Beschneidung bestimmter zum Rechtsstaatsprinzip zugeordneter Rechte tendierte ${ }^{326}$ oder weil die gesellschaftspolitische Lage zu einem Schwund des Glaubens in die Legitimität kraft Legalität bzw. allgemein zu einer Krise der gesellschaftlichen Anerkennung des Rechtsstaats führte ${ }^{327}$. Jenseits solcher aktuellen Problemlagen soll der Begriff der "Krise des Rechtsstaats" hier ausschließlich der Bezeichnung jener strukturellen Krise der Kerninstitutionen des freiheitlichen Rechtsstaats vorbehalten sein, die mit dem grundlegenden Wandel der Funktion des Gesetzes für das gegenwärtige Rechtssystem einhergeht. ${ }^{328}$

323 D.Grimm, Prävention, S.39.

324 H.A.Hesse, Der Schutzstaat, S.46ff.; H.Willke, Ironie, S.262ff.; Vgl. die Beiträge in N.Dose/R.Voigt (Hrsg.), Kooperatives Recht, Baden-Baden 1995.

325 H.A.Hesse, a.a.O.; D.Grimm, Prävention, S.52ff; E.Denninger, Präventions-Staat, S.5ff; O.Backes, Kriminalpolitik ohne Legitimität, KritV 1986, S.315-342, 340ff; P.Alexis-Albrecht, Prävention als problematische Zielbestimmung im Kriminaljustizsystem, KritV 1986, S.55-82, 81.

$326 \mathrm{Vgl}$. z.B. die Kritik an der Beschneidung von Grundrechten durch eine "repressive Verwendung" der fdGO-Formel bei J.Fischer, Theorien zur Krise des freiheitlich-demokratischen Rechtsstaates, in: E.Denninger (Hrsg.), Freiheitliche demokratische Grundordnung, Bd. 1, IV., Ffm 1978, S.369-379, 370.

327 So etwa mit je wechselndem aktuellen Anlaß E.Benda: Der Rechtsstaat in der Krise, Stuttgart 1972, S.9-30 (anläßlich des aufkommenden Terrorismus); ders., Der soziale Rechtsstaat, in: Benda/Maihofer/Vogel (Hrsg.), Handbuch des Verfassungsrechts: 1.Aufl. 1983, S.501ff. (zum Terrorismus); 2.Aufl. 1994, S.746ff. (zum Rechtsextremismus sowie zur Enttäuschung der Ostdeutschen nach der Wiedervereinigung). Vgl. auch E.Schmidt-Aßmann, Rechtsstaat, S.987ff. (zu Sitzdemonstrationen und zivilem Ungehorsam).

328 Grundlegend dazu F.Neumann, Funktionswandel des Gesetzes; E.Forsthoff, Rechtsstaat im Wandel, Verfassungsrechtliche Abhandlungen 1950-1964, Stuttgart 1964, insbes. S.78ff., 147ff., $213 \mathrm{ff}$; I.Maus, Entwicklung; dies., Verrechtlichung, Entrechtlichung und der Funktionswandel von Insti- 
Das allgemeine, inhaltlich bestimmte, auf dauerhafte Geltung angelegte und demokratisch beschlossene Gesetz bildet den Dreh- und Angelpunkt der Idee vom freiheitlichen Rechtsstaat. ${ }^{329}$ Es ist in dreifacher Hinsicht Garant der Freiheit der Bürger: Es gewährt Rechtssicherheit, insofern die Grenzen der Freiheit klar umrissen und staatliche Eingriffe in diese Freiheit daher vorhersehbar sind; es gewährt Gleichheit in Form von Willkürfreiheit, indem es eine klare Trennung von Regelsetzung unter einem "Schleier des Nichtwissens" und strikt regelgebundener Entscheidung des Einzelfalls, also funktionale Gewaltenteilung ermöglicht; und es gewährt Gerechtigkeit, weil jede Freiheitsbeschränkung an die Zustimmung der Bürger geknüpft, also demokratisch legitimiert ist. 330

Das deutsche Rechtssystem hat diesem Ideal zu keiner Zeit entsprochen. ${ }^{331}$ Die Gesetzgebung des 19. Jahrhunderts war zunächst gar nicht und später nur in Ansätzen demokratisch, und der Grundsatz vom Vorbehalt des Gesetzes wurde nur sehr langsam verwirklicht. Das besondere Gewaltverhältnis als Ausnahme vom Gesetzesvorbehalt im Bereich der Eingriffsverwaltung entfaltete sogar noch bis in die zweite Hälfte des 20. Jahrhunderts hinein Wirkung. Weitere Beispiele ließen sich anführen. Dennoch kann man sagen, daß sich Gesetzgeber, Rechtsprechung und herrschende Rechtslehre bis zur Jahrhundertwende zumindest dem beschriebenen Ideal verpflichtet fühlten. ${ }^{332}$ Das 18./19. Jahrhundert war das Jahrhundert der großen systematischen Gesetzgebungswerke. Berühmtheit erlangten insbesondere das Allgemeine Preußische Landrecht, der französische Code civil ${ }^{333}$ und das Bayerische Strafgesetzbuch. Hiervon inspiriert erließ der Reichsgesetzgeber im Bereich des Straf- und Zivilrechts, aber auch für Teile des öffentlichen Rechts systematische Gesetzgebungswerke, die den Anspruch erhoben, die jeweilige Materie in materieller und formeller Hinsicht lückenlos, widerspruchsfrei und dauerhaft zu regeln. Diese Gesetze enthielten ausschließlich abstrakt-generelle Regeln, was ein Grund dafür sein mag, daß sie im wesentlichen noch heute fortgelten. Zudem wurde großer Wert auf begriffliche Präzision gelegt, so daß die Gesetze auch inhaltlich bestimmt waren. Im RStGB hat man auf Generalklauseln gänzlich verzichtet, im BGB hat man sie auf ein Minimum begrenzt. Lediglich im Bereich der öffentlich-rechtlichen Gefahrenabwehr hatten Generalklauseln eine größere Bedeutung. War der Gesetzgeber in diesem Sinne um "gute Gesetze" bemüht, so hielt sich die Rechtsprechung an das Ideal der strikten Gesetzesbindung. Die herrschende Interpretationslehre war im oben

tutionen, in: dies., Rechtstheorie und politische Theorie im Industriekapitalismus, München 1986, S.277-331; D.Grimm, Prävention, S.38ff.; ders., Wandel; K.Günther, Wandel der Staatsaufgaben, S.51ff.; E.Denninger, Präventions-Staat, S.1ff; ders., Technologische Rationalität, S.123ff.; E.W.Böckenförde, Grundrechte als Grundsatznormen, in: ders., Recht, Freiheit, Staat, Ffm 1991, S.189ff.; J.Habermas, FuG, S.519ff.

329 D.Grimm, Wandel, S.295; s.o. II. 1. und 3.; III. 1. und 2.

330 Zur Rechtssicherheit E.Denninger, Präventions-Staat, S. I, 3f.; zur Demokratie vgl. I.Maus, Sinn und Bedeutung von Volkssouveränität in der modernen Gesellschaft, KJ 1991, S.137-150; ein guter Überblick über Funktionen von und Anforderungen an gute Gesetze, sowie die verschiedenen Abweichungen von diesem Ideal findet sich bei R.Dreier, Mißlungene Gesetze, in: U.Diederichsen/R.Dreier (Hrsg.), Das mißglückte Gesetz, Göttingen 1997, S.1-16.

331 F,Neumann, Funktionswandel des Gesetzes, S.49ff.

332 F.Wieacker, Privatrechtsgeschichte, S.545ff.; D.Grimm, Recht und Staat der bürgerlichen Gesellschaft, Ffm 1987, S. 11 ff.; R.Ogorek, Richterkönig oder Subsumtionsautomat? Zur Justiztheorie im 19. Jahrhundert, Ffm 1986.

$333 \mathrm{Zu}$ dessen Bedeutung vgl. M.Weber, WuG, Zweiter Teil, Kap. VII (Rechtssoziologie), § 7. 
beschriebenen Sinne formal, Auslegung contra legem und richterliche Rechtsfortbildung waren verpönt, und die etwa im BGB vorhandenen Generalklauseln spielten in der Rechtsprechung des Reichsgerichts zunächst kaum eine Rolle ${ }^{334}$. Ein richterliches Prüfungsrecht hinsichtlich der Verfassungsmäßigkeit der Gesetze wurde nicht in Anspruch genommen. 335

Diese Situation änderte sich in der Weimarer Zeit. Zwar war die Weimarer Gesetzgebung erstmals eine wirklich demokratische, allerdings wurde diese Umstellung schon bald durch die zunehmende Bedeutung der Notstandsgesetzgebung ausgehöhlt. Wesentlicher war aber eine Änderung der Form der Gesetze. Die mit dem neuen Selbstverständnis als Sozialstaat einhergehende Aufgabenerweiterung des Staates führte dazu, daß Gesetzgebung weniger als die Regelung der grundlegenden Fragen des Zusammenlebens verstanden, sondern als Mittel zur aktiven Steuerung der gesellschaftlichen Entwicklung benutzt wurde. ${ }^{336}$ Das Ziel der Steuerung (social engineering) veränderte aber die Form der Gesetze, denn einerseits mußten immer größere und kompliziertere Bereiche einer gesetzlichen Regelung zugeführt werden, andererseits bedurfte Gesellschaftssteuerung der flexiblen Reaktion auf konkrete Krisensituationen und einer ständigen Nachsteuerung.

Die Allgemeinheit des Gesetzes wurde durch das Auftreten sog. "Maßnahmegesetze" aufgelöst. Solche Gesetze, die eine sich selbst vollziehende, planmäßige Entscheidung aus Anlaß und mit Wirkung für einen konkreten Einzelfall beinhalten ${ }^{337}$, wurden üblich ${ }^{338}$, weil der Gesetzgeber zunehmend soziale Krisenintervention betrieb, die entsprechenden Gesetze also gar nicht mehr auf allgemeine und dauerhafte Geltung angelegt waren ${ }^{339}$. Bei komplexen Materien bediente sich der Gesetzgeber zunehmend unbestimmter Begriffe, wenn er Zweifel hegte, daß eine detaillierte gesetzliche Regelung in einem Rechtsgebiet eine für alle künftigen Fälle lückenlose und gerechte Lösung bereithalten könnte. Auf den sich beschleunigenden sozialen Wandel reagierte er entweder als "motorisierter Gesetzgeber" 340 durch ständige Reformgesetzgebung oder durch die "Flucht in die Generalklausel"341, indem er die Nachsteuerung im Detail an Verwaltung und Rechtsprechung delegierte.

334 Ausführlich mit Nachweisen G.Teubner, Standards und Direktiven in Generalklauseln, Ffm 1971.

335 D.Grimm, Wandel, S.294.

336 J.Habermas, Theorie des kommunikativen Handelns, Bd. 2, S.505ff.

337 So die Definition bei K.Huber, Maßnahmegesetz und Rechtsgesetz, Berlin 1963, S.121.

338 K.Huber, a.a.O., S.128 mit FN 6, kommt zu dem Ergebnis, daß die Hälfte aller Gesetze in der Bundesrepublik Maßnahmegesetze sind. Zur rechtsstaatlichen Kritik vgl. a.a.O., S. 128, 155; und K.Zeidler, Maßnahmegesetz und "klassisches" Gesetz, 1961; E.Forsthoff, Über Maßnahme-Gesetze, in: ders., Rechtsstaat im Wandel, S. 78ff.; M.Kloepfer, Gesetzgebung im Rechtsstaat, VVDStRI 1982 , S. $63 \mathrm{ff}, 97$.

339 Die Maßnahmeform ist deshalb als die für den Sozialstaat typische Rechtsform bezeichnet worden: G.v.Halle, Verrechtlichungs- und Bürokratisierungstendenzen im Sozialstaat, Diss. Berlin 1990, S.82ff. m.w.N.

340 Vgl. C.Schmitt, Die Lage der europäischen Rechtswissenschaft (1943/44), in: ders., Verfassungsrechtliche Aufsätze, 2. Aufl., Berlin 1973, S.386-429, $404 \mathrm{ff}$.

341 J.W.Hedemann, Flucht in die Generalklauseln. 


\section{Exkurs: Generalklausel und Maßnahmegesetz als materiale Normen}

Eine Generalklausel kann zwei grundverschiedene Funktionen haben ${ }^{342}$. Sie kann entweder einen Verweis auf nichtrechtliche, gesellschaftliche Normen beinhalten, die ergänzend zum positiven Recht gelten, vom Richter aber nur erkannt und angewandt werden (Standard), oder aber sie kann als Ermächtigung des Verwaltungsbeamten oder Richters verstanden werden, etwaige Gesetzeslücken oder Unstimmkigkeiten des Gesetzes in einem auch schöpferischen Akt durch eine gerechte Lösung zu beseitigen (Direktive) ${ }^{343}$. Die schon in den systematischen Gesetzgebungswerken der Kaiserzeit enthaltenen Generalklauseln ( $\S \S 138,242,826$ BGB, 1 UWG, 346 HGB) verstanden sich entsprechend dem liberalen Gesellschaftsbild als Standards. Diese beinhalteten eine bloße Verweisung auf die bestehende Vertrags-, Verkehrs- und Geschäftsmoral, die ebenso wie die Ergebnisse des Marktmechanismus selbst als gerecht galten. Mit dem Übergang zum sozialen Interventionsstaat und der einhergehenden Materialisierung des Rechts im 20. Jahrhundert erfuhren die Generalklauseln allerdings eine Umdeutung. Das Vertrauen in die Selbstregulierungskräfte der industriellen Massengesellschaft war verlorengegangen, Vertrag und freier Wettbewerb erschienen angesichts der Vermachtung der Märkte als Instrumente der Herrschaft ${ }^{344}$. Die Generalklauseln wurden daher als Direktiven interpretiert, die der Rechtsprechung ermöglichen, durch wert- und moralbezogene Betrachtungen das konstatierte Marktversagen zu korrigieren und durch eine gerechte Lösung zu ersetzen. Die Argumentationen der Rechtsprechung wurden in diesem Zusammenhang immer offensichtlicher politisch, d.h. mehr normbegründend als normanwendend $^{345}$.

Anhand der Generalklausel als Direktive kann nunmehr der Begriff der materialen Norm als Kennzeichen einer material-rationalen Rechtsordnung erläutert werden. Eine formale Norm wurde definiert als eine allgemeine, inhaltlich bestimmte und auf dauerhafte Geltung angelegte Regel. Ein formal-rationales Rechtssystem baut zudem auf der Unterscheidung zwischen formellem und materiellem Recht auf. Das Legitimationsmodell des demokratischen Rechtsstaats steht und fällt nun mit der Unterscheidbarkeit von formellem und materiellem Recht, da ein System der funktionalen Gewaltenteilung die Abgrenzbarkeit von Kompetenzen voraussetzt. Kennzeichnend für eine materiale Norm ist dagegen die Hintergehung dieser Kompetenzordnung durch eine Aufhebung der Unterscheidung von formellem und materiellem Recht. Genau dies ist aber die Folge der Generalklausel. Sie ist Bestandteil des materiellen (inhaltlichen) Rechts, ohne dessen formale Qualitäten zu erfülen, da es sich um eine unbestimmte Norm handelt. Der materielle normative Gehalt der Generalklausel wird erst im Einzelfall vom Richter festgelegt, weshalb die Generalklausel als Direktive eine Kompetenzzuweisung an den Rechtsanwender beinhaltet, ohne als Ermächtigungsnorm (formelles Recht) in Erscheinung zu treten.

342 Zur Generalklausel vgl. R.Dreier, Generalklausel, in: Staatslexikon Bd. 2, hg. v. der Görres-Gesellschaft, 7. Aufl., Freiburg/Basel/Wien 1986, S.1059-1063; zu weiteren Funktionen vgl. auch F.Neumann, Funktionswandel des Gesetzes, S.62ff. (Sicherung des Einflusses mächtiger Interessengruppen auf die Rechtsanwendung), sowie E.Denninger, Präventions-Staat, S.7 (Dynamischer Grundrechtsschutz: BVerfGE 49, 89).

$343 \mathrm{Vgl} \mathrm{G.Teubner,} \mathrm{Generalklauseln.}$

344 F.Wieacker, Privatrechtsgeschichte, S.545ff., $620 \mathrm{ff}$.

345 G.Teubner, Generalklauseln, S.56ff. 
Während die Generalklausel die durch die Unterscheidung von formellem und materiellem Recht begründete Trennung zwischen Normbegründung und Normanwendung unterläuft, indem sie als unbestimmte Norm Normbegründungskompetenzen auf den Rechtsanwender überträgt, hat das Maßnahmegesetz eine Kompetenzverschiebung in umgekehrter Richtung zur Folge. Durch den Erlaß eines individuell-konkreten Aktes maßt sich der grundsätzlich nur für Normbegründungsfragen zuständige Gesetzgeber Kompetenzen der rechtsanwendenden Gewalten an und unterläuft so ebenfalls die Gewaltenteilung. Die freiheitsverbürgende Funktion des Gesetzes wird dadurch aufgehoben, indem der "Schleier des Nichtwissens", der eine unparteiliche Normbegründung garantieren soll, gelüftet wird. Maßnahmegesetze werden mit "Ansehen der Person" beschlossen und sind daher im Sinne von Kant despotisch.

Während eine formale Norm inhaltlich bestimmt, allgemein und auf Dauer angelegt ist, ist eine materiale Norm also unbestimmt, konkret und kurzlebig.

\begin{tabular}{|c|c|c|}
\hline Normen & formelles Recht & materielles Recht \\
\hline formal-rational & $\begin{array}{c}\text { Zuständigkeit, } \\
\text { Form, Verfahren }\end{array}$ & $\begin{array}{c}\text { inhaltlich bestimmt, } \\
\text { allgemein, dauerhaft }\end{array}$ \\
\hline material-rational & \multicolumn{2}{|c|}{$<--------$----konbestimmt (Generalklausel) } \\
& \multicolumn{2}{|c|}{ <----oßnahmegesetz) } \\
\hline
\end{tabular}

Generalklausel und Maßnahmegesetz können daher als materiale Normen bestimmt werden, die wegen fehlender Allgemeinheit oder Verstoß gegen das Bestimmtheitsgebot zugleich materielle und formelle Normen sind, da sie das vorgesehene Kompetenzgefüge der funktionalen Gewaltenteilung unterlaufen.

[Ende des Exkurses]

Die so veränderte Gesetzgebung hat Auswirkungen auf die Gesetzesbindung der Exekutive und Judikative. Denn unbestimmte Normen entfalten wenig Bindungskraft und nötigen den Rechtsanwender, seine Entscheidungsmaßstäbe außerhalb des Gesetzes zu suchen. Das gilt selbst dort, wo der Gesetzgeber auf den ersten Blick detaillierte Regelungen getroffen hat. Denn zunehmend werden solchen Gesetzen einleitende Zielformeln vorangestellt, die eine Relativierung der folgenden Einzelvorschriften im Wege der Auslegung erlauben. Zur Ermöglichung von Einzelfallgerechtigkeit oder - etwa im technischen Sicherheitsrecht - zur Bewirkung eines dynamischen Grundrechtsschutzes $^{346}$ werden häufig Generalklauseln eingefügt, die es im Ergebnis freistellen, ob eine konkrete Entscheidung aus dem Gesetz oder über die Generalklausel unter Rückgriff auf außergesetzliche Wertungsmaßstäbe begründet wird (duale Legistik ${ }^{347}$ ). Weil die Formalität eines Gesetzbuches so schon durch eine einzige Generalklausel aufgehoben werden kann, besteht das paradoxe Phänomen einer fortschreitenden Entrechtlichung trotz allseits beklagter Verrechtlichung ${ }^{348}$.

346 E.Denninger, Präventions-Staat, S.7; gemeint ist die Formel "Stand von Wissenschaft und Technik".

347 Zur Kritik am System der dualen Legistik (entweder Generalklausel oder Kasuistik) vgl. H.Hill, Gesetzesgestaltung und Gesetzesanwendung im Leistungsrecht, in: VVDStRL Heft 47 (1989), S.172ff, 173; ders., Bemühungen zur Verbesserung der Gesetzgebung, ZG 1993, S.1-11, 8, m.w.N.

348 I.Maus, Verrechtlichung, S.278, die angesichts der Kombination von Präzision und Unbestimmtheit von "Gesetzesatrappen" spricht. 
Andererseits führt die Fülle von gesetzlichen Detailregelungen ("Normenflut"349) zur Unübersichtlichkeit des Normensystems und damit zu vermehrten systematischen Widersprüchen, Normkonflikten und Auslegungsproblemen. Angesichts einer Vielzahl von teils parallel anwendbaren, teils in einem Stufenverhältnis zueinander stehenden Normen gerät die Frage nach dem für einen konkreten Fall geltenden Recht in den Bereich des beliebig Begründbaren. Im Dickicht der Satzungen, Rechtsverordnungen, Landesgesetze, Bundesrahmengesetze, verfassungsrechtlichen Vorgaben bis hin zu unter Umständen auch unmittelbar geltenden europarechtlichen Richtlinien läßt sich eine Norm unschwer gegen die andere ausspielen, so daß man unter der Geltung des allgegenwärtigen Verhältnismäßigkeitsprinzips unversehens bei einer gerechten Abwägung aller betroffenen Interessen endet, in die die verschiedenen Normen nur noch als Abwägungsgesichtspunkte einfließen. ${ }^{350}$ In Verbindung mit der schnellebigen, wenig überdachten und im Rahmen der föderalistischen Abstufung ungleichzeitigen, häufig von gegensätzlichen politischen Willen getragenen Reformgesetzgebung einer sozialtechnologischen Gesellschaftssteuerung ${ }^{351}$ verliert das Gesetz an normativer Autorität ${ }^{352}$. Über die fehlende Bindungskraft unbestimmter Gesetze hinaus begegnet die Rechtsprechung im Rahmen der "Materialisierung des Rechts" den Gesetzen daher auch dort anders, wo diese relativ klare Vorgaben enthalten (sog. "Wertungsjurisprudenz") ${ }^{353}$.

Die strikte Bindung von Verwaltung und Rechtsprechung an das Gesetz impliziert zudem, daß eine dem Subsumtionsideal entsprechende Bindung der Rechtsanwender durch Gesetzestexte theoretisch überhaupt möglich ist. Hatte schon die Interessenjurisprudenz entdeckt, daß eine wertneutrale Rechtsanwendung nicht möglich ist und daß

349 Vgl. dazu die Beiträge von H.Maassen, D.Simon, E.Bülow, H.Simon und S.Simitis, in: Gesetzesflut - Gesetzesperfektionismus, Verhandlungen des 53. Deutschen Juristentages Bd. II, Sitzungsbericht Q, München 1980; K.Eichenberger, R.Novak, M.Kloepfer, Gesetzgebung im Rechtsstaat, VVDStRL Heft 40 (1982); N.Huber, Rechts- und Verwaltungsvereinfachung - Notwendigkeit und Strategien der Effektivierung und Rationalisierung rechtlicher Steuerung, Diss. Mannheim 1990, S. 1-19 m.w.N., der wegen der Ursachen allerdings etwas kurzsichtig auf die Ausdehnung des Gesetzesvorbehalts durch die Wesentlichkeitstheorie des BVerfGs abstellt, ohne die Probleme der anwachsenden Staatsaufgaben zu sehen; R.Holtschneider, Normenflut und Rechtsversagen: wie wirksam sind rechtliche Regelungen?, Baden-Baden 1991, mit Nachweisen aus der umfangreichen Debatte; allein der Bestand des geltenden Bundesrechts beläuft sich derzeit auf 1928 Gesetze und 2946 Rechtsverordnungen mit insgesamt über 84900 Einzelvorschriften (Quelle: Datenbank JURIS), zitiert nach dem Zwischenergebnis (Januar 1996) der Arbeit des Sachverständigenrates "Schlanker Staat", der 1995 unter Leitung von Rupert Scholz bei der Bundesregierung eingesetzt wurde.

350 So konkurrieren beispielsweise im Bereich des Gewässerschutzes das bundesrahmenrechtliche, teils unmittelbar anwendbare Wasserhaushaltsgesetz mit landesrechtlichen Wassergesetzen und Bodenschutzgesetzen, mit europäischen Richtlinien und deutschen Verordnungen über Trinkwasser sowie mit zivil- und öffentlichrechtlichen Regelungen der Gefährdungshaftung.

351 So sind selbst so zeitlose Gesetze wie z.B. die StPO und die ZPO allein von 1990 bis 1994 jeweils durch 19. verschiedene Gesetze, also knapp fünfmal pro Jahr geändert worden. Insbesondere mit den Gesetzen zur Vereinfachung und Entlastung der Rechtspflege waren dabei derart unüberlegte Eingriffe in die Gesamtstruktur des Verfahrensrechts verbunden, daß contra-legem-Auslegungen allseits anerkannt mit den Argumenten "Der Gesetzgeber wollte nicht, was er gesagt hat", oder "Der Gesetzgeber hat die Anpassung der Vorschrift X an die Änderung der Vorschrift $Y$ schlicht vergessen" begründet werden müssen. Durch tägliche Arbeit in der Rechtspraxis verfestigt sich so die Ansicht "Der Gesetzgeber weiß nicht, was er tut".

352 E.Denninger, Präventions-Staat, S.7f.; J.Habermas, FuG, S.521f.

353 Vgl. dazu und zum Folgenden K.Larenz, Methodenlehre, Kap. 1: Die Methodendiskussion in der Gegenwart; J.Habermas, FuG, Kap. V. 
deshalb bei Auslegungsfragen auch die hinter den begrifflichen Problemen liegenden gesellschaftlichen Interessen zu berücksichtigen sind, so wies die Freirechtsschule darauf hin, daß richterliche Rechtsschöpfung nicht die Ausnahme sondern eher die Regel ist, weil das positive Gesetz "mehr Lücken als Worte" enthält. Besonders gründlich ist die Gesetzesbindung durch die juristische Hermeneutik in Frage gestellt worden. Danach setzt jede Textinterpretation, auch die eines inhaltlich bestimmten Gesetzes, ein Vorverständnis voraus, so daß der Interpret aus einem Text nur das herausholen kann, was er zuvor in diesen hineingelegt hat (hermeneutischer Zirkel) ${ }^{354}$. Die Herrschaft des Gesetzes wird damit zur Illusion. ${ }^{355}$

Derart theoretisch abgesichert wurde die Aufgabe der Rechtsprechung zunehmend in der Suche nach einer gerechten Entscheidung des Einzelfalls gesehen, wobei die Maßstäbe der Entscheidung mangels gesetzlicher Bindung im Rückgriff auf objektive Werte bestimmt wurden, welche sich aus der Verfassung, insbesondere aus den Grundrechten ergeben. Nach der Wertordnungstheorie des BVerfG haben Verwaltungsbehörden und Gerichte bei der Auslegung und Anwendung der Gesetze in jedem Einzelfall eine am Verhältnismäßigkeitsgrundsatz orientierte Güterabwägung vorzunehmen. ${ }^{356}$ Dadurch wird den rechtsanwendenden Instanzen ermöglicht, die im Gesetz enthaltene Güter- und Interessenabwägung des Gesetzgebers im Einzelfall zu hinterfragen und gegebenenfalls auch gegen den Wortlaut des Gesetzes aufzuheben. Die solchermaßen grob umrissene Wertjurisprudenz eröffnet dem Rechtsanwender ein Maß an Freiheit im Umgang mit dem Gesetz, welches die Folgen der Unbestimmtheit der Gesetzgebung selbst bei weitem übertrifft. ${ }^{357}$ Diese Freiheit wird im übrigen nicht nur durch den Bezug des Rechts zu materialer Gerechtigkeit begründet, sondern auch funktional mit dem Argument abgestützt, daß der rapide soziale Wandel ein flexibles Reagieren auf neue gesellschaftliche Problemlagen erfordere, ohne daß im Einzelfall auf eine Reaktion des ohnehin überforderten Gesetzgebers gewartet werden könne ${ }^{358}$.

Hat die richterliche Rechtsfortbildung gegen den Wortlaut des Gesetzes aber noch prinzipielle Grenzen ${ }^{359}$, so verschärft sich die Problematik durch die Kompetenz des BVerfG zur Überprüfung der Verfassungsmäßigkeit der Gesetze, wenn das Verfassungsgericht die Wertabwägungen des Gesetzgebers teilweise bis ins Detail hinein anhand der objektiven Wertordnung überprüft und durch eigene Wertabwägungen ersetzt. Soweit das BVerfG das Grundgesetz als "juristisches Weltenei (benutzt), aus dem alles hervorgeht, vom Strafgesetzbuch bis zum Gesetz über Fieberthermometer" 360 , führt dies

354 H.G.Gadamer, Wahrheit und Methode, Grundzüge einer philosophischen Hermeneutik, 4. Aufl. 1975; J.Esser, Vorverständnis und Methodenwahl in der Rechtsfindung, Ffm 1970; U.Schroth, Philosophische und juristische Hermeneutik; vgl. auch die Diskussion bei J.Habermas, FuG, Kap. V.

355 D.Simon, Die Unabhängigkeit des Richters, 1975, S.88; ähnlich W.Hassemer, Rechtssystem und Kodifikation.

356 Darstellung bei R.Alexy, Grundrechte, bes. Kap. 3 u. 10.

357 I.Maus, Verrechtlichung, S.278.

358 So z.B. selbst für den besonders sensiblen Bereich des Strafrechts BVerfGE 73, 206 (235); vgl. auch R.Dreier, Rechtsstaat, S.87.

359 BVerfGE 35, 263, 278ff.; 37, 67, 81; 38, 386, 396f.; 65, 182, 190ff.; 82, 6, 11 ff.; vgl. Wiethölter, Rechtsfortbildung, S.7ff.

360 So die Kritik bei E.Forsthoff, Umbildung; ders., Der Staat der Industriegesellschaft, München 1971, S.126ff. 
zur Entmündigung des Gesetzgebers, zum Übergang vom Rechtsstaat zum Justizstaat ${ }^{361}$. Denn unter dem Verhältnismäßigkeitsgrundsatz wird Gesetzgebung zum richterlich überprüfbaren Verfassungsvollzug reduziert, während gleichzeitig Verfassungsrechtsprechung von der Normanwendung zur schöpferischen Normkonkretisierung aufgewertet wird. Der qualitative Unterschied zwischen Gesetzgebung und Verfassungsrechtsprechung wird dadurch eingeebnet. ${ }^{362}$ Selbst bei wohlwollender Betrachtungsweise sind damit evidente Gewichtsverschiebungen im Gewaltenteilungssystem in Richtung der Judikative verbunden, die in dem Verweis auf das Prinzip der richterlichen Selbstbeschränkung ${ }^{363}$ eine bestenfalls vorläufige Antwort gefunden haben ${ }^{364}$. Die Kritik an der verfassungsrichterlichen Normenkontrolle, die über das Institut des "dissenting vote" schon Eingang in die Verfassungsrechtsprechung selbst gefunden hat ${ }^{365}$, ist inzwischen weit verbreitet ${ }^{366}$ und beschränkt sich keinesfalls nur auf ein politisches Lager ${ }^{367}$.

Auf die Verwaltung haben die beschriebenen Veränderungen ambivalente Auswirkungen. Die im Kern politisch handelnde Verwaltung war ursprünglich in doppelter Weise an das demokratische Parlament zurückgebunden: Die durch Vorrang und Vorbehalt des Gesetzes gesicherte Rechtmäßigkeit des Verwaltungshandelns unterlag der repressiven Kontrolle durch die Verwaltungsgerichte (Individualrechtsschutz), während die $Z$ weckmäßigkeit des Verwaltungshandelns politisch über die Fachaufsicht sichergestellt wurde (Ministerverantwortlichkeit). Eine gerichtliche Rechtmäßigkeitskontrolle setzt nun justitiable, d.h. hinreichend bestimmte Normen voraus. Die prospektiv und flächendeckend wirkende präventive Staatstätigkeit läßt sich aber gedanklich nicht vollständig vorwegnehmen und kann daher nur begrenzt in Konditionalprogrammen eingefangen werden. Präventionsnormen beschränken sich deswegen auf die Vorgabe von

361 Vgl. dazu schon oben III. 3. zur Materialisierung des Rechtsstaats; vgl. auch I.Maus, Aufklärung, Anhang S.298ff.

362 E.W.Böckenförde, Grundrechte als Grundsatznormen, S.189ff.; Daß die logische Struktur von Abwägungsentscheidungen der von Normbegründungsdiskursen gleicht, hat R.Alexy erhellt (Grundrechte, S.79ff, 83f.). Nach dem "Kollisionsgesetz" ist Ergebnis der Abwägung zwischen kollidierenden Prinzipien (Interessen, Werten) nämlich eine definitive Regel, nach der unter den Umständen a 1 bis a n (Tatbestand), die Rechtsfolge des vorgehenden Prinzips ausgesprochen wird.

363 R.Dreier, Rechtsstaat, S.87; G.F.Schuppert, Self-restraints der Rechtsprechung - Überlegungen zur Kontrolldichte in der Verfassungs- und Verwaltungsgerichtsbarkeit, DVB1. 1988, S.1191-1200; C.Starck, Das Bundesverfassungsgericht im politischen Prozeß der Bundesrepublik Deutschland, Tübingen 1976, S.12f.; Zum amerikanischen Begriff des Judicial Self-Restraint vgl. K.L.Hall (Ed.), The Oxford Companion to the Supreme Court of the United States, New York, Oxford 1992, S.470f.

364 Vgl. E.Denninger, Verfassungsrechtliche Schlüsselbegriffe, in: ders., Der gebändigte Leviathan, Baden-Baden 1990, S.174ff.; D.Grimm, Die Zukunft der Verfassung, Ffm 1991; J.Habermas, FuG, Kap. VI.; Giovanni Biaggini, Verfassung und Richterrecht, Basel/Ffm 1991.

365 Dissenting vote Böckenförde/Mahrenholz, BVerfGE 69, 1 (58ff).

366 Ein Überblick bei Ki-Cheol Lee, Schonung des Gesetzgebers bei Normenkontrollentscheidungen durch das Bundesverfassungsgericht. Eine verfassungstheoretische Betrachtung von Kompetenzstreitigkeiten, Diss. Göttingen 1993, insbes. Abschn. III. m.w.N.

367 So aber noch D.Grimm (Reformalisierung, S.709), der der Kritik am BVerfG der siebziger Jahre Linkslastigkeit unterstellt, weil mehrere sozialliberale Reformvorhaben verhindert wurden. Der universelle Rollentausch (hier zwischen Regierung und Opposition) hat inzwischen auch dieses Problem gelöst, die aktuelle Kritik (z.B. Kruzifixurteil; Soldaten-sind-Mörder-Urteil; Sitzdemonstrationen II) kommt vornehmlich von rechts. Unabhängig von aktuellen Betroffenheiten scheint ein wahrer Kern an der Kritik zu sein: so jetzt auch D.Grimm, Wandel, S.296. 
Zielen und die Aufzählung von Gesichtspunkten, die bei der Zielverfolgung vorrangig berücksichtigt werden sollen (Zweckprogramme). ${ }^{368}$

Da solche Normen nicht vollziehbar sind, sondern der situativen Vervollständigung und Korrektur durch gerechte Abwägung der betroffenen Belange im Einzelfall bedürfen, programmiert sich die präventiv tätige Verwaltung weitgehend selbst ${ }^{369}$. Der damit verbundenen Gefahr der Verselbständigung der Verwaltung gegenüber dem Gesetzgeber sowie des Leerlaufs des Individualrechtsschutzes ist die Rechtsprechung zunächst durch eine Erhöhung der Kontrolldichte begegnet, indem die präventiven Zweckformeln als unbestimmte Rechtsbegriffe verstanden wurden, deren Auslegung und Anwendung durch die Behörden gerichtlich voll überprüfbar ist. Der Verwaltung eingeräumte Ermessensspielräume wurden über den Verhältnismäßigkeitsgrundsatz zunehmend "auf Null reduziert". Das Problem der fehlenden Vorhersehbarkeit staatlichen Handelns blieb dadurch allerdings ungelöst, das System der Rechtssicherheit wurde über den Anspruch auf umfassenden gerichtlichen Rechtsschutz durch ein System der Rechtsgütersicherheit ersetzt. ${ }^{370}$ Das Legitimationsproblem einer Verselbständigung gegenüber dem demokratischen Gesetzgeber wurde lediglich von der Verwaltung auf die Rechtsprechung verlagert. 371

Mit der intensiven gerichtlichen Kontrolle anhand des Verhältnismäßigkeitsgrundsatzes war zudem eine Usurpation politisch-gestaltender und naturwissenschaftlichbeurteilender Funktionen der Verwaltung durch die Gerichte verbunden. ${ }^{372}$ Denn mit den Kriterien der Geeignetheit und Erforderlichkeit wurde die ursprünglich der politischen Fachaufsicht vorbehaltene Überprüfung der Zweckmäßigkeit des Verwaltungshandelns zum Bestandteil der Rechtmäßigkeitskontrolle. Ein eigenständiger Bereich des gerichtlich nicht voll überprüfbaren Handelns wurde den Behörden erst später über den Begriff der "Verwaltungsverantwortung" eingeräumt. ${ }^{373}$ Die Rechtsprechung befindet sich im Bereich präventiven Staatshandelns daher in dem Dilemma, entweder eine weitgehende Selbstprogrammierung der Verwaltung hinzunehmen, oder aber selbst politisch verwaltend tätig zu werden und dadurch die Überstrapazierung ihrer Legitimationsbasis in Kauf zu nehmen.

Die so beschriebenen Versatzstücke der Flexibilisierung und Materialisierung des Rechts führen zusammengenommen zu einer tiefgreifenden Strukturkrise des demokratischen Rechtsstaats, die sich aus der Aufhebung, mindestens aber aus der Relativierung

368 D.Grimm, Prävention, S.39f.; ders., Wandel, S.299f.

369 I.Maus, Verrechtlichung, S.283ff. mit Beispielen; W.Brohm, Zum Funktionswandel der Verwaltungsgerichtsbarkeit, NJW 1984, S.8-14; ders., Situative Gesetzesanpassung durch die Verwaltung, NVwZ 1988, S.794-799; W.Hoffmann-Riem, Selbstbindungen der Verwaltung, VVDStRL 1982, S.187-239.

370 E.Denninger, Präventions-Staat, S.7.

371 R.Dreier, Rechtsstaat; J.Habermas, FuG, Kap. V.

372 Vgl. J.Burmeister, Grundgesetzliche Verfahrensstrukturierungsgebote, S.123.

373 W.Brohm, Die staatliche Verwaltung als eigenständige Gewalt und die Grenzen der Verwaltungsgerichtsbarkeit, DVwB1 1986, S.321ff.; G.Püttner/F.Kopp/O.Kaufmann, Handlungsspielräume der Verwaltung und Kontrolldichte gerichtlichen Rechtsschutzes, in: Götz/Klein/Starck (Hrsg.), Die öffentliche Verwaltung zwischen Gesetzgebung und richterlicher Kontrolle, 1985, S.13Iff.; H.J.Papier, Zur verwaltungsgerichtlichen Kontrolldichte, DÖV 1986, S.621ff.; vgl. auch schon R.Scholz, Verwaltungsverantwortung und Verwaltungsgerichtsbarkeit, VVDStRL 1975, S.145ff.; Ein solcher Vorbehalt der Verwaltung für bestimmte Bewertungen wird anerkannt von BVerwG, NVwZ 1986, S.208ff. 
der Herrschaft des Gesetzes ergibt. Der Kern allen rechtsstaatlichen Denkens, das vernunftrechtliche Postulat nach einer "rule of laws, and not of men", das über das sachliche, zeitliche und soziale Auseinanderziehen von Regelsetzung und gebundener Anwendung das unparteiliche Entscheiden "ohne Ansehen der Person" verwirklichen soll, wird seines ursprünglichen Sinns in einem "System der polyzentrischen Rechtserzeugung" 374 beraubt, in welchem alle drei Gewalten in sozialer Personalidentität, in sachlicher Kenntnis des konkreten Einzelfalles sowie der betroffenen Menschen und zeitlich gleichzeitig Normbegründungs- und Normanwendungsdiskurse führen. Dem Bürger treten Maßnahmegesetzgeber, Präventionsverwaltung und Wertejudikative als Inhaber jener einheitlichen Gewalt gegenüber, die ursprünglich dem absoluten Fürsten als Richterkönig in Form der jurisdictio zukam ${ }^{375}$ und zu deren Abschaffung die Rechtsstaatsbewegung mit der Forderung nach Gewaltenteilung einst angetreten war.

Als Ersatz für die formalen Garantien des Rechtsstaats bietet der materiale Rechtsstaat "Einzelfallgerechtigkeit" durch den Bezug auf "objektive Werte". Das Problem der wertorientierten Rechtsprechung ist allerdings, daß in der Philosophie nicht ein einziges überzeugendes Konzept für eine objektive Wertetheorie angeboten wird. Bloß an Werten oder Prinzipien orientierte Entscheidungen führen keinesfalls zu objektiven Ergebnissen, sondern sind wesentlich von den Ansichten der Entscheider geprägt und können nicht zu Rechtssicherheit führen. Der Werttheorie ist zudem eine grundlegend antidemokratische Tendenz immanent, da im Falle der objektiven Entscheidbarkeit von Wertungsfragen durch einige wenige, besonders qualifizierte Entscheidungsträger die Demokratie bestenfalls überflüssig, schlimmstenfalls aber irrational wäre.

Selbst wenn man der Ansicht ist, daß die Rückkehr zur Herrschaft des Gesetzes wegen des zunehmenden sozialen Wandels, der gewachsenen Staatsaufgaben und der damit verbundenen Interventionsbedürfnisse des Präventionsstaats nicht möglich ist, läßt die Materialisierung des Rechts eine Legitimationslücke offen, die durch den Bezug auf objektive Werte nicht geschlossen werden kann. Diese Lücke wird hier als Krise des Rechtsstaats bezeichnet.

\section{Krise des Sozialstaats}

Jenseits des ursprünglichen Leitbildes von der sozialen Marktwirtschaft ist der deutsche Sozialstaat heute zu einer gigantischen Umverteilungsmaschinerie herangewachsen, in der 153 Sozialleistungen von 37 verschiedenen Sozialbürokratien gewährt werden, wobei der Großteil des Geldes nicht etwa an Bedürftige ${ }^{376}$, sondern nach Abzug der nicht unerheblichen Verwaltungskosten an eben diejenigen Bürger ausgeschüttet wird, denen es zuvor über Steuern und Sozialabgaben weggenommen wurde. ${ }^{377}$ In Zahlen von 1994 arbeitete der durchschnittliche Arbeitnehmer über das Jahr gesehen bis zum 11. Juni ausschließlich für Fiskus und Sozialversicherung, die Staatsquote betrug $54 \%$, die öf-

374 W.Brohm, Verwaltung und Verwaltungsgerichtsbarkeit als Steuerungsmechanismen in einem polyzentrischen System der Rechtserzeugung, DÖV 1987, S.265ff.

375 Vgl. N.Luhmann, RdG, S.300; J.Habermas, FuG, S.176f.

376 Die gehen nach wie vor leer aus: S.Leibfried, Zeit der Armut, Lebensläufe im Sozialstaat.

377 K.D.Grüske, Personale Verteilung und Effizienz der Umverteilung. Analyse und Synthese, Göttingen 1985, kommt im Rabmen einer ökonomischen Analyse des Rechts zu dem Ergebnis, daß empirisch nachgewiesen sei, daß sich der gestiegene Sozialanteil (Staatsquote) nicht in redistributiven Wirkungen niederschlage, weshalb er dem deutschen Sozialstaat "redistributive Ineffizienz" bescheinigt (S.443). 
fentliche Verschuldung 61,2 \% (2 Billionen DM) und die Kosten des Sozialstaats 33,1 $\%$ (1 Billion DM) der Wirtschaftsleistung. ${ }^{378}$ Voraussetzung dieses Systems sind wirtschaftliches Wachstum und technischer Fortschritt, die allererst die materiellen Grundlagen der Umverteilung bilden. ${ }^{379}$ Mit dem Erreichen der Grenzen eines ungehemmten industriellen Wachstums ist der Sozialstaat Ende der siebziger Jahre in eine Krise der Finanzierbarkeit geraten, die sich bis heute weiter verschärft hat und angesichts der wirtschaftlichen Probleme der deutschen Einheit in einer breiten Debatte über Umbau und Abbau des Sozialstaats kulminiert is $\mathrm{t}^{380}$.

Gleichzeitig - und nur das soll hier interessieren - ist auch die normative Legitimationsbasis des Sozialstaats in eine Krise geraten. Die aus allen politischen Lagern ${ }^{381}$ vorgebrachte Kritik kann unter dem Schlagwort des Paternalismus zusammengefaßt werden. Der Sozialstaat findet seine unbestrittene normative Grundlage in der Einsicht, daß der Gebrauch der formalen Freiheitsrechte ein Mindestmaß an materieller sozialer Sicherheit voraussetzt. Die sozialstaatliche Dimension der Grundrechte als Leistungsund Teilhaberechte versteht sich daher als notwendige Ergänzung und logische Konsequenz aus der Garantie der negativen Abwehrrechte. Freiheit und Sicherheit erscheinen als komplementäre Prinzipien der entwickelten bürgerlichen Gesellschaft. ${ }^{382}$ Die aktuelle Sozialstaatskritik setzt nun bei den nichtintendierten Nebenfolgen einer auf faktische Gleichheit gerichteten Politik an. ${ }^{383}$ Dort, wo die Ermächtigung zu individueller Entfaltung und eigenverantwortlicher Lebensführung im Sinne einer "Staatsbürgerqualifikationspolitik" 384 beabsichtigt sei, werde durch die Verrechtlichung und Bürokratisierung sozialer Solidarität faktisch eine Entmündigung und Infantilisierung des Bürgers zu einem auf sozialautoritäre Betreuung angewiesenen Klienten bewirkt. ${ }^{385}$ Staatliche Sozialpolitik setzt sich daher überall dort dem Vorwurf des Paternalismus aus, wo sich die beabsichtigte Autorisierung zum Gebrauch der Freiheit in bevormundende Betreuung verkehrt. ${ }^{386}$

378 Angaben zusammengestellt aus "Demokratiereform", Schriftenreihe des Unternehmerinstituts, Bonn 1995.

379 C.Sachße, Freiheit, Gleichheit, Sicherheit: Grundwerte im Konflikt, in: ders./T.Engelhardt (Hrsg.), Sicherheit und Freiheit, S.9-27, $10 \mathrm{f}$.

380 Vgl. aus der aktuellen Literatur z.B. W.Schönig (Hrsg.), Sozialstaat wohin? Umbau, Abbau oder Ausbau der sozialen Sicherung, Darmstadt 1996; A.Zaenker, Der bankrotte Sozialstaat. Wirtschaftsstandort Deutschland im Wettbewerb, München 1994; J.Becker, Der erschöpfte Sozialstaat. Neue Wege zur sozialen Gerechtigkeit, Ffm 1994; K.Stopp, Wider die Raffgesellschaft - oder wie der Sozialstaat noch zu retten ist, München 1994; J.Borchert, Renten vor dem Absturz. Ist der Sozialstaat am Ende?, Ffm 1993; für die amerikanische Diskussion vgl. U.Wössner, Die Debatte um den amerikanischen Sozialstaat, Ffm 1995.

381 Ein Überblick bei C.Sachße, Freiheit, Gleichheit, Sicherheit, S.14 bei FN 5.

382 S.o. IV. 2.; T.Blanke, Sozialer Rechtsstaat, S.134ff., 154.

383 Ein Überblick über die Argumente findet sich bei C.Starck, Überlegungen zur Gesetzgebungslehre, ZG 1988, S.1-22, $16 \mathrm{ff}$.

384 U.Preuß, Überlegungen.

385 P.Koslowski, Der soziale Staat der Postmoderne, S.53; J.Habermas, Theorie des kommunikativen Handelns, Bd. 2, S.505-547, 515; ausführlich ausgearbeitet bei Armin Bauer, Armutsbekämpfung als Fortschreibung der Unterentwicklung: wie der Wohlfahrtsstaat die Anrechte auf Entwicklung durch eine Politik zur Verringerung der Armut umgeht, Diss. Konstanz 1991.

386 J.Habermas, FuG, S.502. 
Zunächst wird dabei die im Kern schon durch v.Humboldt und Kant vorgebrachte liberale Kritik am Wohlfahrtsstaat aktualisiert. ${ }^{387}$ Danach setzt die der Logik des Sozialstaats folgende Sozialisierung individueller Risiken ${ }^{388}$ das Verursacherprinzip außer $\mathrm{Kraft}^{389}$, wodurch der intrinsische Zusammenhang von Freiheit und Verantwortung aufgehoben wird. Der "von der Wiege bis zur Bahre" gegen alle Wechselfälle des Lebens abgesicherte Bürger ist der Folgen seines individuellen Tuns enthoben ${ }^{390}$, sein Leben wird zum "Kinderspiel" unter der Aufsicht von "Vater Staat"391. Auf der Kehrseite schlagen die sozialisierten Kosten der Pluralisierung der Lebensformen der Mitbürger in Form einer hohen Steuer- und Abgabenlast auf das individuell verfügbare Budget durch. ${ }^{392}$ Dadurch werden nicht nur die Möglichkeiten zu einer eigenverantwortlichen Lebensgestaltung eingeschränkt, sondern es geht auch die individuelle Bereitschaft $\mathrm{zu}$ Selbsthilfe und privater Solidarität verloren. ${ }^{393}$ Die Anonymität der Solidargemeinschaft führt zudem in eine Rationalitätsfalle, weil übermäßige Inanspruchnahme sozialer Leistungen zwar objektiv irrational, subjektiv hingegen rational ist. ${ }^{394}$ Ein System, in dem die "Ehrli-chen die Dummen" sind, korrumpiert aber auf lange Sicht die Moral der Versicherten $^{395}$, und zwar umso mehr, je häufiger in der Öffentlichkeit die Rede von "Sozialbetrug" ist. So wird schließlich ein sich selbst verstärkender Prozeß ausgelöst, in welchem die bürokratischen Kontrollbefugnisse ständig erweitert werden müssen. 396

Die Zunahme staatlicher Definitions- und Kontrollbefugnisse bildet den zweiten Kern der Sozialstaatskritik. Im Gegensatz zu negativen Abwehrrechten setzen positive Leistungs- und Teilhaberechte eine inhaltliche Ausrichtung von Freiheit voraus. ${ }^{397}$ Wer die materiellen Minimalbedingungen der Freiheitsausübung aktiv herstellen will, muß

387 Zu Humboldts Kritik s.o. IV. 1.; P.Koslowski, Versuch zu einer philosophischen Kritik des gegenwärtigen Sozialstaats, in: ders./Ph.Kreuzer/R.Löw (Hrsg.), Chancen und Grenzen des Sozialstaats, Tübingen 1983, S.1-23; M.Spieker, Legitimitätsprobleme des Sozialstaats, Bern 1986; H.Baier, Ehrlichkeit im Sozialstaat. Gesundheit zwischen Medizin und Manipulation, Zürich 1988; H.-M.Sass, Zielkonflikte im Wohlfahrtsstaat, S.71ff.; P.Gross, Selbsthilfe und Selbstverantwortung als normative Leitideen der Sozialpolitik, in: Sachße/Engelhardt (Hrsg.), Sicherheit und Freiheit, S.85-105; G.Habermann, Der Wohlfahrtsstaat.

388 Vgl. dazu N.Luhmann, Politische Theorie im Wohlfahrtsstaat.

389 H.Bonus, Die Verführung zur Verantwortungslosigkeit. Vom Verursacherprinzip in der Sozialpolitik, NZZ v. 16. August 1989.

390 R.Pitschas, Soziale Sicherung durch fortschreitende Verrechtlichung, in: R.Voigt (Hrsg.), Verrechtlichung, Königstein/Ts. 1980, S.155ff.

391 Daher der Begriff Paternalismus, der schon von Kant (Gemeinspruch, S.145: "imperium paternale") benutzt wurde.

392 Zur Externalisienung der Kosten der Pluralisierung der Lebensformen am Beispiel der Sozialhilfe für Alleinerziehende, soweit diese Situation als alternative Lebensform frei gewählt ist, vgl. P.Koslowski, Der soziale Staat der Postmoderne, S.55. Ähnliche Probleme ergeben sich auch im Rahmen der Krankenversicherung und der Lohnfortzahlung; wo die Wiedereinführung des Schuldprinzips diskutiert wird.

393 So im Anschluß an v.Humboldt T.Blanke, Sozialer Rechtsstaat, S.144f.; vgl. auch J.Habermas, Theorie des kommunikativen Handelns, Bd. 2, S.532; G.Habermann, Der Wohlfahrtsstaat, S.34ff.

394 P.Gross, Selbsthilfe, S.100.

395 Für das Gesundheitssystem vgl. H.Baier, Ehrlichkeit im Sozialstaat; zum Phänomen der "VollkaskoMentalität" vgl. auch F.Ewald, Die Versicherungs-Gesellschaft, S.385ff.

396 Wie am Gesundheitssystem gegenwärtig zu beobachten, führt dieser Prozeß auf direktem Wege in die Planwirtschaft.

$397 \mathrm{Zu}$ dieser Problematik im Bereich der Grundrechte vgl. schon E.W.Böckenförde, Grundrechtstheorie und Grundrechtsinterpretation, NJW 1974, S.1529-1538. 
diese zunächst definieren. Da in einem liberal-pluralistischen System keine Übereinkunft über eine allgemeinverbindliche Form von Gleichheit, Sicherheit, Wohlstand etc. gefunden werden kann, vielmehr jeder auf seine Art glückselig werden soll, beinhaltet staatliche Sozialpolitik notwendig eine heteronome Definition von Wohlfahrt. ${ }^{398}$ So ist etwa das System der Sozialversicherungen am "Normalarbeitsverhältnis" eines vollzeitbeschäftigten, im Familienverband lebenden Arbeiters ausgerichtet, das als normatives Leitbild zugleich implizite Standards über das Verhältnis von Lohnarbeit und Leben, das Verhältnis der Geschlechter und Generationen sowie über gesellschaftliche Sinnund Gerechtigkeitsvorstellungen enthält. ${ }^{399} \mathrm{Mag}$ man die damit verbundene Assimilation individueller Lebenspläne an normative Leistungstatbestände ${ }^{400}$ für den Fall der staatlichen Sicherung des Existenzminimums noch als unumgänglich akzeptieren, so wird diese verhaltensuniformierende Wirkung problematisch, wenn infolge der sozialstaatlichen Eigendynamik der "Inklusion"401 ein immer größeres Maß an Sicherheit zur Pflicht wird. Ziel der Rentenversicherung ist nicht etwa die Grundsicherung, sondern der Rentner soll im Alter nicht aus seiner bisherigen Sozialschicht herausfallen. ${ }^{402}$ Diesem "Mehr" im Alter entspricht dabei ein "Weniger" in der Jugend, wobei angesichts des demographischen Wandels die Freiheit der Jungen immer mehr zugunsten der Sicherheit der Alten beschnitten wird. ${ }^{403}$ Die Umsetzung solcher Besitzstandswahrung im Wege der Zwangsversicherung läßt sich keineswegs als Schaffung von faktischen Voraussetzungen der Grundrechtsausübung legitimieren. Vielmehr handelt es sich um die autoritative Vorgabe eines bestimmten Lebensplanes, der alternative Lebensentwürfe ausschließt. 404

Dieser "sanfte Zwang" zur Anpassung wird noch einmal überboten, wo der Staat nicht nur indirekt über das Medium Geld, sondern direkt im Medium Macht in soziale Bereiche wie Ehe, Familie, Schule oder Arbeit interveniert. Die Kritik bezieht sich hier auf die dilemmatische Struktur der Verrechtlichung vormals informell geregelter Sphären der Lebenswelt. ${ }^{405}$ Potentiell benachteiligte Rolleninhaber wie Ehefrau, Kind, Schüler, Arbeitnehmer, Mieter usf. werden mit im Zweifelsfalle gerichtlich durchsetzbaren Rechtspositionen ausgestattet, die dem Ziel der faktischen Gleichstellung dienen sollen. Die Rechtssubjekte erkaufen ihre Befreiung aus naturwüchsigen sozialen Abhängigkei-

398 H.M.Sass, Zielkonflikte im Wohlfahrtsstaat, S.78.

399 U.Mückenberger, Normalarbeitsverhältnis: Lohnarbeit als normativer Horizont sozialer Sicherheit?, in: Sachße/Engelhardt, Sicherheit und Freiheit, S.158-178.

400 S.Simitis, Selbstbestimmung: Illusorisches Projekt oder reale Chance?, KJ 1988, S.32ff.

401 Vgl. dazu C.Sachße, Freiheit, Gleichheit, Sicherheit, S.11.

402 Vgl. dazu P.Koslowski, Der soziale Staat der Postmoderne, S.56.

403 C.Sachße, Freiheit, Gleichheit, Sicherheit, S.13. Die Rentenversicherung ist daher auch keineswegs moralisch neutral (so aber C.Offe, Akzeptanz und Legitimität strategischer Optionen in der Sozialpolitik, in: Sachße/Engelhardt (Hrsg.), Sicherheit und Freiheit, S.179-202, 185). Angesichts der vielfältigen versicherungsfremden Leistungen würde sich etwa ein privat versicherter Renter bei gleichem finanziellen Aufwand ca. viermal (!) besser stehen als der gesetzlich Versicherte: vgl. dazu G.Habermann, Der Wohlfahrtsstaat, Kap. 6.

404 P.Koslowski, Der soziale Staat der Postmoderne, S.58.

405 Vgl. die zahlreichen Beiträge in R.Voigt (Hrsg.), Verrechtlichung. Analysen zu Funktion und Wirkung von Parlamentarisierung, Bürokratisierung und Justizialisierung sozialer, politischer und ökonomischer Prozesse, Königstein/Ts. 1980; F.Kübler (Hrsg.), Verrechtlichung von Wirtschaft, Arbeit und sozialer Solidarität. Vergleichende Analysen, Baden-Baden 1984; G.Teubner (Hrsg.), Dilemmas of Law in the Welfare State; ders. (Hrsg.), Juridification of Social Spheres. 
ten (etwa der patriachalischen Gewalt in der Familie, oder dem besonderen Gewaltverhältnis der Schule) dabei allerdings mit der Kompetenz lebensweltfremder Instanzen (Arbeits-, Jugend-, Sozial- und Wohnungsämter oder Gerichte) zu inhaltlichen Entscheidungen. ${ }^{406}$ Die subjektiven Ansprüche auf Intervention von Seiten Dritter bewirken dabei tendenziell eine Umstellung von an Verständigung orientiertem kommunikativen Handeln auf strategische Optionen. Das über die Verrechtlichung vermittelte Eindringen der systemischen Medien Geld und Macht (Kolonialisierung der Lebenswelt ${ }^{407}$ ) ist für die verständigungsbasierte Reproduktion der Lebenswelt daher dysfunktional bis hin zur Zerstörung traditioneller Muster der Sozialintegration. ${ }^{408}$

Die so umschriebene Krise des Sozialstaats fühtt nun keineswegs zur Forderung nach der schlichten Abschaffung des Sozialstaats, denn die soziale Frage bleibt als politisches Anliegen aktuell - wenn auch unter veränderten gesellschaftlichen Bedingungen. Der Hinweis auf Dysfunktionalitäten und pathologische Nebeneffekte der gegenwärtigen Form des Sozialstaats führt allerdings zu der Frage nach Alternativen, die eine freiheitsverbürgende Autorisierung der Staatsbürger jenseits paternalistischer Betreuungskonzepte ermöglichen. Vergegenwärtigt man sich den engen Zusammenhang zwischen sozialstaatlichem Interventionsanspruch und Materialisierung des Rechts, so entfällt mit der Kritik am sozialstaatlichen Paternalismus die Schicksalhaftigkeit, mit der nach herrschender Meinung die durch die Materialsierung des Rechts bewirkte Krise des Rechtsstaats hingenommen werden muß. Da sich der Paternalismus gerade in den Formen eines materialisierten Rechts vollzieht ${ }^{409}$, besteht mit der Krise des Rechtsstaats und des Sozialstaats doppelt Grund zur Suche nach Alternativen.

\section{Steuerungskrise des Rechts}

Das an den Begriffen des Sozialstaats und des Präventionsstaats erläuterte Konzept des politischen Interventionismus setzt eine hohe Steuerungskapazität von Politik und Recht voraus. Denn der "activist state" legitimiert sich an der Einlösung seiner Sicherheitsversprechen und ist somit vom Erfolg der politischen Steuerung der Gesellschaft abhängig. ${ }^{410}$ Als Rechtsstaat darf er sich der Steuerungsmedien Macht und Geld allerdings nur in den Formen des Rechts bedienen (Vorbehalt des Gesetzes). Mit der Ausdehnung der Staatstätigkeit geht daher ein Prozeß der zunehmenden Verrechtlichung einher, womit neben einer Ausdehnung des Rechts auf bisher nicht rechtlich geregelte Bereiche auch die Zunahme von Regelungsdichte und Regelungstiefe und neben einer Vergesetzlichung auch Bürokratisierung und Justizialisierung gemeint sind. ${ }^{411}$ Weil aber staatliche

406 S.Simitis, Zur Verrechtlichung der Arbeitsbeziehungen, in; F.Kübler (Hrsg.), Verrechtlichung, S.73166; H.F.Zacher, Verrechtlichung im Bereich des Sozialen, in: F.Kübler (Hrsg.), Verrechtlichung, S.14-72; für die Bereiche Familie und Schule vgl. J.Habermas, Theorie des kommunikativen Handelns, Bd. 2, S. 542ff. m.w.N.; zur Frauenpolitik vgl. ders., FuG, S.506ff.

407 J.Habermas, Theorie des kommunikativen Handelns, Bd. 2, S.522.

408 Am deutlichsten wird dies anhand der Auflösung der Familie als Solidarverband: vgl. U.Beck, Risikogesellschaft, Kap. IV., S.161ff.

409 Zum Zusammenhang von sozialstaatlichem Interventionsanspruch, Unbestimmtheit und Maßnahmecharakter des Rechts vgl. nochmals G.v.Halle, Verrechtlichungs- und Bürokratisierungstendenzen im Sozialstaat; I.Maus, Verrechtlichung.

410 R.Voigt, Politik und Recht: Beiträge zur Rechtspolitologie, Bochum 1990, S. 1.

411 Zur Verrechtlichung vgl. FN 434; Zur sog. Normenflut vgl. auch die Beiträge von H.Maassen, D.Simon, E.Bülow, H.Simon und S.Simitis, in: Gesetzesflut - Gesetzesperfektionismus, Verhand- 
Steuerung im Gewand des Rechts auftritt, ist insbesondere im Zuge des Planungsoptimismus der 60er und 70er Jahre ${ }^{412}$ Recht selbst als Steuerungsinstrument verstanden worden. Vor der Hintergrundannahme, Recht sei Struktur der Gesellschaft ${ }^{413}$, bot sich Gesetzgebung als unhinterfragt wirksames Mittel der Gesellschaftsreform an. Dieses freilich etwas naiv anmutende Bild der monokausalen Veränderung von Gesellschaftsstrukturen durch Recht zerbrach allerdings schon bald an der Komplexität der gesellschaftlichen Realität.414 Der etwas ratlosen Diagnose von der "Unregierbarkeit"415 folgte eine umfangreiche Debatte um die Grenzen rechtlicher Steuerung ${ }^{416}$, deren Ergebnis in der Formel "Wachsende Staatsaufgaben - sinkende Steuerungsfähigkeit des Rechts"417 eingefangen werden kann. Die Phänomene dieser Steuerungskrise des Rechts können an den Begriffen des Vollzugsdefizits, der symbolischen Gesetzgebung sowie der nichtintendierten (negativen) Folgen staatlicher Regulierung erläutert werden.

\section{a) Vollzugsdefizite}

Nach einer Phase der intensiven Reformgesetzgebung richtete sich Ende der siebziger Jahre das Augenmerk auf die faktische Durchsetzung der Reformprogramme in der Gesellschaft. Ernüchternde Bilanz der "Implementations-forschung" 418 war, daß das "law in the books" nur wenig mit dem "law in action" zu tun hatte. Die festgestellten Vollzugsdefizite wurden dabei im wesentlichen auf zwei Ursachen zurückgeführt. Zum einen wurde beobachtet, daß die gesetzgeberischen Programme bei ihrem Vollzug sowohl in der Verwaltung als auch in der Rechtsprechung auf erhebliche Widerstände stoßen. Aufgrund der Eigenlogik der Arbeitsweise dieser Institutionen ${ }^{419}$ werden die Intentionen des Gesetzgebers im Vollzugsprozeß erheblich verfremdet bis hin zum teilweisen Nichtvollzug von Normen. Auf die Folgen der mit der Materialisierung des Rechts verbunden Politisierung der Justiz bzw. der Justitialisierung der Politik wurde bereits hin-

lungen des 53. Deutschen Juristentages Bd. II, Sitzungsbericht Q, München 1980; K.Eichenberger, R.Novak, M.Kloepfer, Gesetzgebung im Rechtsstaat, VVDStRL Heft 40 (1982); N.Huber, Rechtsund Verwaltungsvereinfachung, S.1-19 m.w.N; R.Holtschneider, Normenflut und Rechtsversagen.

412 Vgl. dazu H.Schelsky, Planung der Zukunft. Die rationale Utopie und die Ideologie der Rationalität, in: ders., Die Soziologen und das Recht, Opladen 1980, S. 288ff.; eine gute Darstellung findet sich bei E.-H.Ritter, Staatliche Steuerung bei vermindertem Rationalitätsanspruch? Zur Praxis der politischen Planung in der Bundesrepublik Deutschland, in: Jahrbuch zur Staats- und Verwaltungswissenschaft 1987, S.321-352, S.322ff.

413 So z.B. noch N.Luhmann, Rechtssoziologie (1973), Kap. III.

414 Vgl. E.-H.Ritter, Das Recht als Steuerungsmedium im kooperativen Staat, in: D.Grimm (Hrsg.), Wachsende Staatsaufgaben, 1990, S.69-112.

415 Vgl. dazu C.Offe, "Unregierbarkeit" - zur Renaissance konservativer Krisentheorien, in: J.Habermas (Hrsg.), Stichworte zur geistigen Situation der Zeit, Ffm 1979, S.294-318.

416 Vgl. A.Görlitz/R.Voigt (Hrsg.), Grenzen des Rechts; R.Voigt (Hrsg.), Limits of Legal Regulation, Pfaffenweiler 1989, jeweils m.w.N.

417 So der Titel von D.Grimm (Hrsg.), Wachsende Staatsaufgaben, 1990.

418 R.Mayntz (Hrsg.), Implementation politischer Programme. Empirische Forschungsberichte, Königsstein/Ts. 1980; dies. (Hrsg.), Implementation politischer Programme II. Ansätze zur Theoriebildung, Opladen 1983; R.Holtschneider, Normenflut und Rechtsversagen.

419 R.Voigt spricht z.B. von unterschiedlichen Rationalitäten, was bedeute, daß je unterschiedliche Argumente und Verhaltensweisen als erlaubt gelten bzw. in Verfahrensvorschriften fixiert sind (Politik und Recht, S.3). 
gewiesen. ${ }^{420}$ Im Hinblick auf die Eigendynamik des administrativen Gesetzesvollzugs sei hier nur ein Beispiel herausgegriffen: Angesichts der Normenflut im Steuerrecht sowie steigender Fallzahlen pro Bearbeiter wird im Bereich der Finanzverwaltung - abgesegnet durch die Finanzminister - die statistisch meßbare Fallerledigung über die Sachverhaltsaufklärung im Einzelfall gestellt, und es kommt zu vielfältigen Formen "individueller Rechtsvereinfachung" durch die Steuerbeamten. Diese verstehen die steuerrechtlichen Vorschriften nurmehr als "nicht verbindliche Grundsatzanweisungen", weshalb nicht mehr von Gesetzesvollzug im klassischen Sinne gesprochen werden kann. ${ }^{421}$ $\mathrm{Da}$ Gesetze vollzogen werden müssen, scheint den mit der Produktion der Normenflut beschäftigten Gesetzgeber in der Vergangenheit nicht sonderlich gekümmert zu haben. ${ }^{422}$ Wie die Diskussion um das sog. New Public Management ${ }^{423}$ zeigt, entstehen Vollzugsdefizite aber nahezu zwangsläufig, wenn die Verwaltung angesichts knapper finanzieller und personeller Ressourcen eine an Kosten und Nutzen orientierte, selektive Einstellung gegenüber Normen einnimmt. Die dem Bild eines monokausalen Gesetzesvollzugs entgegenstehende "Eigenlogik" der Verwaltung liegt darüber hinaus auch in politischen Einflüssen auf Verwaltungsentscheidungen begründet. 424

Ferner stehen den gesetzgeberischen Intentionen gegenläufige Interessen der Rechtsadressaten entgegen, weshalb der Gesetzesvollzug auch auf Widerstand aus den regulierten Gesellschaftsbereichen trifft. Besonders deutlich wird dies im Bereich staatlicher Interventionen in die Wirtschaft, wenn die Logik der rechtlichen Regulierung (Gebote/ Verbote) auf die Eigenlogik wirtschaftlicher Prozesse (Gewinn/Verlust) trifft. Wie die ökonomische Analyse des Rechts dargelegt hat, werden Normen in der Wirtschaft als Preise gelesen, weshalb die Nichtbefolgung von Normen die Regel ist, wo der Normbruch als effizient erscheint. ${ }^{425}$ Darüber hinaus wird der Gesetzesvollzug durch die Verwaltung dort behindert, wo der Gesetzgeber durch Verwendung unbestimmter Rechts-

420 S.o. zur Krise des Rechtsstaats; aus politikwissenschaftlicher Sicht vgl. auch R.Voigt, Politik und Recht, Teil 3: Gegensteuerung durch das judizielle System; I.Maus, Verrechtlichung, S.283ff.

421 Vgl. die empirische Untersuchung von J.Weingarten, Kooperatives Recht in der Finanzverwaltung, in: N.Dose/R.Voigt (Hrsg.), Kooperatives Recht, 1995, S.149-184.

422 Institutionell abgesichert durch den Grundsatz der Landesexekutive (Art. 83 GG) findet sich in den Begründungen zu Gesetzesentwürfen lediglich die lapidare Anmerkung "Kosten: keine", oder aber es wird offen erklärt, die Kosten seien nicht abschätzbar: vgl. dazu mit Beispielen W.Hack, Die Gesetzgebung in der Krise, Stadt und Gemeinde 1995, S.99-102; C.Böhret, Wenn wir nur wüßten, wie Gesetze wirken ..., in: Für Recht und Staat, FS f. H.Helmrich, München 1994, S. 487; H.Hill, Verbesserung der Gesetzgebung, S.1ff.; Kosten-Nutzen-Analysen von Gesetzen werden demgegenüber im Rahmen der Ökonomischen Analyse des Rechts betrieben (vgl. im Überblick M.R.Deckert, Zur Methodik der Folgenantizipation in der Gesetzgebung, ZG 1995, S.240-254 m.w.N.).

$423 \mathrm{Vgl}$. đazu K.Schedler, Ansätze einer wirkungsorientierten Verwaltungsfïhrung, Von der Idee des New Public Managements (NPM) zum konkreten Gestaltungsmodell: Fallstudie Schweiz, Bern/Stuttgart/Wien 1995; K.König, "Neue" Verwaltung oder Verwaltungsmodernisierung: Verwaltungspolitik in den 90er Jahren, DÖV 1995, S.349ff; F.Behrens et. al. (Hrsg.), Den Staat neu denken: Reformperspektiven für die Landesverwaltungen, Berlin 1995; P.Hablützel (Hrsg.), Umbruch in Politik und Verwaltung, Bern, Stuttgart, Wien 1995.

424 Der politische Charakter der Verwaltung ist immer wieder von N.Luhmann betont worden: vgl. zuletzt wieder in RdG, S. 431, wo den Implementationsanalysen vorgeworfen wird, diese gingen von dem "Vorurteil (aus), daß Gestze durchgeführt werden müßten".

$425 \mathrm{Zu}$ den Implikationen der ökonomischen Analyse des Rechts vgl. G.Teubner, Recht als autopoietisches System, S.115f. und öfter; Eine Einführung in die Ökonomische Analyse des Rechts findet sich bei H.-D.Assmann, C.Kirchner, E.Schanze (Hrsg.), Ökonomische Analyse des Rechts, 3. Aufl., Tübingen 1993. 
begriffe das Eindringen gegenläufiger Interessen in den Vollzugsprozeß ermöglicht. So war etwa im Immissionsschutzgesetz von 1974 die Sanierung einer Anlage an deren "wirtschaftliche Vertretbarkeit" geknüpft. ${ }^{426}$ Verbesserungen der Luftqualität waren unter dieser Bedingung nur durch intensive Verhandlungsprozesse zwischen Verwaltung und Unternehmen erreichbar. ${ }^{427}$ Generell kann man sagen, daß die Verwaltung überall dort, wo klare normative Vorgaben fehlen, bei der Konkretisierung von Generalklauseln, unbestimmten Begriffen und Verhältnismäßigkeitsformeln auf Kooperation mit den Rechtsadressaten angewiesen ist. ${ }^{428}$ Das Gesetz ist damit zwar nicht wirkungslos, aber es kann ebenfalls nicht (mehr) vom klassischen Gesetzesvollzug gesprochen werden.

\section{b) Symbolische Gesetzgebung}

An diesen Befund der weitgehenden Wirkungslosigkeit vieler moderner Gesetze schließt die These von der symbolischen Gesetzgebung an. ${ }^{429}$ Eine solche ist dann gegeben, wenn die Ineffektivität eines Normbefehls von vornherein erkennbar ist und die spezifischen Motive der am Gesetzgebungsverfahren Beteiligten gar nicht auf die Verwirklichung der Norm gerichtet sind. ${ }^{430}$ Nach den Motiven können dabei vier Gruppen unterschieden werden: Gesetzgeberische Wertbekenntnisse sollen ethische Grundwerte zum Ausdruck bringen, ohne da $\beta$ auf technische Fragen, wie etwa die Erforderlichkeit oder Durchsetzbarkeit eines Verbotes Rücksicht genommen wird (z.B. Abtreibungsverbot); Gesetze mit moralischem Apellcharakter wollen hingegen auf die Einstellungen der Bürger einwirken, ohne überhaupt den Anspruch auf Wirksamkeit zu erheben (z.B. Einfuigung der Umweltdelikte in das StGB); Alibigesetze sollen etwa in Krisensituationen kontrafaktisch Lagebeherrschung demonstrieren, um so die Bevölkerung zu beruhigen (z.B. Anti-Terror-Gesetze); Kompromißgesetze schließlich wollen es allen recht machen, indem etwa auf Veranlassung einer bestimmten Gruppe eine Verbotsnorm aufgestellt wird, als Zugeständnis an die Verbotsgegner aber erforderliche Vorkehrungen für die Normdurchsetzung unterlassen werden. ${ }^{431}$ Im ersten Fall spielt die Durchsetzbarkeit der Norm keine Rolle, im zweiten und dritten Fall wird die faktische Unwirksamkeit der Normen bewußt in Kauf genommen, im vierten Fall ist sie sogar beabsichtigt. Aus der Sicht des politischen Systems ist diese symbolische Gesetzgebung solange vorteilhaft, wie etwa zwecks Zugewinn an Wählerschaft politische Handlungsfähigkeit ohne Vollzugskosten - sei es in Form von Verwaltungskosten, sei es in Form von negativen wirtschaftlichen Effekten etwa von Umweltschutzpolitik - demonstriert werden

$426 \S 17$ Abs. 2 BImSchG a.F.

427 N.Dose, Kooperatives Handeln der Umweltschutzverwaltung, in: ders./Voigt (Hrsg.), Kooperatives Recht, S.91-130; vgl. auch schon E.Bohne, Der informale Rechtsstaat, Eine empirische und rechtliche Untersuchung zum Gesetzesvollzug unter besonderer Berücksichtigung des Immissionsschutzes, Berlin 1981; W.Pflügner, Nutzen-Analysen im Umweltschutz, Göttingen 1988.

428 N.Dose/R.Voigt, Kooperatives Recht: Norm und Praxis, in: dies. (Hrsg.), Kooperatives Recht, S.1139.

429 Vgl. dazu P.Noll, Symbolische Gesetzgebung, ZfSchwR 1981, S.347ff.; H.Kindermann, Symbolische Gesetzgebung, Jahrbuch für Rechtssoziologie und Rechtstheorie Bd. XIII, Opladen 1988, S.222-245.

430 P.Noll, Symbolische Gesetzgebung, S.355.

431 Vgl. M.Voß, Symbolische Gesetzgebung, Ebelbach 1989, S.25-34 m.w.N.; Bei H.Kindermann, Symbolische Gesetzgebung, sind Fall 1 und 2 hingegen zusammengefasst. 
kann. ${ }^{432}$ Über kurz oder lang führen die Allzuständigkeitsrhetorik und die ständigen Sicherheitsversprechen der Politik jedoch in eine Legitimationskrise. Denn die bloß symbolisch bearbeiteten Probleme holen die Politik früher oder später wieder ein. Der dadurch ausgelöste Prozeß der Selbstwiderlegung der Politik ${ }^{433}$ legt den bloß symbolischen Charakter der Gesetze offen und beraubt diese ihrer beruhigenden Wirkung. ${ }^{434}$

\section{c) Negative Folgen und Nebenwirkungen}

Mit der wenn schon nicht faktischen, so doch immerhin symbolischen Wirksamkeit von Gesetzen kann man sich schon deshalb nicht zufrieden geben ${ }^{435}$, weil auch mit symbolischen Gesetzen negative Folgen und Nebenwirkungen verbunden sein können. Denn symbolische Gesetze sind geltendes Recht. Da ihre symbolische Wirkung gerade darauf beruht, daß sie äußerlich nicht als solche erkennbar sind ${ }^{436}$, gilt für sie, was für alle Gesetze gilt: Im Prozeß des Gesetzesvollzugs werden sie der Eigenlogik von Verwaltung, Rechtsprechung oder reguliertem gesellschaftlichen Teilbereich unterworfen, interpretiert und mißinterpretiert, als Preise gelesen oder ignoriert usf.437 In dem Maße, in welchem Rechtsanwender und Rechtsadressaten sich die Norm aneignen, wird diese ihres vom Gesetzgeber beabsichtigten Sinnes beraubt und verfremdet. Die Norm entwickelt ein vom Gesetzgeber nicht vorherzusehendes Eigenleben. Schließlich kann die Norm etwas bewirken, das den Zielen des Gesetzgebers konträr zuwiderläuft. Im Bereich der symbolischen Gesetzgebung könnte etwa ein Kompromißgesetz entgegen aller gesetzgeberischen Intention von Verwaltung und Rechtsprechung durchgesetzt werden. Damit wären unter Umständen wirtschaftliche oder soziale Folgen verbunden, die der Gesetzgeber gerade vermeiden wollte. Aber auch prinzipiell auf Wirksamkeit angelegte Gesetze haben häufig nichtintendierte Nebenfolgen, die sich negativ auf die gesetzgeberischen Ziele auswirken.

Die pathologischen Nebeneffekte der Sozialpolitik wurden bereits unter dem Stichwort der Kolonialisierung der Lebenswelt angesprochen. ${ }^{438}$ Solche Effekte rechtlicher Regulierungen beschränken sich allerdings nicht auf die Reproduktion der Lebenswelt, sondern treten auch in den systemisch organisierten Subsystemen Wirtschaft, Wissenschaft, Gesundheit etc. auf. ${ }^{439}$ So produziert etwa das System der Arbeitslosenversiche-

432 H.Kindermann, Alibigesetzgebung als symbolische Gesetzgebung, in: R.Voigt (Hrsg.), Symbole der Politik, Politik der Symbole, Opladen 1989, S. $257 \mathrm{ff}$., 269.

433 Vgl. dazu U.Beck, Gegengifte, Kap. IV.

434 M.Voß, Symbolische Gesetzgebung, S.72ff.

435 Positiv bis neutral wird symbolische Gesetzgebung hingegen von den Vertretern der positiven Generalprävention bewertet: vgl. M.Voß, Symbolische Gesetzgebung, S.102ff.

436 Denn sonst würden symbolische Gesetze sich der Lächerlichkeit preisgeben. Die Fiktion der Wirksamkeit wird deshalb durch gesetzgeberischen "double-talk" aufrechterhalten: vgl. E.Blankenburg, Rechtssoziologie und Rechtswirksamkeitsforschung - Warum es so schwierig ist, die Wirksamkeit von Gesetzen zu erforschen, in: Plett/Ziegert (Hrsg.), Empirische Rechtsforschung zwischen Wissenschaft und Politik, 1984, S. 45ff.

437 G.Teubner, Gesellschaftsordnung durch Gesetzgebungslärm? Autopoietische Geschlossenheit als Problem für die Rechtssetzung, Jahrbuch für Rechtssoziologie und Rechtstheorie Bd. XIII, Opladen 1988, S.45-64. Zur Logik des "konstruktiven Mißverstehens" s.u. Kap. 2 I. 3. und II. 1. f) und Kap. $3 \mathrm{I}$.

438 S.o. zur Krise des Sozialstaats.

439 G.Teubner, Verrechtlichung - Begriffe, Merkmale, Grenzen, Auswege, in: F.Kübler (Hrsg.), Verrechtlichung, S. $289 \mathrm{ff}, 322$. 
rung Arbeitslosigkeit, weil die Kosten der Versicherung als Lohnnebenkosten das Wegrationalisieren von Arbeitsplätzen wirtschaftlich sinnvoll machen. ${ }^{40}$ Die Ausgestaltung des Umweltrechts durch Ge- und Verbote führt dazu, daß Umweltschutz in der Wirtschaft lediglich als Kostenfaktor, nicht aber als möglicher Gewinn erscheint, weshalb das Umweltrecht vornehmlich Ausweich- und Umgehungsstrategien auslöst. Die Liste ließe sich um eine Vielzahl rechtlicher Regelungen erweitern. ${ }^{441}$

Als Beispiel für die unselige Verquickung von symbolischer Gesetzgebung, Vollzugsdefiziten und kontraproduktiven Folgen soll hier die Gesetzgebung zur Bekämpfung der Wirtschaftskriminalität herausgegriffen werden. ${ }^{442}$ Der Gesetzgeber zielte mit diesen Vorschriften zumindest auch auf eine symbolische Wirkung: Nachdem das Strafrecht in den Verdacht geraten war, "die Kleinen zu hängen und die Großen laufenzulassen", sollte die Entschlossenheit zum Vorgehen gegen das "white-collar-crime" demonstriert werden. Für den Präventionsstaat typisch wurde dabei gleichzeitig der Schutz des kollektiven Rechtsguts der "Funktionsfähigkeit des Kreditwesens" angestrebt. Obwohl das Kreditgewerbe selbst ablehnend Stellung nahm ${ }^{443}$, wurde u.a. der Mißbrauch von Scheck- und Kreditkarten unter Strafe gestellt ( $\$ 266$ b StGB). Nach Ansicht der Banken bedroht $\S 266$ b StGB die "flexible Kreditpraxis" 444 der Banken, unterminiert das sensible Bank-Kunden-Verhältnis und belastet die Kreditentscheidung der Bank mit kreditfremden, d.h. strafrechtlichen Gesichtspunkten. Die Norm verfehlt daher nicht nur das vorgegebene Ziel, die Rahmenbedingungen wirtschaftlicher Prozesse zu sichern, indem sie die Eigenlogik der Kreditwirtschaft mißachtet, sondern destruiert darüber hinaus die zu schützende Ordnung, indem sie der Kreditwirtschaft die Fremdlogik des strafrechtlichen Systems aufzwingt. 445 Das Kreditgewerbe reagiert darauf notwendig mit Ignoranz (Nicht-Anzeige), das so entstehende Vollzugsdefizit läßt von der Norm nur ihre symbolische Wirkung übrig.

\section{d) Gesetzesfolgenabschätzung: Kosten/Nutzen-Analysen}

Ausgehend von dieser Problemlage hat sich innerhalb der Gesetzgebungslehre eine Forschungsrichtung der Gesetzesfolgenabschätzung mit dem Ziel etabliert, Effektivität und Effizienz der Gesetzgebung durch wissenschaftliche Beratung zu steigern. ${ }^{446}$ Unter An-

440 Vgl. z.B. W.Harders, Folgekosten der Sozialgesetze. Eine Analyse der direkten und indirekten Zusatzlasten, Göttingen 1988.

$441 \mathrm{Vgl}$. insbesondere die Beiträge zur Verrechtlichung von Wirtschaft und Arbeit in: G.Teubner (Hrsg.), Juridification of Social Spheres.

442 Vgl. dazu B.Haffke, Symbolische Gesetzgebung? Das Wirtschaftsstrafrecht in der Bundesrepublik Deutschland, KritV 1991, S.165-176, 439 f.

$443 \mathrm{Vgl}$. die Stellungnahmen des Zentralen Kreditausschusses sowie des Bundesverbands deutscher Banken, abgedruckt bei H.Otto, Bargeldloser Zahlungsverkehr und Strafrecht, 1978, S.131ff, $141 \mathrm{ff}$; vgl. ders., Konzeption und Grundsätze des Wirtschaftsstrafrechts, ZStW Bd. 96, 1984, S.339ff.

444 Gemeint ist damit die Entscheidung des Sachbearbeiters, im Einzelfall auch eine Inanspruchnahme über die vereinbarte Kreditlinie hinaus zu genehmigen (sog. "Duldung"): vgl. H.Otto, Probleme des Kreditbetruges, des Scheck- und Wechselmißbrauchs, Jura 1983, S.16ff.

445 So das Fazit bei B.Haffke, Symbolische Gesetzgebung?, S.170.

446 Vgl. schon C.Böhret/W.Hugger, Test und Prüfung von Gesetzentwürfen, Köln, Bonn 1980; Zum Begriff Gesetzesfolgenabschätzung vgl. auch C.Böhret, Wenn wir nur wüßten, wie Gesetze wirken ...; H.Hill, Gutachten D zum 58. Deutschen Juristentag, 1990, S.65; ders., Verbesserung der Gesetzgebung, S.7 m.w.N. in FN 32; M.R.Deckert, Folgenantizipation in der Gesetzgebung, S.240ff; Eine prospektive Gesetzesfolgenabschätzung für den Bereich der Humangenetik wird unter Leitung 
knüpfung an die Methoden der Ökonomischen Analyse des Rechts werden dabei zunächst Nutzen und sodann Kosten von Gesetzen untersucht. ${ }^{447}$ Der Nutzen kann angesichts der beschriebenen Vollzugsdefizite relativ gering ausfallen. Als Kosten können zunächst Kosten der Steuererhebung, Kosten der Gesetzgebung, Kosten des Vollzugs in Bund, Ländern und Gemeinden, Vollzugskosten in der Wirtschaft, sodann negative Nebenfolgen wirtschaftlicher, sozialer und ökologischer Art gemessen werden. Alle Kosten addiert können dem Nutzen gegenübergestellt zu einem negativem Saldo führen. Dann spricht man von kontraproduktiven Gesetzen.

Soweit sich Gesetzesfolgenabschätzung auf die in Geld meßbaren Kosten beschränkt, ist in aufwendigen Untersuchungen zu einzelnen Gesetzen festgestellt worden, daß allein die Vollzugskosten, d.h. die personellen und sachlichen Aufwendungen auf Seiten der staatlichen Verwaltung, den ebenfalls in Geld meßbaren Nutzen eines Gesetzes überwiegen können. So hat eine Kosten/Nutzen-Analyse der Steuergesetzgebung ergeben, daß die Erhebung einzelner Steuerarten mehr kostet, als Einnahmen erzielt werden. ${ }^{448}$ Komplizierter werden solche Untersuchungen, wenn etwa auch die sog. "überwälzten Kosten" eines Gesetzes, d.h. die Vollzugskosten auf Seiten der Regelungsadressaten berücksichtigt werden. ${ }^{449}$ Darüber hinaus können auch nicht direkt in Geld meßbare Folgen einer gesetzlichen Regelung als "soziale Kosten"450 Berücksichtigung finden, und schließlich kann das Augenmerk auf nichtintendierte Folgen und Nebenwirkungen von Gesetzen gerichtet werden. ${ }^{451}$

Wenngleich der Ruf nach einer Verankerung einer institutionalisierten Gesetzesfolgenabschätzung im Gesetzgebungsprozeß allerorten laut wird ${ }^{452}$, so stellt sich die Frage, ob damit nicht mehr Probleme geschaffen als gelöst würden. Denn angesichts der Komplexität der zu berücksichtigenden Kosten, Folgen und Nebenwirkungen sind sowohl Politik als auch Wissenschaft mit der Durchführung von brauchbaren Gesetzesfolgenanalysen hoffnungslos überfordert. ${ }^{453}$ Den sog. "Blauen Prüffragen" des Bundes zur

von Prof. Carl Böhret zur Zeit an der Hochschule für Verwaltungswissenschaften in Speyer durchgeführt. Für Hinweise danke ich der Assistentin Frau Maleika Grün.

447 M.Deckert, Folgenantizipation in der Gesetzgebung, S.240ff.

448 E.-R.Bauer, Was kostet die Steuererhebung? Eine kritische Analyse des Steuersystems, Göttingen 1988; G.Täuber, Folgekosten der Besteuerung, Spardorf 1984.

$449 \mathrm{Vgl}$. C.Tiebel, Überwälzte Kosten der Gesetze. Eine empirische Analyse der Folgekosten für den Markt, Göttingen 1986.

$450 \mathrm{Vgl}$. R.H.Coase, Das Problem der sozialen Kosten, (1960), dt. Übersetzung in: Assmann et.al.(Hrsg.), Ökonomische Analyse des Rechts, S.129ff.

451 Siehe zur Erweiterung des Analyserahmens durch Modifikation des Kostenbegriffs M.R.Deckert, Folgenantizipation in der Gesetzgebung, S.240ff.; vgl. auch die oben unter c) genannten Beispiele.

452 Vgl. etwa den Zwischenbericht des von der Bundesregierung unter Leitung von Rupert Scholz eingesetzten Sachverständigenrats "Schlanker Staat" vom Januar 1996, S.7f.; vgl. dazu auch K.MeyerTeschendorf/H.Hofmann, Zwischenergebnisse des Sachverständigenrats "Schlanker Staat", DÖV 1997, S.268ff.; Anfrage der FDP/DVP Fraktion im Landtag von Baden-Württemberg vom 7.12.95, Landtagsdrucksache 11/6884; W.Hack, Die Gesetzgebung in der Krise, S.99; C.Böhret, Wenn wir nur wüßten, wie Gesetze wirken ...!, S.497.

453 So sind etwa selbst die Länder nicht in der Lage, die voraussichtlichen staatlichen Vollzugskosten eines Gesetzes zu berechnen, was auch damit zusammenhängt, daß in der öffentlichen Verwaltung produktbezogene Kostenrechnungen unüblich sind: vgl. Stellungnahme der Landesregierung in Landtag BW, Drucksache 11/6848, S.4; Darüber hinaus besteht Unsicherheit über die Berechenbarkeit sog. intangibler Kosten, das heißt Kosten, die nicht auf dem Markt bewertet werden können, vgl. M.Deckert, Folgenantizipation in der Gesetzgebung, S.251. Wie der lange Streit um die ökolo- 
Vorprüfung von Gesetzesvorhaben blieb der Erfolg verwehrt, da ihre Umsetzung nicht institutionell abgesichert war. Dem Vorschlag des Sachverständigenrates "Schlanker Staat", eine Normprüfstelle beim Bundeskanzleramt mit der Kontrolle des Prüfverfahrens zu beauftragen, ist die Bundesregierung nicht gefolgt, da aus Sicht der einzelnen Ministerien Bedenken wegen eines möglichen politisch motivierten Mißbrauchs der Normprüfung bestehen. ${ }^{454}$ Das Problem der Überforderung des Rechts als Steuerungsmedium bleibt damit ungelöst.

Ist das Recht aber nicht nur schlicht wirkungslos, sondern vielfach sogar kontraproduktiv, so ist eine Qualität der Verrechtlichungskritik erreicht, die die Rede von einer Steuerungskrise des Rechts erst als berechtigt erscheinen läßt.

\section{Das regulatorische Trilemma}

In den vorangehenden Abschnitten wurden Krisenphänomene des Rechts aus unterschiedlichen Blickwinkeln und Diskussionszusammenhängen vorgestellt. Dabei sind zwar erste Verbindungslinien offengelegt worden, aber um ein Gesamtbild der Ausgangslage für eine Prozeduralisierung des Rechts zu ergeben, müssen die verschiedenen Argumentationsfäden zu einem einheitlichen Krisenszenario zusammengefügt werden. Gunther Teubner hat ein solches Modell in systemtheoretischen Begriffen als regulatorisches Trilemma entworfen ${ }^{455}$, das im folgenden vorgestellt und an einem Beispiel erläutert werden soll.

Teubner verortet Steuerung als Prozeß zwischen den Systemen Politik, Recht und dem reguliertem gesellschaftlichen Teilbereich (z.B. Wirtschaft). Recht ist in diesem Modell nicht mehr unhinterfragt Struktur der Gesellschaft. Vielmehr werden Rechtsnormen zunächst als Struktur des Rechtssystems verstanden, der die Strukturen (Werte, Normen, Regeln, Programme, Handlungsanleitungen) anderer Systeme gegenüberstehen. Steuerung wird dann als Versuch der Kompatibilisierung der Strukturen von Politik, Recht und reguliertem System problematisiert. Solche strukturellen Kopplungen können nach Teubner nur gelingen, wenn die Eigenlogik der beteiligten Systeme einer Strukturverschleifung nicht entgegensteht. ${ }^{456}$ Die von den Theorien der Natur der Sache her bekannte Forderung nach Respektierung der sachlogischen Strukturen eines Gegenstands werden so gleichsam ins Systemische übersetzt: Die Grenzen von Regulierung sind durch die dreifachen Grenzen der Selbstreproduktion der beteiligten Systeme definiert. 457

gischen Kosten des Individualverkehrs zeigt, stehen sich Experten und Gegenexperten gegenüber (vgl. dazu U.Beck, Gegengifte). Zu den Problemen der Folgenabschätzung in der EU-Gesetzgebung vgl. auch H.v.Moltke, Gesetzgebung der Europäischen Gemeinschaften. Das System der Folgenabschätzung, ZG 1993, S.212ff.

454 Vgl. O.Fliedner, Vorprüfung von Gesetzentwürfen, ZG 1991, S.40ff.; ders., Notwendigkeit, Verständlichkeit und Praktikabilität von Rechtsvorschriften, ZG 1993, S.347ff.; Zu den politischen Problemen einer institutionalisierten Gesetzesfolgenabschätzung vgl. N.Huber, Rechts- und Verwaltungsvereinfachung, S.123ff.; Schon die jetzt bestehende formale Gesetzesprüfung im BMJ wurde zuletzt unter dem Minister Jochen Vogel zur Steigerung seines persönlichen politischen Einflusses ge- bzw. mißbraucht. Für Hinweise zur Gesetzesprüfung danke ich den zuständigen MitarbeiterInnen des BMJ.

455 G.Teubner, Das regulatorische Trilemma, S.109ff.; ders., Verrechtlichung, S.313ff.

$456 \mathrm{Vgl}$. dazu auch G.Teubner, Gesellschaftsordnung durch Gesetzgebungslärm, S.45ff.

457 G.Teubner, Das regulatorische Trilemma, S.128; ausfiihrlich s.u. Kap. 2 I. 3. u. II. 1. 
Das regulatorische Trilemma kann dann als Folge der Nichtbeachtung der Bedingungen der strukturellen Kopplung von Politik, Recht und Gesellschaft formuliert werden. Grenzenloser Staatsinterventionismus führt demnach in das Trilemma einer Desintegration aller beteiligten Systeme.

\section{a) Desintegration der Politik}

Eine inkongruente Regulierung führt zu wechselseitiger Indifferenz von Recht, Politik und Gesellschaft. Da das Steuerungsprogramm den Relevanzkriterien von Recht und reguliertem System nicht entspricht, ist es schlicht irrelevant. Die entstehenden Vollzugsdefizite führen zum Phänomen der symbolischen Politik. Die mit der ausbleibenden Einlösung der Sicherheitsversprechen des Präventionsstaates verbundene Selbstwiderlegung der Politik treibt diese in eine Glaubwürdigkeitskrise und führt zu Politikverdrossenheit (Steuerungskrise).

\section{b) Desintegration des Rechts}

Die von einem aktiven Staat an das Recht herangetragenen Steuerungsansprüche führen zur Materialisierung des Rechts. Die mit der Verwendung von unbestimmten Rechtsbegriffen und Generalklauseln verbundene Öffnung des Rechts gegenüber seiner gesellschaftlichen Umwelt führt zu einer Übersozialisierung des Rechts. Das Recht wird von der Politik und den regulierten Teilbereichen erobert, politisiert, ökonomisiert, moralisiert, technisiert etc., wodurch die spezifisch formalen Qualitäten des Rechts deformiert werden (Krise des Rechtsstaats).

\section{c) Desintegration des regulierten Systems}

Werden politische Steuerungsansprüche mit aller Macht von Recht und Politik durchgesetzt, so führt dies zu desintegrierenden Effekten im regulierten Feld, die als Kolonialisierung der Lebenswelt durch den Wohlfahrtsstaat einerseits, als Deformation wirtschaftlicher Prozesse durch nichtintendierte Nebenfolgen der Verrechtlichung andererseits beschrieben werden können. Die negativen Effekte einer Überlegalisierung der Gesellschaft stellen so die positiven Wirkungen politischer Steuerung in Frage.

Im politischen Steuerungsalltag stehen sich diese drei möglichen Folgen von hochgetriebenen Interventionsansprüchen nicht als Alternativen gegenüber, sondern liegen als Gemengelage in mehr oder weniger ausgeprägter Form gleichzeitig vor. Ihre trilemmatische Struktur findet Steuerung gerade darin, daß keine monokausalen Lösungskonzepte ersichtlich sind, vielmehr in dem unübersichtlichen Beziehungsgeflecht zwischen Politik, Recht und reguliertem System jede Aktion angesichts unvorhersehbarer Reaktionen immer tiefer in das Trilemma hineinführen. Dies soll am Beispiel der Einführung des Kreditbetrugs ( $\$ 265$ b StGB) erläutert werden.

Wie bereits erwähnt, dienten die Gesetze zur Bekämpfung der Wirtschaftskriminalität dem politischen System vornehmlich dazu, einen in der Logik von Wiederwahl und Abwahl entstandenen Handlungsbedarf in Bezug auf "white-collar-crime" symbolisch abzuarbeiten. Dabei wurde weder auf die Bedürfnisse des Rechts, noch auf die Eigenlogik der Wirtschaft Rücksicht genommen. Was die Eigenrationalität des Rechts betraf, so sah sich die Politik nicht in der Lage, das strafwürdige Unrecht in einer dem 
rechtsstaatlichen Bestimmtheitsgebot aus Art. 103 II GG entsprechenden Weise zu definieren. § $265 \mathrm{~b}$ StGB zeichnet sich vielmehr durch eine Anhäufung äußerst unscharfer Begriffe wie etwa "unrichtige Angaben oder Unterlagen", "vorteilhaft" und "für die Entscheidung über den Kreditantrag erheblich" aus. ${ }^{458}$ Einem für das materiale Rechtsparadigma typischen "Rechtsimperialismus" folgend reagierte das Rechtssystem aber nicht mit Ignoranz (hier etwa mit Verwerfung der Norm wegen Verstoßes gegen Art. 103 II GG), sondern erklärte die unbestimmte Norm für anwendbar, da durch die Rechtsprechung bestimmbar. ${ }^{459}$ Die Rechtsprechung legitimiert ihre Nachsicht gegenüber unbestimmten Strafgesetzen nun damit, daß der Bürger bei "erkennbaren Grauzonen", d.h. bei für den einzelnen erkennbar unklaren Strafbarkeitsgrenzen, bewußt das Risiko einer Bestrafung eingehe und dieses Risiko auch zu tragen habe. ${ }^{460}$ Wenn es nun um so extrem komplizierte, auch in der Rechtsdogmatik und den Wirtschaftswissenschaften hochumstrittene Fragestellungen geht, wann etwa eine Bilanz unrichtig und diese Unrichtigkeit für einen Kreditantrag erheblich und vorteilhaft is ${ }^{461}$, dann gerät angesichts der Unschärfe der Grenzen dieser Begriffe unvermittelt der gesamte Bereich der Kreditgeschäfte in die "erkennbare Grauzone des Strafrechts".

Das marktwirtschaftliche System lebt nun aber gerade von Unternehmern, die Risiken eingehen und diese Risiken auch über Kredite finanzieren. Die Angaben, die der Kreditnehmer beim Kreditantrag macht, beziehen sich auf dessen zukünftige (Rück-) Zahlungsfähigkeit, beruhen also auf Prognosen über die Geschäftsentwicklung. Naturgegeben wird der Unternehmer eine positive Prognose abgeben, andernfalls würde er das Geschäft selbst nicht vornehmen. Wegen Kreditbetruges wird in der Regel erst dann ermittelt, wenn etwas schiefgegangen ist, die Rückzahlung also ausbleibt. Damit werden dann diejenigen bestraft, die ein Risiko eingegangen sind. ${ }^{462}$ Wirtschaftslogik ("Wo kein Risiko, da kein Gewinn") und Strafrechtslogik ("Wer Risiken eingeht, befindet sich in der Grauzone") stehen sich diametral gegenüber. Eine Strafdrohung erscheint wirtschaftlich eher dysfunktional.

Die Kreditwirtschaft reagierte darauf in eigenem Interesse mit Ignoranz (Nichtanzeige). ${ }^{463}$ Kommt es trotzdem einmal zum Prozeß, so zeigt sich, daß die Strafrechtspflege mit der Verarbeitung hochkomplexer wirtschaftlicher Vorgänge hoffnungslos überfordert ist. Fern von allen Regeln des Strafprozeßrechts enden Wirtschaftsstrafprozesse in der Regel mit Absprachen zwischen Justiz und Verteidigung, in denen ein Teilgeständnis gegen eine milde Bestrafung eingetauscht wird. ${ }^{464}$ Dieser "Handel mit Ge-

458 Vgl. E.J.Lampe, Entscheidungsbesprechung zu BGHSt 30, 285, JR 1982, S.424ff.;

459 BGHSt 30, 285.

460 So etwa BVerfGE 73, 206 (235).

461 Vgl. dazu H.Brodmann, Probleme des Tatbestandes des Kreditbetruges ( 265 b), Diss. Köln 1984.

462 Vgl. dazu F.Haft, Die Lehre vom bedingten Vorsatz, ZStW Bd. 88, 1976, S.365ff.

463 Nicht nur, um den Bereich Kreditwirtschaft nach Möglichkeit aus der "Grauzone" des Strafrechts herauszuhalten, sondern auch, weil es für eine Bank geschäftsschädigend wirkt, als Opfer eines Betrügers in die Schlagzeilen zu kommen, da der Betrogene in der Regel als der Dumme gilt und der Betrug gegenüber den "übermächtigen" Banken oft Schadenfreude und eine gewisse Sympathie mit dem Täter auslösen (vgl. Arzt, Strafrecht BT, LH 3 zu $§$ 263ff. StGB). Zur wirtschaftlichen Schadensbegrenzung wird vielmehr eine Art "Vergleich" über Teilrückzahlungen getroffen, und zwar um so eher, je größer der Betrug ist.

464 K.Bussmann, Absprachen in Wirtschaftsstrafprozessen, in: Dose/Voigt, Kooperatives Recht, S. 185ff., der empirisch belegt, daß Absprachen in Wirtschaftsstrafprozessen "normale Verfahrens- 
rechtigkeit" führt das Recht wiederum tiefer in die rechtsstaatliche Krise. Für die Politik bleibt dieser Zustand nur solange unproblematisch, wie die Bevölkerung (Wähler) diesen nicht wahrnimmt. Je öfter hingegen über einen "Deal" im Strafprozeß berichtet wird, desto eher setzt sich der Eindruck fest, daß "Weiße-Kragen-Täter" eine Sonderbehandlung erhalten, weil sie Strafhöhe, Bewährungszusage, Strafanstalt und künftige Vergünstigungen (Freigang) aushandeln können. Damit sind die Gesetze zur Bekämpfung der Wirtschaftskriminalität ihrer symbolischen Wirkung beraubt, die Politik wird unglaubwürdig.

Ist damit in der gebotenen Kürze beschrieben, wie staatliche Steuerung in der Rückkopplung der beteiligten Systeme unvorhersehbar und deshalb nicht steuerbar immer tiefer in das regulatorische Trilemma hineinfüht, so stellt sich die Frage nach Auswegen. Ein erster Ausblick auf das, was mit einer Prozeduralisierung des Rechts gemeint sein könnte, soll im folgenden Abschnitt gegeben werden.

\section{Auswege: Prozedurale Rationalisierung des Rechts}

Thema dieser Arbeit ist die Ablösung des materialen Rechtsparadigmas durch ein prozedurales Rechtsparadigma, wie dies von verschiedener Seite beschrieben und eingefordert wird. Bei allen Schwierigkeiten im Detail kann man holzschnittartig feststellen, daß damit die Umstellung des Rechts auf Verfahrensrationalität, oder besser die Orientierung des Rechtssystems an prozeduraler Rationalität mit allen Konsequenzen für die grundlegenden dogmatischen Probleme des Rechts gemeint ist.

Prozedurale Rationalität ist ein äußerst unscharfer, ja vieldeutiger Begriff. Für ein erstes Vorverständnis kann auf die obige Darstellung der prozeduralen Gerechtigkeitstheorien verwiesen werden. ${ }^{465}$ Aus juristischer Sicht geht es bei der Frage nach der Rationalität des Rechts immer um die Rationalität von Entscheidungen, die im Recht Anspruch auf Geltung erheben, also hauptsächlich um die Rationalität von Gesetzen und Urteilen. Während eine juristische Entscheidung material-rational ist, wenn sie inhaltlich mit gegebenen Werten, Zielen und Regeln übereinstimmt, hängt ihre prozedurale Rationalität von dem Entscheidungsprozeß selbst ab. ${ }^{466}$ Man kann daher auch von Verfahrensrationalitä $t^{467}$ oder von Verfahrensgerechtigkeit ${ }^{468}$ sprechen.

praxis" sind. Er führt dies auf die Differenz der Prozeßlogik des Strafrechts und der Prozeßlogik des Wirtschaftssystems zurïck.

465 S.o. II. 3.

466 Neben der oben zitierten Definition von R.M.Unger (s.o. II) sei noch eine Definition von H.A.Simon (From Substantive to Procedural Rationality, in: Latsis 1976, S.129-148, 130f.) genannt: "Behaviour is substantively rational when it is appropriate to the achievement of given goals within the limits imposed by given conditions and constraints ... Behaviour is procedurally rational when it is the outcome of appropriate deliberation. Its procedural rationality depends on the process that generated it (zit. nach B.Peters, Rationalität, S.227).

$467 \mathrm{Zu}$ einem auf Verfahren verengten Begriff prozeduraler Rationalität vgl. die Darstellung bei B.Peters, Rationalität, Kap. VII.

468 Im Anschluß an die amerikanische "Procedural-Justice"-Forschung ist der Begriff Verfahrensgerechtigkeit nunmehr auch in Deutschland in Mode gekommen: vgl. die zusammenfassende Darstellung bei R.Hoffmann, Verfahrensgerechtigkeit: Studien zu einer Theorie prozeduraler Gerechtigkeit, Paderborn 1992; W.Bottke, Materielle und formelle Verfahrensgerechtigkeit im demokratischen Rechtsstaat, Berlin 1991; G.Bierbrauer/W.Gottwald/B.Birnbreier-Stahlberger (Hrsg.), Verfahrensgerechtigkeit, Rechtspsychologische Forschungsbeiträge für die Justizpraxis, Köln 1995. 
Die Rede von Verfahrensrationalität kann allerdings leicht zu Mißverständnissen führen, wenn man darunter die Bedeutung von Kompetenz-, Form- und Verfahrensvorschriften für die Rationalität des Rechts versteht. Die rationalitätssichernde und fördernde Funktion von Verfahrensnormen ist dem Juristen nämlich gut bekannt. Unter Prozeduralisierung könnte man dann eine verdeckte Reformalisierung des Rechts verstehen und schnell die bekannten Argumente gegen einen juristischen Positivismus hervorholen, der etwa die Geltung von Gesetzen bloß von ihrer formal korrekten Setzung abhängig macht. 469

Der für den Juristen typische, auf Normen fixierte Blick führt hier aber eher in die Irre. Denn prozedurales Recht hat nur am Rande auch etwas mit Verfahrensnormen zu tun. ${ }^{470}$ Wie sich aus dem bisherigen Gedankengang des ersten Kapitels ergibt, verweist der Begriff Rechtsparadigma vielmehr auf jenseits der konkreten Normen liegende Leitbilder, auf Annahmen über die Möglichkeit von Wissenschaft und Erkenntnis, auf Theorien der Gerechtigkeit, Philosophien vom richtigen Staat und Soziologien über das Funktionieren von Gesellschaft, kurz: auf das juristische Weltbild. ${ }^{471}$

Das formale Paradigma geht mit dem Beginn der Marktwirtschaft, mit naturwissenschaftlichem Empirismus und moralwissenschaftlichem Wertrelativismus einher, das materiale Paradigma stellt die philosophisch unreflektierte und erkenntnistheoretisch nicht abgesicherte Antwort des Rechts auf die mit dem aufkommenden Sozialstaat an das Recht herangetragenen Interventionsansprüche dar. Das prozedurale Paradigma kann vielleicht am treffendsten als Reaktion des Rechts auf die kommunikative Wende in den Nachbarwissenschaften sowie die kommunikative Revolution in der Gesellschaft verstanden werden.

Beides, sowohl der Anbruch der Kommunikationsgesellschaft als auch die kommunikative Wende in der Wissenschaft, erfolgte nicht von heute auf morgen, ein Anfang der Diskussion ist daher schwer auszumachen. Aus Sicht der Rechtswissenschaften können lediglich einige Beiträge von besonderer Bedeutung herausgegriffen werden. So gehört Luhmanns Buch über Legitimation durch Verfahren von 1969472 mit Sicherheit zu den für die deutsche Jurisprudenz bisher einflußreichsten Schriften ${ }^{473}$, wenn es auch für die Diskussion um prozedurales Recht nur untergeordnete Bedeutung hat ${ }^{474}$. Zu nennen wä-

469 Vgl. dazu oben III. 2. u. 3. zur Entwicklung des Rechtsstaatsbegriffs; Zur Reformalisierung vgl. D.Grimm, Reformalisierung, S.704ff.

470 Diese These kann ausführlich erst in Kap. 2 begründet werden. Aus dieser These rechtfertigt sich der Verzicht auf die Darstellung einer Vielzahl von juristischen, soziologischen oder psychologischen Verfahrenstheorien.

471 Den Begriff Sozialmodell benutzt F.Wieacker, Privatrechtsgeschichte der Neuzeit; den Begriff Paradigma benutzt J.Habermas, Faktizität und Geltung, VI. Zum Begriff s.o. IV.

472 N.Luhmann, Legitimation durch Verfahren, Neuwied, Berlin 1969.

473 Siehe den Rückblick bei S.Machura, Niklas Luhmanns "Legitimation durch Verfahren" im Spiegel der Kritik, ZfRSoz 1993, S.97-114 m.w.N.

474 Was daran liegt, daß Luhmann von seinem soziologischen Erkenntnisinteresse her schon die Frage nach einem Zusammenhang von Verfahrensausgestaltung und distributiver Gerechtigkeit zurückweist, vielmehr eine anormative "Isolierungstheorie" (vgl. K.F.Röhl, Verfahrensgerechtigkeit (Procedural Justice), ZfRSoz 1993, S.1-34, 19ff.) entwirft, die danach fragt, welche faktischen Mechanismen die Akzeptanz, bzw. den fehlenden Widerstand gegen Verfahrensergebnisse bewirken. Da hier eine normative, an Gerechtigkeit interessierte Rechtstheorie aus einer soziologisch aufgeklärten Teilnehmerperspektive (s.u. Kap. 2) entworfen wird, ist Luhmanns Ansatz nur von begrenztem Interesse. 
ren die Beiträge von Teubner und Willke ${ }^{475}$ über reflexives Recht aus den frühen achtziger Jahren, die eine lange Diskussion zum Thema auslösten. Ein anderer Strang der Diskussion wurde Ende der siebziger Jahre durch Alexys ${ }^{476}$ Buch über juristische Argumentation aufgenommen. Schließlich bildet Habermas'477 Werk über Faktizität und Geltung von 1992 den vorläufigen Höhepunkt der Diskussion.

Dennoch, das Thema Kommunikation und Recht ist älter und - auf einer anderen Ebene - schon in Begriffen wie dem "Rechtsgespräch"478 oder dem "dialogischen Recht" $^{479}$ angesprochen, wo das dialogische Prinzip ${ }^{480}$ im Recht als "Ich und Du" im Gespräch zwischen Richter und Prozeßbeteiligten oder als Interaktion zwischen "ego, alter und alter ego" in der dialogischen Struktur der Strafrechtsnorm ${ }^{481}$ gefunden wird. Für die Diskussion um ein prozedurales Rechtsparadigma ist diese dialogische Betrachtungsweise allerdings zu individualistisch. Die Frage nach der Rationalität "des Rechts" insgesamt kann nicht im Rückgriff auf den Dialog zwischen einzelnen Aktoren beantwortet werden, denn das scheitert schon an der bloßen Quantität von rechtlicher Kommunikation. Wer das moderne Recht in seiner Komplexität erfassen will, um nach der Rolle des Rechts in der Kommunikationsgesellschaft $z u$ fragen, muß systemisch denken. Rationalität des Rechts beweist sich dann in der Interaktion von Systemen, wenn das Recht (ego) im Umgang mit seiner Umwelt (alter) durch von einem Paradigma geleitete Reflexion auf das Wohl der Gesellschaft (alter ego) ${ }^{482}$ seine Identität und damit seine Grenzen bestimmt. ${ }^{483}$

Wie bei der Diskussion der prozeduralen Theorien der Gerechtigkeit angesprochen, wird auch gern auf Kant als Urvater des Gedankens der prozeduralen Rationalität zurückgegriffen. ${ }^{484}$ Daran ist jedenfalls soviel richtig, als Kant die Bedingungen der Vernunft in der "Form der Anschauung", also gerade in den Bedingungen des Erkenntnisprozesses gefunden hat. Die kommunikative Wende, nämlich die Verlegung der Bedingungen der Erkenntnis von Wahrheit und Gerechtigkeit vom Subjekt in die Intersubjektivität der Sprache ${ }^{485}$ bzw. in die Kommunikation selbst, wodurch der soziale Diskurs zum epistemischen "Subjekt" der Erkenntnis wird ${ }^{486}$, erfolgte aber erst später.

475 G.Teubner, Reflexives Recht, ARSP 1982, S.13ff.; G.Teubner/H.Willke, Kontext und Autonomie, ZfRSoz 1984, S.4ff.

476 R.Alexy, Theorie der juristischen Argumentation (1978), 2.Aufl., Ffm 1983.

477 J.Habermas, Faktizität und Geltung, Beiträge zur Diskurstheorie des Rechts, Ffm 1992.

478 A.Arndt, Das Rechtsgehör, NJW 1959, S.6-8.

479 R.-P.Calliess, Dialogisches Recht, in: EvTh 1965, S.297ff.; ders., Theorie der Strafe im demokratischen und sozialen Rechtsstaat, Ffm 1974, S.68ff, 80ff, und öfter.

480 Vgl. etwa unter Rückgriff bis auf Sokrates: M.Buber, Das dialogische Prinzip, 5. Aufl., Heidelberg 1984, S.68f.

481 Etwa nach der Grundstruktur des $\S 212$ StGB: "Wer (ego) einen anderen Menschen (alter) tötet, wird (durch einen Dritten: alter ego) bestraft. Vgl. R.-P.Calliess, Theorie der Strafe.

482 I.e. der "generalized other" im Sinne von G.H.Mead, Geist, Identität und Gesellschaft (1934), Ffm 1988.

483 S.u. Kap. 2 III.

484 So z.B. die Kantinterpretation bei I.Maus, Aufklärung; vgl. auch A.Kaufmann, Prozedurale Theorien.

485 J.Habermas (Die Einbeziehung des Anderen, Ffm 1996, S.396) spricht auch von "linguistischer Wende".

486 Vgl. dazu ausführlich die Diskussion von Habermas, Foucault und Luhmann bei G.Teubner, Die Episteme des Rechts, in: D.Grimm (Hrsg.), Wachsende Staatsaufgaben, 1990, S.115-154. 
Erst mit dieser kommunikativen Wende konnte der bis dahin vorherrschende Methodendualismus durchbrochen werden, der strikt zwischen empirisch-naturwissenschaftlicher Erkenntnis zugänglichem Sein und wertrelativistischer Erkenntnis nicht zugänglichem Sollen unterschied. ${ }^{487}$ In dem Maße, in dem die Objektivität naturwissenschaftlicher Erkenntis durch Aufzeigen ihrer Standpunktabhängigkeit (Relativität) bzw. ihrer Strukturgebundenheit bis hin zur Theorie des radikalen ${ }^{488}$ und sozialen ${ }^{489}$ Konstruktivismus hinterfragt wurde, faßte die Moraltheorie wieder Fuß. Denn ist die Erkenntnis von Wahrheit mangels unmittelbaren Zugangs zu dieser weitgehend von Idealisierungen in bezug auf die Bedingungen des Erkenntnisprozesses abhängig, so konnte die Philosophie darauf verweisen, daß unter ähnlichen Idealisierungen in bezug auf den Erkenntnisprozeß auch die Erkenntnis von Gerechtigkeit möglich ist. Besonders deutlich wurden die Grenzen zwischen Sein und Sollen diesbezüglich durch die Sprechakttheorie eingerissen. ${ }^{490}$ Diese zeigte nämlich, daß sich kommunikative Handlungen mit empirischem Gehalt von normativen Aussagen strukturell nicht unterscheiden. Sowohl empirischer Wahrheitsanspruch als auch normativer Richtigkeitsanspruch verweisen vielmehr auf ihre argumentative Einlösung in einem Diskurs, der unter idealisierten Bedingungen zu einem Konsens führen soll. ${ }^{491}$

Real stattfindende Kommunikationen arbeiten mit diesen Idealisierungen unabhängig von der hochumstrittenen Frage, ob die Einlösung der erhobenen Geltungsansprüche, also das Erreichen eines Konsens in einem Diskurs unter idealen Bedingungen möglich und sinnvoll ist oder nicht. Je nach Standpunkt in dieser Frage kann man die der alltäglichen sozialen Konstruktion von Wirklichkeit zugrundeliegenden Kommunikationsstrukturen beschreibend untersuchen ${ }^{492}$ oder in bezug auf normative Idealisierungen kritisch reflektieren ${ }^{493}$. Interessant ist dabei allemal, daß der Fokus des wissenschaftlichen Interesses auf den Kommunikationsstrukturen bzw. auf den die Kommunikationsprozesse ermöglichenden, bestimmenden und begrenzenden Verfahrensbedingungen liegt.

Für ein neues Rechtsparadigma sind beide Forschungsrichtungen interessant. Denn auf der Suche nach einem der modernen Gesellschaft adäquaten Rechtsparadigma wird der Jurist zunächst an die Entwicklung der Erkenntnistheorie Anschluß suchen, sodann bezüglich der Kernfrage des Rechts nach der Möglichkeit von Gerechtigkeit von der Philosophie lernen wollen, ohne aber die soziologischen Gesellschaftsbeschreibungen zu ignorieren. Denn ein neues juristisches Weltbild, das die Augen vor der Faktizität

487 Darstellung bei A.Kaufmann, Problemgeschichte, S.90ff.; außer Betracht bleiben kann hier, daß H.Kelsen vermöge einer fingierten Grundnorm das positive Recht als objektiv gesollt nimmt.

488 Vgl. S.J.Schmidt (Hrsg.), Der Diskurs des radikalen Konstruktivismus, Ffm 1987.

489 Zur Theorie eines sozialen Konstruktivismus vgl. neben den Klassikern (P.L.Berger, T.Luckmann, Die gesellschaftliche Konstruktion der Wirklichkeit. Eine Theorie der Wissenssoziologie, 3.Aufl., Ffm 1980; P.Watzlawick (Hrsg.), Die erfundene Wirklichkeit. Wie wissen wir, was wir zu wissen glauben? Beiträge zum Konstruktivismus, München 1985) vor allem die Arbeitspapiere der Bochumer Arbeitsgruppe für Sozialen Konstruktivismus und Wirklichkeitsprüfung, insbes. Arbeitspapier Nr. 7, Variationen über den Konstruktivismus, Universität Bochum, Fakultät für Psychologie 1990.

490 Klassisch die Ausführungen von J.R.Searle, Sprechakte (1969), 3. Aufl., Ffm 1988, S.26lff.

491 Ausführlich zur Diskurstheorie s.u. Kap. 2 II. 2.

492 So insbesondere die neuere Systemtheorie von Niklas Luhmann, s.u. Kap. 2 I. 1.

493 Klassisch der Ansatz der Diskurstheorie, s.u. Kap. 2 II. 2. 
verschließt, um sich ins rein Normative zu flüchten, würde zur Lösung der dargestellten Krisen des Rechts nichts beitragen. 494

Prozedurale Rationalität verspricht also einerseits einen Ausweg aus dem juristischen Dilemma, sich entweder wertrelativistisch auf eine "reine Rechts-Leere" beschränken zu müssen oder aber unter dem wissenschaftstheoretisch fundierten Spott der Nachbarwissenschaften todesmutig eine materiale Wertordnung zu postulieren. Eine prozedurale Rationalisierung bedeutet gegenüber formaler Rationalität ein Mehr, da normative Fragen als rational entscheidbar erscheinen. Gleichzeitig beschränkt sie das Recht gegenüber materialer Rationalität auf ein Weniger, da normative Inhalte weder im Wege einer Wertschau "aus den Sternen", noch konkretistisch aus der Natur der Sache gewonnen werden können, vielmehr nur auf einer Metaebene Aussagen über rationalitätsfördernde Verfahrensstrukturen möglich sind.

Mit dem hier angedeuteten Verständnis prozeduraler Rationalität werden andererseits verschiedene der möglichen Verfahrenstheorien als für das hier zur Debatte stehende Thema unbedeutend ausgeschieden. Dies gilt zum einen für jene Ansätze, die - wie etwa N.Luhmanns Untersuchung zu Legitimation durch Verfahren - aus einem anormativen Blickwinkel die faktische Funktionsweise von Verfahren behandeln, ohne einen Bezug zur normativen Richtigkeit herzustellen, oder für die sozialpsychologische "ProceduralJustice"-Forschung, soweit sie sich auf das empirische Abfragen subjektiver Gerechtigkeitsempfindungen beschränkt. ${ }^{495}$ Solche Theorien werden nur in dem Rahmen herangezogen, in dem sie ein normatives Verfahrensverständnis im Hinblick auf faktische Einschränkungen erhellen können. Zum anderen gilt dies aber auch für eine Reihe rein-normativer Verfahrenstheorien wie etwa J.Rawls Theorie der Gerechtigkeit, die entweder die kommunikative Wende in der Philosophie nicht mitvollzogen haben und deshalb als monologische Theorien prozeduraler Gerechtigkeit bezeichnet wurden ${ }^{496}$, oder die als Argumentationstheorien zwar kommunikative Aspekte beinhalten, aber die gesellschaftlichen Realitäten in abstrakt-normativer Perspektive ausblenden und deshalb keinen Beitrag zu der Frage liefern, wie prozedurale Rationalität angesichts der Probleme der modernen Kommunikationsgesellschaft institutionalisiert werden kann. ${ }^{497}$

Aus der hier entfalteten Sicht soll eine prozedurale Rationalisierung des Rechts einen Ausweg aus der dreifachen Krise des Rechts weisen. Mit dem prozeduralen Paradigma verbinden sich vor dem Hintergrund der trilemmatischen Struktur modernen Rechts also äußerst anspruchsvolle Hoffnungen:

494 Dieser Ansatz zwischen Faktizität und Geltung findet sich bei Habermas. Vgl. näher unten Kap. 2. I. 4. b)

$495 \mathrm{Zu}$ Luhmmanns Legitimation durch Verfahren vgl. o. FN 500-502; Zur Verfahrensgerechtigkeit s.o. FN 497 und die Beiträge in ZfRSoz 1993, Heft 1, insbes. den Überblick bei K.F.Röhl, Verfahrensgerechtigkeit (Procedural Justice), ZfRSoz 1993, S.1-34. Die Ergebnisse dieser empirisch-sozialpsychologischen Debatte erscheinen zwar im Hinblick auf die Entdeckung eines gegenüber der Ergebnisgerechtigkeit selbständigen "Eigenwertes" von fairen Verfahren (Röhl, a.a.O., S.6) interessant, für die Diskussion um eine Prozeduralisienung des Rechts sind die Beiträge allerdings zu konkretistisch auf individuelle Einflüsse auf Entscheidungsverfahren (process-control, voice) beschränkt, weshalb auf eine Darstellung im folgenden verzichtet wird.

496 S.o. II 3. d), wo neben Rawls weitere Beispiele gegeben werden. Ein Überblick über solche prozeduralen Gerechtigkeitstheorien, die hier nicht weiter problematisiert werden, findet sich auch bei R.Hoffmann, Verfahrensgerechtigkeit, S.53ff., $166 \mathrm{ff}$.

497 Deshalb werden eine Vielzahl von prozeduralen Gerechtigkeitstheorien, wie etwa die von John Rawls, im folgenden nicht aufgegriffen. 
Erstens soll eine Antwort auf die Frage gefunden werden, wie die den demokratischen Rechtsstaat kennzeichnenden Grundsätze der Gewaltenteilung und der Rechtssicherheit in einem Rechtssystem verwirklicht werden können, das den Anforderungen der modernen Kommunikationsgesellschaft entspricht. Vorhandene Ansätze des Grundrechtsschutzes durch Verfahren (bzw. neuerdings prozeduraler Grundrechtsschutz) ${ }^{498}$, des Verständnisses der Grundrechte als kommunikative Teilhaberechte ${ }^{499}$ sowie die Idee prozeduraler Verfassungsprinzipien ${ }^{500}$ müssen dabei in einen Zusammenhang gebracht und zu einer Theorie des prozeduralen Rechtsstaats ausgebaut werden.

Zweitens soll ein prozeduralistisches Verständnis der Rechte einen Weg aufzeigen, wie die Idee des Sozialstaats jenseits paternalistischer Betreuungs- und Bevormundungsverhältnisse in die Zukunft hinübergerettet werden kann, indem soziale Rechte auf ihren ursprünglichen Sinn der Autorisierung zu eigenverantwortlicher Lebensgestaltung reduziert werden. Die Erkenntnis, daß auch soziale Rechte aktiv ausgeübt werden wollen, führt zu einem Verständnis von faktischer Grundrechtsverwirklichung, in welchem die sozial-autoritäre Definition von Bedürfnissen durch eine gemeinschaftliche Praxis der Interpretation von Gleichheit durch die Betroffenen abgelöst wird. ${ }^{501}$ Neben der Gewährleistung der Grundsicherung wird die Rolle des Staates dabei auf Angebote zum Erwerb kommunikativer Kompetenz im Sinne einer Staatsbürgerqualifikationspolitik beschränkt. 502

Schließlich soll drittens ein Weg aus der Steuerungskrise des Rechts gewiesen werden, indem indirekte Formen prozeduraler Steuerung aufgezeigt werden, die sich dadurch auszeichnen, daß vorhandene Formen der gesellschaftlichen Selbststeuerung gesetzgeberisch durch reflexives Recht lediglich überformt werden, um so die nötige Berücksichtigung von Allgemeinwohlinteressen zu gewährleisten. Die Idee dabei ist, daß die vorhandenen hochspezialisierten Kommunikationskreisläufe in den ausdifferenzierten gesellschaftlichen Teilbereichen durch vorsichtiges Setzen kommunikativer Unterbrecher dabei unterstützt werden können, das Gemeinwohl im geführten Diskurs zu berücksichtigen. Die staatlichen Eingriffe in das regulierte System werden dadurch auf ein Minimum beschränkt, weshalb man davon ausgeht, daß auch die potentiellen Folgen und Nebenfolgen politischer Steuerung auf ein Mindestmaß reduziert werden. Die erstrebte Selbstverwicklung der regulierten Systeme in Allgemeinwohldiskurse soll zu-

498 Vgl. dazu die Darstellung bei R.Alexy, Grundrechte, S.428ff.; J.Burmeister, Grundgesetzliche Verfahrensstrukturierungsgebote, S.121ff. mw.N.; aus der neueren Rechtsprechung des BVerfGs vgl. den Fall Mutzenbacher, BVerfG, EuGRZ 1991, 33ff., 39; sowie das Rundfunkgebührenurteil, BVerfG, ZUM 1994, S.173ff., wo auch erstmals der Begriff des prozeduralen Grundrechtsschutzes benutzt wird (a.a.O., S.183); Zur Bedeutung des Verfahrensgedankens im Verwaltungsrecht vgl. auch die Untersuchungen von E.Schmidt-ABmann, Der Verfahrensgedanke in der Dogmatik des öffentlichen Rechts, in: P.Lerche/W.Schmitt-Glaeser/E.Schmidt-Aßmann, Verfahren als staats- und verwaltungs-rechtliche Kategorie, Heidelberg 1984; R.Pitschas, Verwaltungsverantwortung und Verwaltungsverfahren, München 1990.

499 Zum Verständnis der Grundrechte als Garantie von Kommunikationschancen vgl. N.Luhmann, Grundrechte als Institution, Berlin 1965, S.23ff, 80ff.; Zur demokratisch-funktionalen Grundrechtstheorie vgl. E.-W.Böckenförde, Grundrechtstheorie und Grundrechtsinterpretation, NJW 1974, S.1529ff.; $\mathrm{Zu}$ einem prozeduralen Verständnis der Grundrechte vgl. J.Habermas, FuG, Kap. II, S.151ff.

500 Vgl. dazu R.Alexy, Grundrechte, S.89, 120, 267, 384; R.Dreier, Rechtsstaat, S.88.

501 Vgl. dazu J.Habermas, FuG, S.504ff.;

502 Vgl. U.Preuß, Überlegungen, S.124ff. 
dem Vollzugsdefizite vermeiden, da reflexives Recht als gesteuerte Selbststeuerung aus Sicht des regulierten Systems nicht als Fremdsteuerung empfunden wird. Das so entstehende selfenforcing arrangement macht staatliche Kontrolle weitgehend überflüssig ${ }^{503}$.

Im folgenden Kapitel sollen diese recht unterschiedlichen Vorstellungen theoretisch fundiert und zu einem einheitlichen Konzept prozeduralen Rechts zusammengefaßt werden.

Im Rückblick auf das erste Kapitel kann das Drei-Stadien-Modell der formalen, materialen und prozeduralen Rationalisierung des Rechts in folgender Grafik veranschaulicht werden:

\section{Rationalisierung des Rechts ${ }^{504}$}

\begin{tabular}{|l|l|l|l|l|}
\hline Staat & Problem & Medium & Rechtsform & Rationalität \\
\hline Liberaler Staat & Gewalt & Macht & $\begin{array}{l}\text { Konditionalpro- } \\
\text { gramm }\end{array}$ & formal \\
\hline Wohlfahrtsstaat & Armut & Geld & Zweckprogramm & material \\
\hline Präventionsstaat & Risiko & Wissen & $\begin{array}{l}\text { Relationierungs- } \\
\text { programm }\end{array}$ & $\begin{array}{l}\text { prozedural/ } \\
\text { reflexiv }\end{array}$ \\
\hline
\end{tabular}

503 Siehe nur G.Teubner, Steuenung durch plurales Recht. Oder: Wie die Politik den normativen Mehrwert der Geldzirkulation abschöpft, in:Wolfgang Zapf (Hrsg.), Die Modernisierung moderner Gesellschaften, Verhandlungen des 25. Deutschen Soziologentages, Frankfurt/New York 1990, S.528551.

504 Grafik in Anlehnung an H.Willke, Ironie, S.180, 269, 288. 
